CALIFORNIA STATE UNIVERSITY, NORTHRIDGE

\title{
THE PERCEPTION OF NUMEROUSNESS ON II \\ DOT MAPS
}

A thesis submitted in partial satisfaction of the requirements for the degree of Master of Arts in

Geography

by

Robert Warren Provin

July, 1975 
The thesis of Robert Warren Provin is approved:

California State University, Northridge

Ju1y, 1975 


\section{DEDICATED}

To

Bruce Meier...

He pointed the way. 


\section{ACKNOWLEDGMENTS}

I want to express appreciation to my committee for their guidance these past semesters, with special thanks to Dr. I-Shou Wang for his vital contributions. In addition, I am indebted to Dr. Kang-tsung Chang for his aid in the initial stages of this project, and also to Ann Welling for her work in the preparation of the final manuscript.

Finally, to my wife and family, I am grateful for their constant support and encouragement these past years. 
DEDICATION • . . . . . . . . . . . . . . .

ACKNOWLEDGMENTS. . . . . . . . . . . . . . . .

LIST OF TABLES . . . . . . . . . . . . . . . . v vi

LIST OF ILLUSTRATIONS. . . . . . . . . . . . . . v vii

ABSTRACT . . . . . . . . . . . . . . . . . . . x

\section{CHAPTER}

I. INTRODUCTION. . . . . $. \cdot . \cdot . \cdot . \cdot . \cdot \cdot$

Classification of the Dot Map

Evaluation of the Dot Map

The Problem and Methodology

II. PSYCHOPHYSICS AND DOT MAP PERCEPTION. • .

Summary

III. EXPERIMENTAL DESIGN . • . • • • • •

Purpose of the Tests

Map Design and Rationale

Subjects and Testing Procedures

IV. FINDINGS. • • • . • . . . . • • • • •

Test 1

Test 2

Test 3

Test 4

Summary and Conclusions

SELECTED BIBLIOGRAPHY . • . • • • • • • • • .

Appendix I • . . . . . . . . . . . . 125

Appendix 2... . . . . . . . . . . . 130

Appendix 3... . . . . . . . . . . . . 136 
1. Summary of Tests Making Up This Study . . . . . . . . . . . . . . 


\section{LIST OF ILLUSTRATIONS}

Figure

$\underline{\text { Page }}$

1. Classification of the dot map. . . .

2. Dot map with unit value of one . . . 6

3. Small value dot map. . . . . . . 6

4. Large value dot map. . . . . . . . 7

5. Percentage dot map . . . . . . 7

6. Effect of pattern and density on dot perception ......... 12

7. The relationship between action number of dots and estimated number of dots . . . . . . . .

8. Anchors under conditions of assimilation and contrast. . . . . . .

9. Design of Bevan and Turner's experiment . • . . . . . . . • .

10. The effects of assimilation and contrast on the estimation of dot number . . . . . . . . . .

11. Numerousness shown as a function of time and background brightness. .

12. Control map, Test 1. . . . . . . 50

13. 10 dot anchor map, Test 1. . . . . 51

14. 50 dot anchor map, Test 1. . . . . 52

15. 100 dot anchor maṕ, Test 1. . . . 53

16. Full range anchor map, Test 1. . . . 54

17. Control map, Test 2. . . . . . . 56

18. Medium dot map, Test 2. . . . . 57

19. Small dot map, Test 2. . . . . . 58 
20. Control map, Test 3 . . . . . . . . 60

21. 10 percent screen tint map, Test 3.... 61

22. 30 percent screen tint map, Test 3... . 62

23. Horizontal rectangle map, Test 4. . . . 64

24. Vertical rectangle map, Test 4..... 65

25. Circle map, Test 4.......... 66

26. Oval map, Test 4.......... 67

27. $Z$ score distribution, Test 1 , sections 1 and 2.......... 74

28. Z score distribution, Test 1, sections 3,4, and 5........ 75

29. The relationship between mean estimates and stimulus value for Test $1 . . .976$

30. Range of response and standard deviations for Test 1, Stimulus A. . . . . 77

31. Range of response and standard deviations for Test 1, Stimulus B. . . . . 78

32. Range of response and standard deviations for Test 1, Stimulus C. . . . . 79

33. Range of response and standard deviations for Test 1, Stimulus D .... 80

34. Range of response and standard deviations for Test 1, Stimulus E. . . . .

35. Range of response and standard deviations for Test 1, Stimulus F. . . . 82

36. $Z$ score distribution for Test 2 . . . 87

37. The relationship between mean estimates and stimulus value for Test $2 \ldots 88$

38. Range of response and standard deviations for Test 2, Stimulus A. . . . .

39. Range of response and standard deviations for Test 2, Stimulus B..... 
40. Range of response and standard deviations for Test 2, Stimulus C. . . .

41. Range of response and standard deviations for Test 2, Stimulus D. . . .

42. Range of response and standard deviations for Test 2, Stimulus E. . ...

43. Range of response and standard deviations for Test 2, Stimulus F. . . .

44. $Z$ score distribution for Test 3 . . .

45. The relationship between mean estimates and stimulus values for Test 3.

46. Range of response and standard deviations for Test 3 , Stimulus A. . . .

47. Range of response and standard deviations for Test 3, Stimulus B. . . . .

48. Range of response and standard deviations for Test 3, Stimulus C. . . . 103

49. Range of response and standard deviations for Test 3, Stimulus D. . . . . 104

50. Range of response and standard deviations for Test 3, Stimulus E. . . .

51. Range of response and standard deviations for Test 3, Stimulus F. . . .

52. The relationship between mean estimates and stimulus value for Test 4 , shape of stimulus area. . . . . . . . .

53. The relationship between mean estimates and stimulus value for Test 4 , class level...............

54. The relationship between mean estimates and stimulus value for Test 4 , area of study. . . . . . . . . . . . 


\author{
ABSTRACT \\ THE PERCEPTION OF NUMEROUSNESS ON \\ DOT MAPS \\ by \\ Robert Warren Provin \\ Master of Arts in Geography \\ July, 197.5
}

\begin{abstract}
Very little work has been done by cartographers toward a precise description of how map users perceive numerousness on dot maps. This study, in order to investigate some of the problems in this area, incorporated three tests designed to examine the perceptual characteristics of dot maps in general along with the effects of anchors (legends), variable dot size, and selected figure-ground relationships. In addition, a fourth test was carried out to detect possible design bi.as in the first three tests and to measure the effect of the subjects' backgrounds on previous results. All of the tests in this study consisted of dot maps designed and executed to have characteristics similar to those commonly used in geographic study. Subjects were given these maps and asked to estimate dot numbers in selected areas. The results of these tests indicated that in general people underestimate dot numbers and are
\end{abstract}


relatively insensitive to variation in density. Anchors, along with dot sizes smaller than those normally employed and lightly tinted base data, were all found to improve perceptual accuracy. The fourth test detected little design bias in the first three tests and established that the perceptual characteristics of various populations are very similar when divided along lines of class rank or area of study. 


\section{CHAPTER I}

\section{INTRODUCTION}

The dot map and its variations is probably the most widely used method for showing quantitative distributions. Although it usually cannot communicate absolute quantitative data, this particular kind of statistical map is capable of accurate representations of distributional pattern and relative density when well designed and executed. In addition, the dot map is clearly understood by most map readers because of its familiarity and its rather simple and direct relationship between the symbol and the mapped object. Recently, however, cartographers have come to realize that accurate graphic representation and simple symbol-object relationships do not always communicate information effectively. Specifically, it has been recognized that dot map users typically have problems in correctly perceiving dot numbers and in visualizing relative densities. It is this dichotomy between the mathematical-statistical and the perceptual aspects of the dot map that provides the area of investigation for this thesis. 
In addition to examination of the various classes of point symbolization along with the dot map's place in this scheme, further discussion will be devoted to the purposes and uses of the quantitative uniform dot map. Finally, attention will be focused on the conceptual aspects of the dot symbol and the mathematical-statistical versus perceptual characteristics of these maps in an attempt to evaluate the strengths and weaknesses of the symbol.

Classification of the Dot Map

The many different forms of the dot map belong to the broad class of thematic maps that employ point symbolization. The primary purpose of point symbolization, as opposed to area or line symbols, is to represent position rather than space or direction. Point symbols can be differentiated through the use of variable shape, color, and size in order to represent territorial extent, a nominal locational quality, or to give ordinal or scale characteristics to a particular place. ${ }^{1}$ All of these variations in the use of the point symbol can be classified as either qualitative or quantitative and can be subdivided further into nonuniform (graduated or range graded) or uniform sub-classes. This classification system is based on the fact that thematic data can be either qualtitative or quantitative in nature and that point symbols can be uniform or graduated. The combination of the type 
of data represented and form of the point symbol establishes the four classes. The simple dot map, which is the primary object of study in this thesis, can generally be classified as a quantitative uniform point symbol.

Although dot maps may be divided into four classes, all share common characteristics. Their principal purpose is to portray location and in a broader sense to convey impressions of distributional pattern along with relative densities. The varying treatments of his symbolobject relationship are numerous, but each is designed around a specific purpose within the theme of distribution representation.

Qualitative point distribution maps are designed mainly to communicate nominal categories of geographic data. $^{2}$ Differentiation among these nominal categories can be achieved simply by changing the appearance of the symbol, which is accomplished through changes in shape and color, or scale. Qualitative uniform point symbols are differentiated through shape and color (or value, with black and white limitations) only, while the nonuniform symbol has the added dimension of variable scale (Figure 1).

A much wider and more diversified class of thematic map is encountered with quantitative distributions. Like qualitative maps, those that employ point symbols to portray quantities can be classified as either nonuniform or uniform. The most common forms of the nonuniform 


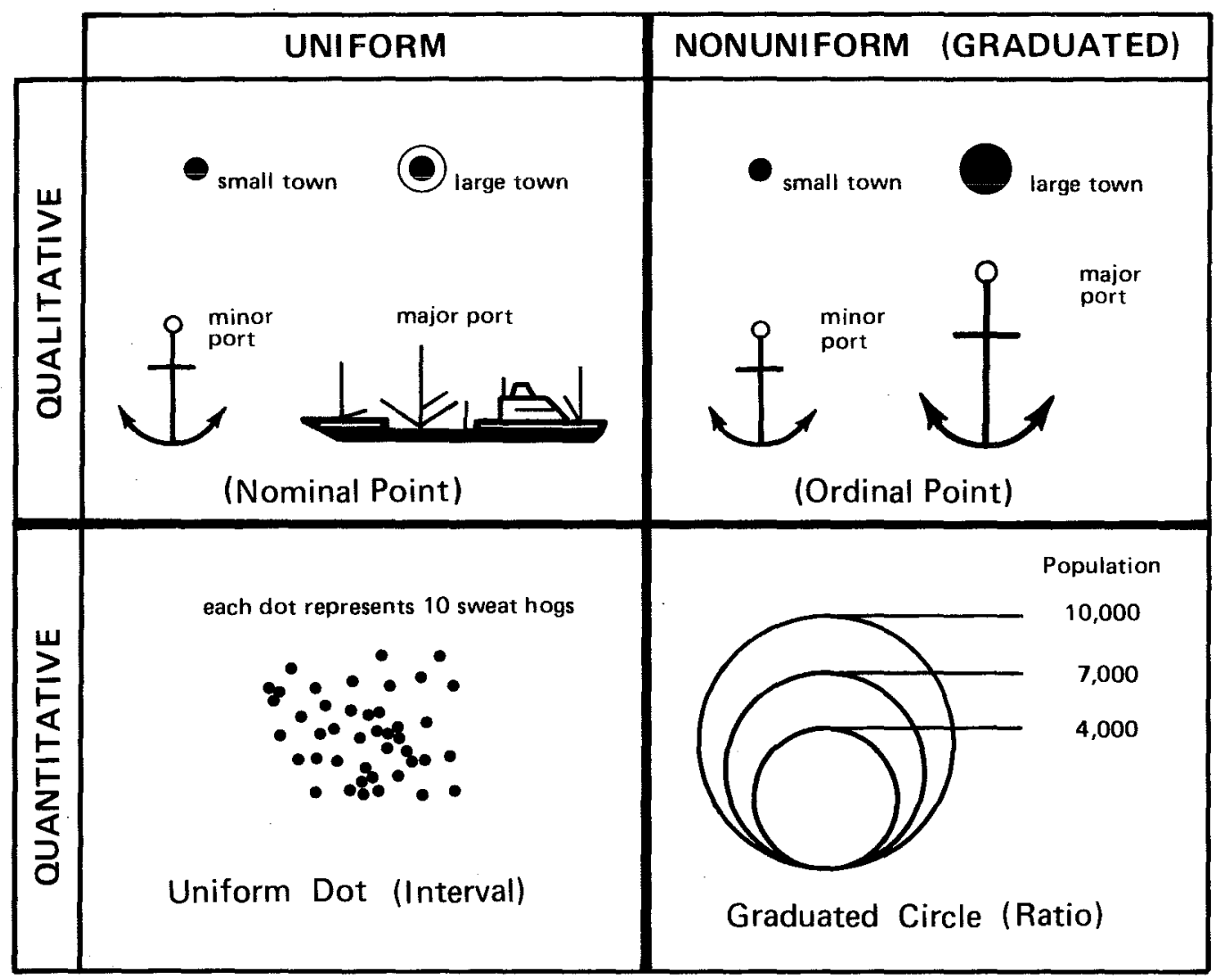

Figure 1. Diagram showing the four classes of point symbolization. The dot map is classed as a uniform quantitative interval point. 
quantitative point symbol include graduated circles, spheres, or cubes. The area or apparent volume of these graduated shapes is mathematically related to the quantity that the symbol represents. As for the uniform equivalent, the common dot map is by far the most prevalent (Figure 1). One of the most widely used kinds of thematic map is the simple dot map on which statistical data are displayed by numbers of uniform dots each representing the same amount of a given phenomenon. ${ }^{3}$ In its simplest form it employs a one to one relationship between symbol and subject. An example of this is the symbolization of slope shown in Figure 2. ${ }^{4}$ In this case each dot represents one degree of slope. More common, however, is the case where the dot value (the number of mapped objects that each dot represents) is greater than one. These can be divided roughly into two classes in terms of the symbol value: small and large value dot maps. Those with relatively small dot values are the most commonly used, and they are characterized by large numbers of dots with extreme ranges in density. The density may range from areas of great concentration where dots coalesce to form solid core areas, to areas with no dots at all (Figure 3). The primary purpose of this kind of map is to communicate spatial pattern of distribution.

Figure 4 shows a large value dot map. Because there is a relatively small number of points on the map, 


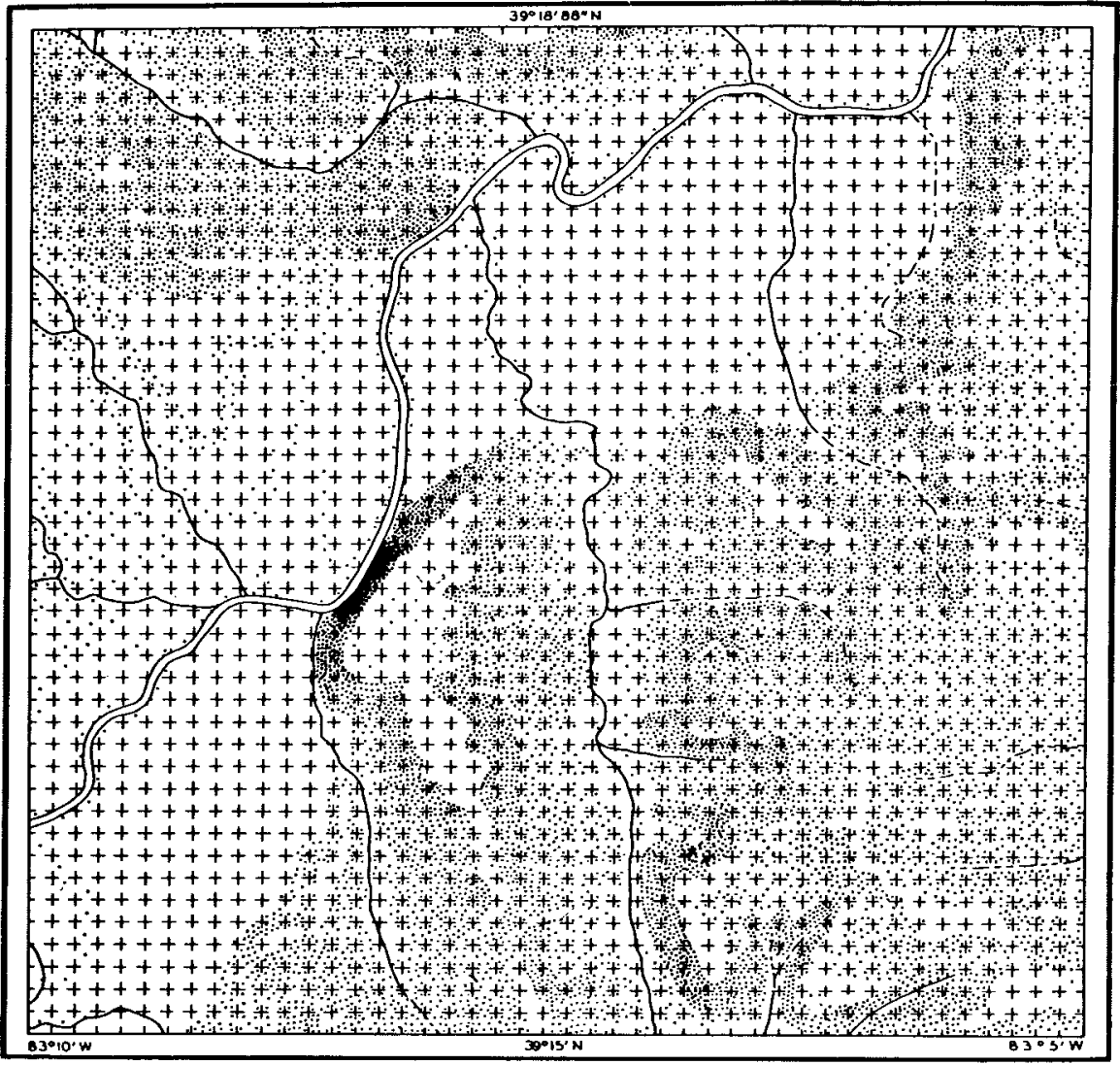

Figure 2. A dot map on which each dot represents one mapped object. In this case each dot represents one degree of slope. (A. H. Robinson, "A Method for Producing Shaded Relief from Areal Slope Data."

Surveying and Mapping, 8, (July, 1948), 157 - 160.)

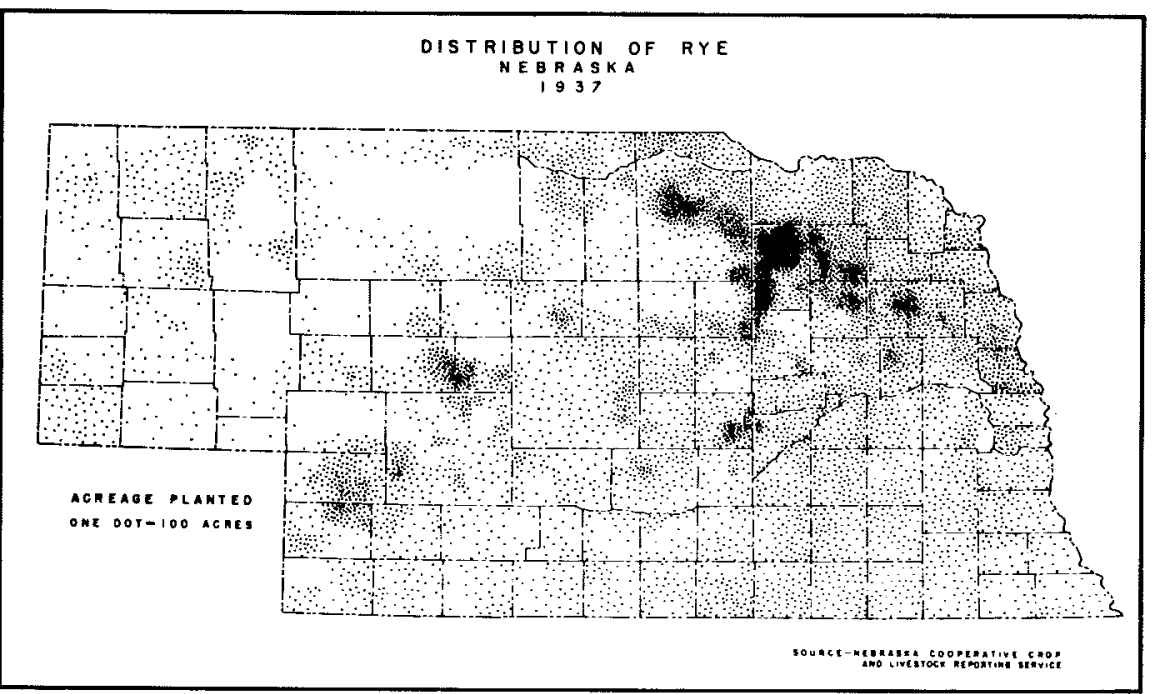

Figure 3. A dot map with a low dot value. As the dots represent a relatively small portion of the total data, low dot value maps generally have large numbers of dots and wide ranges in dot density. (The Nebraska State Planning Board, Atlas of Nebraska, 1938.) 


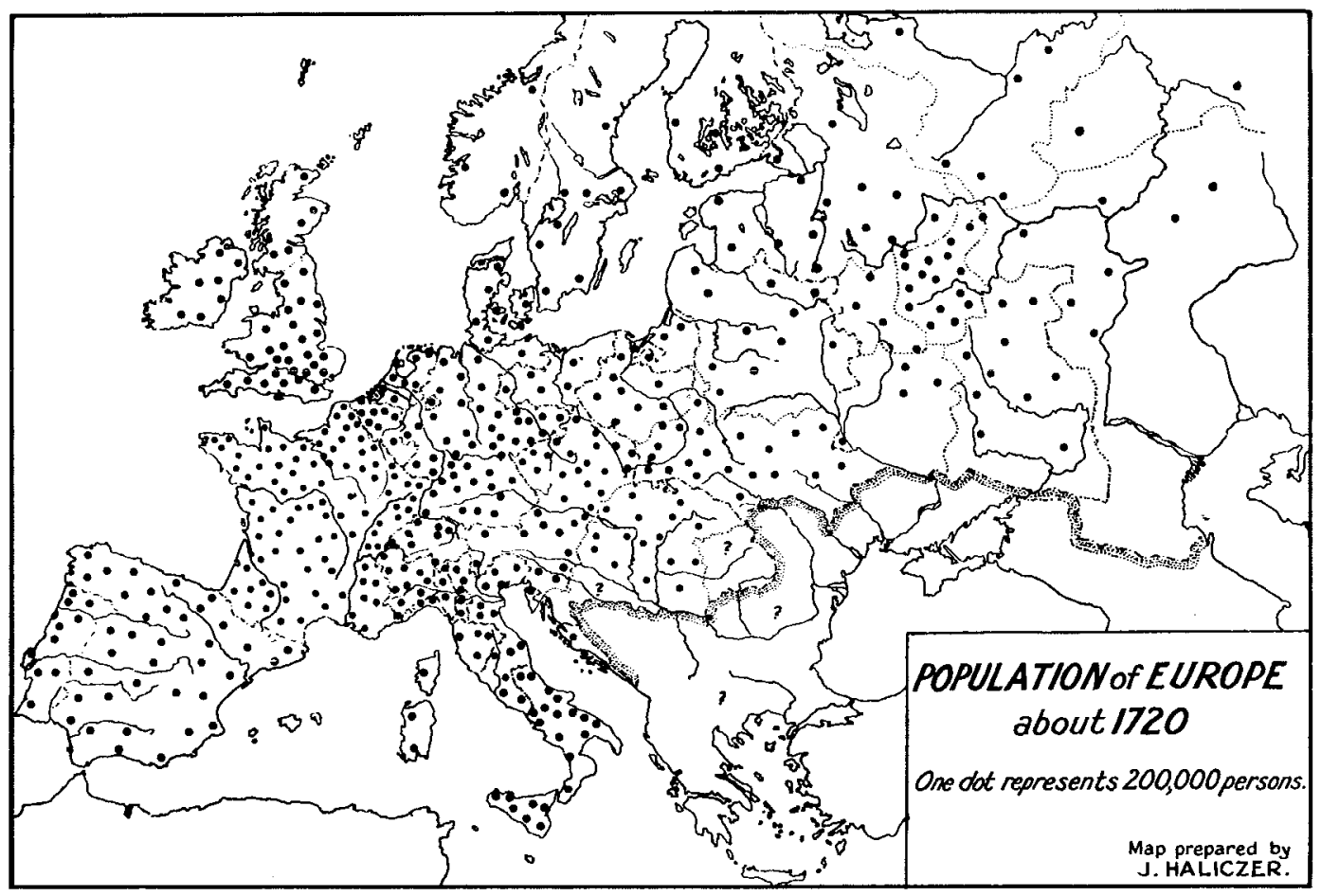

Figure 4. A dot map with a high dot value. As the dots represent a relatively large portion of the total data, high dot value maps generally have small numbers of dots with little variation in dot density. (J. Haliczer, “ The Population of Europe,1720,1820,1930." Geography, 19, (December, 1934), 261 - 273.)

Figure 5. A percentage dot map. A variation on the large value dot map, this map shows the distribution of oats in Britain. With approximately two million acres, each dot represents 0.1 per cent of the total. (D. Stamp, The Land of Britain: Its Use and Misuse. London: Longmans, Green and Co., 1962.)

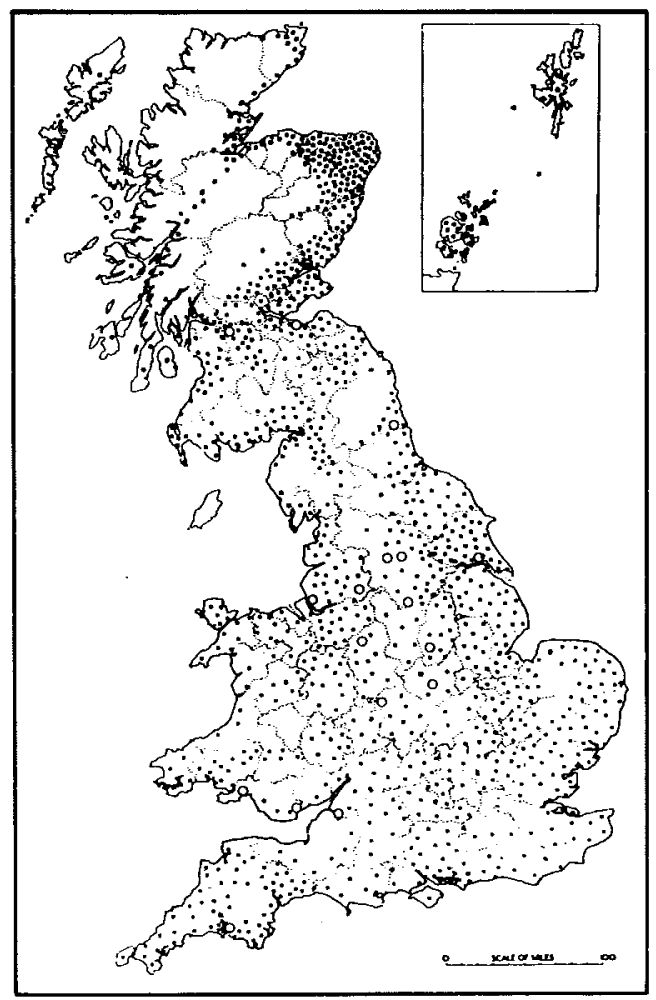


each symbol represents a significant portion of the total data. This kind of map is designed to show general patterns of distribution and allows the reader to retrieve approximate numbers. Another form is the percentage dot map on which each dot represents a percentage of the total data rather than an absolute value (Figure 5). Thus on a map with exactly 200 dots, each dot would represent onehalf of one per cent of the total. 5

Although the quantitative uniform dot map has been divided into different categories, it is not meant to imply that each case is exclusive or completely independent. 6 Each specific form overlaps somewhat on others by sharing some of the same characteristics. The basic difference between the three categories lies not in exclusive purpose or characteristic, but rather on variation within the theme of graphic representation of pattern and relative densities in geographic quantitative distribution.

Evaluation of the Dot Symbol

Even though the dot map is widely accepted there are some limitations inherent to this form of symbolization. One fundamental problem is the interpretation of the meaning of the dot symbol itself. This difficulty arises when one tries to determine whether a single dot represents a dispersed or a condensed population. For example, in a map on which each dot represents 1,000 people, it is difficult to know whether the population 
that each dot represents is located on or even near the chosen position. 7 Uniess complete information as to location technique is indicated, the kind of distribution characteristics each symbol represents is unknown. Thus, even though most dot maps are designed to emphasize pattern, this purpose is somewhat limited by mapping scale, the characteristics of the real distribution and dot value.*

Another problem relates to the judgment of the effective value of the dot. This arises in two different situations. The first involves areas where dots overlap or are stacked in areas of high density. These solid cores can result from errors of placement or from too much emphasis on prominent agglomerations within the distribution. This situation should be avoided since it tends to degrade the quantitative integrity of the map, ${ }^{8}$ but most dot maps display this trait probably because of the nature of real distributions.

The second case occurs as a result of the division of the given population of each political unit by the unit value of the dots. The problem becomes clear when one considers that with a dot value equal to 1,000 , a given

\footnotetext{
*This is but one aspect of the generalization problem with dot maps. The only form of the dot map that renders pattern perfectly is that with unit value of one.
} 
political unit would be represented by one dot with any actual population that lies between 500 and 1,499. This surplus or deficit of population when added together for numerous political units may result in some cases in a substantial error. The map reader is seldom told whether the surplus or deficit population from adjacent political units is ignored, or converted into additional dots. 9

A further problem is the difficulty of the map user in deriving actual figures for such information as population number or density. Although densitometers ${ }^{10}$ can be $^{10}$ used to give accurate density counts, in most cases sophisticated equipment is not available, and thus only approximations of relative densities can be obtained. Even if a densitometer is available, its use is complicated by the fact that the maps to be scanned must be of very high accuracy.

Related to the problem of communicating quantitative data is the question of how variations in numbers and densities of dots are perceived by map users. To this point, it has been assumed that with proper construction techniques a dot map could be made to faithfully represent an objective distribution and that this representation would effectively communicate to the map reader. As early as 1931, however, cartographers began to suspect that this was not the case. Birch observed that "even when a map is produced with dots uniform in size, shape, and value, and 
accurately distributed, it does not necessarily give a correct visual impression."ll He illustrated this point, demonstrating that visual impression of dot numbers is modified by dot pattern and variations in dot density (Figure 6). Fawcett pointed out in 1935 that subjects viewing dot maps "with a low percentage of exceptions, considerably underestimated, rather than overestimated," dot densities. In addition, he observed that the many variations in dot density over a given map can complicate the map reader's optical impression in such a way as to make the perceived distribution differ considerably from the actual one. 12 Mackay in 1949 was more specific when he stated that an arithmetic increase in dot density will not produce a graded series to the human eye. ${ }^{13}$ In the same article, Mackay summed up this problem area when he pointed out that while dot maps have been found not to give accurate representations of the numbers or ratios of dots from the perceptual viewpoint, if care is given to their preparation, some of these disadvantages may be minimized and the merits utilized to best advantage. 14 The primary problems related to mapping with a uniform quantitative point symbol can be classed as either conceptual or perceptual in nature. Both the map user and the cartographer should be aware of the limitations that characterize the dot map due to uncertain interpretation of the dot symbol itself. While the conceptual 


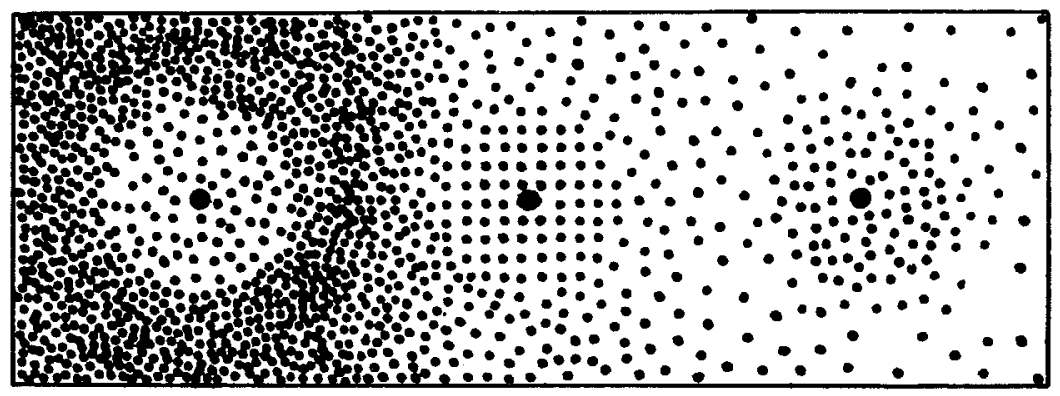

Figure 6. The effect of dot density and arrangement on the perception of dot numbers. The three circular areas containing equal numbers of dots are made to appear unequal through changes in dot pattern and in the density of dots in surrounding areas. (After Birch). 
limitations of quantitative point distributions are well known, knowledge of the perceptual aspects is sadly lacking. It is known that density variation on dot maps is seldom perceived correctly and that in general dot numbers are underestimated, but work beyond this has not been attempted up to this time.

The Problem and Methodology

Although the perceptual problems of the dot map have been recognized by cartographers, little work has been done toward a more precise description of the basic characteristics of perceptual errors. The observations cited above raise some interesting questions regarding the precise nature of dot map perception. Questions that immediately come to mind include: How do dot map users. perceive variations in number and densities of dots? What effect does the nature of the distribution have on these. kinds of perceptions? What if any is the influence of various figure-ground relationships on perceptual accuracy? And finally, do legends and variations in dot size significantly affect perceptual accuracy? These are the questions this thesis attempts to answer.

To focus more clearly on these questions, it was necessary to first look into the psychophysical literature pertinent to the dot map. Using the literature as a foundation, specific tests were designed to measure the perceptual characteristics of populations using uniform 
quantitative dot maps constructed by generally accepted conventions. ${ }^{*}$ In addition, other tests were given to establish the effects on perceptual accuracy of such factors as anchoring stimuli (legends), dot size, and the value intensity of the base map. The data from these tests were interpreted through the use of basic statistical. descriptions consisting of mean, standard deviation, standard error of the mean and range. Further analysis consisted of the establishment of modes and construction of $Z$ score frequency diagrams along with graphs showing variation in range and standard deviations. All of the results and conclusions drawn in this study are based on analysis of the statistical descriptive functions listed above.

* Nearly all standard cartography textbooks agree on these conventions. 


\section{REFERENCES}

${ }^{1}$ A. H. Robinson and R. D. Sale, Elements of Cartography, 3rd edition. (New York: John Wiley and Sons Inc., 1969), p. 97.

\section{Ibid., p. 118 .}

${ }^{3}$ Hans J. Meihoeffer, "The Utility of the Circle As An Effective Cartographic Symbol," Canadian Cartographer VI (December 1969): 106.

${ }^{4}$ A. H. Robinson, "A Method for Producing Shaded Relief from Areal Slope Data," Surveying and Mapping VIII (July 1948): 157 .

${ }^{5}$ For a more complete discussion of this kind of map, see J. Ross Mackay's "Percentage Dot Maps," Economic Geography XXIX (July 1953): 263-266.

${ }^{6}$ For a more complete classification, see R. E. Dahlberg in his article entitled "Towards the Improvement of the Dot Map," International Yearbook of Cartography (1967), p. 158 .

7 J. W. Alexander, "An Isarithmic Dot Population. Map," Economic Geography XIX (October 1943) : 431.

${ }^{8}$ R. E. Dahlberg, "Towards the Improvement of the Dot Map," International Yearbook of Cartography (1967), P. 160.

${ }^{9}$ Ibid., p. 160.

${ }^{10}$ For more information concerning densitometers and dot maps, see W. G. Byron, "Use of the Recording Densitometer in Measuring Density for Dot Maps," Surveying and Mapping XVIII (January 1958): 41-48.

${ }^{11}$ T. W. Birch, Maps: Topographical and Statistical. (Oxford: Clarendon Press, 1941), 155.

${ }^{12}$ C. B. Fawcett, "Population Maps: A Discussion," Geographical Journal LXXXV (February 1935): 151-152.

${ }^{13}$ R. J: Mackay, ㅇp. cit., p. 8.

${ }^{14}$ Ibid., p. 10 . 


\section{CHAPTER II}

\section{PSYCHOPHYSICS AND DOT MAP PERCEPTION}

Although cartographers have long suspected that map users have difficulty perceiving dot distributions, most early work in this area was done by psychologists. These researchers, working under the broad topic of psychophysics (the study of the relationship between physical stimuli and mental processes) have studied the capabilities and limitations of human visual perception through various experiments designed to define the processes involved in the translation of physical (visual) stimulus into subjective response. Even though this work was not done in a cartographic context, it is valuable, for the perceptual problems investigated are highly relevant to the dot map. Through these studies questions have both been answered and created, and some general relationships between stimulus and response have been well established. The earliest studies dealing with the perception of dot number were carried out between 1911 and the late 1920's. Oberly reported that with a small number (4 to 11) of black dots on a white background, there appeared 
to be a primary level of perception which did not require grouping for accurate estimation of dot numbers. ${ }^{1}$ Grouping is a process by which adults mentally arrange numbers of objects so that the determination of number can more easily be made. This only applies to objects seen for a very brief period of time. In a study by Freeman, adults were found to be much better at estimating numbers than children when a large number of irregularly spaced dots were presented to them. 2

Regarding tendencies to over or underestimate the number of dots, the early literature presents conflicting results. Messinger showed that if dots were scattered over a large field, their number is almost always overestimated and that increased scatter tended to increase the amount of overestimation. In addition, increase in dot size also resulted in greater overestimation. ${ }^{3}$ An experiment by Mokre, however, as described by Taves, showed an opposite tendency. ${ }^{4}$ It was observed that with larger dots and greater separation between the dots; numbers were perceived as smaller than with smaller dots and less separation. Taves, in looking at these results concluded that perceived number is a "complex quality" concerned with total impression, and that anything that tends to isolate individual items, such as increase in dot size and separation, tends to reduce apparent number. 5

The landmark study by Exnest Taves concerning the mechanisms of dot number perception will be discussed in 
some detail as it can be considered a foundation on. which many later works are based. 6 In trying to define the processes involved in the perception of number, Taves displayed fields of dots, one at a time, to 133 subjects. Dot fields having from 2 to 180 dots each were shown for one-fifth of a second, and subjects were asked to estimate number of dots seen (without counting) and indicate the degree of confidence they had in their estimates. The results showed that estimates were accurate up to and including the six dot field, but from somewhere between six and eight dots estimates decreased both in accuracy and in confidence. Based on these results, Taves suggests that there are two mechanisms at work in the perception of number. The first mechanism works with a smaller number of objects and results in accurate perception (few and small errors) while the second mechanism operates when large numbers of objects are perceived and results in substantial underestimation of dot numbers (Figure 7).

In other tests conducted by Taves, the problems of area and density variation were examined, along with configuration. The author wanted to establish in the first of these tests if area and density are perceived independent of dot number. The test procedure was the same as for the previous test, except that the subjects were instructed to make judgments of area or density that were equal to one-half of the stimulus field. The judgments were made through selection from a number of 


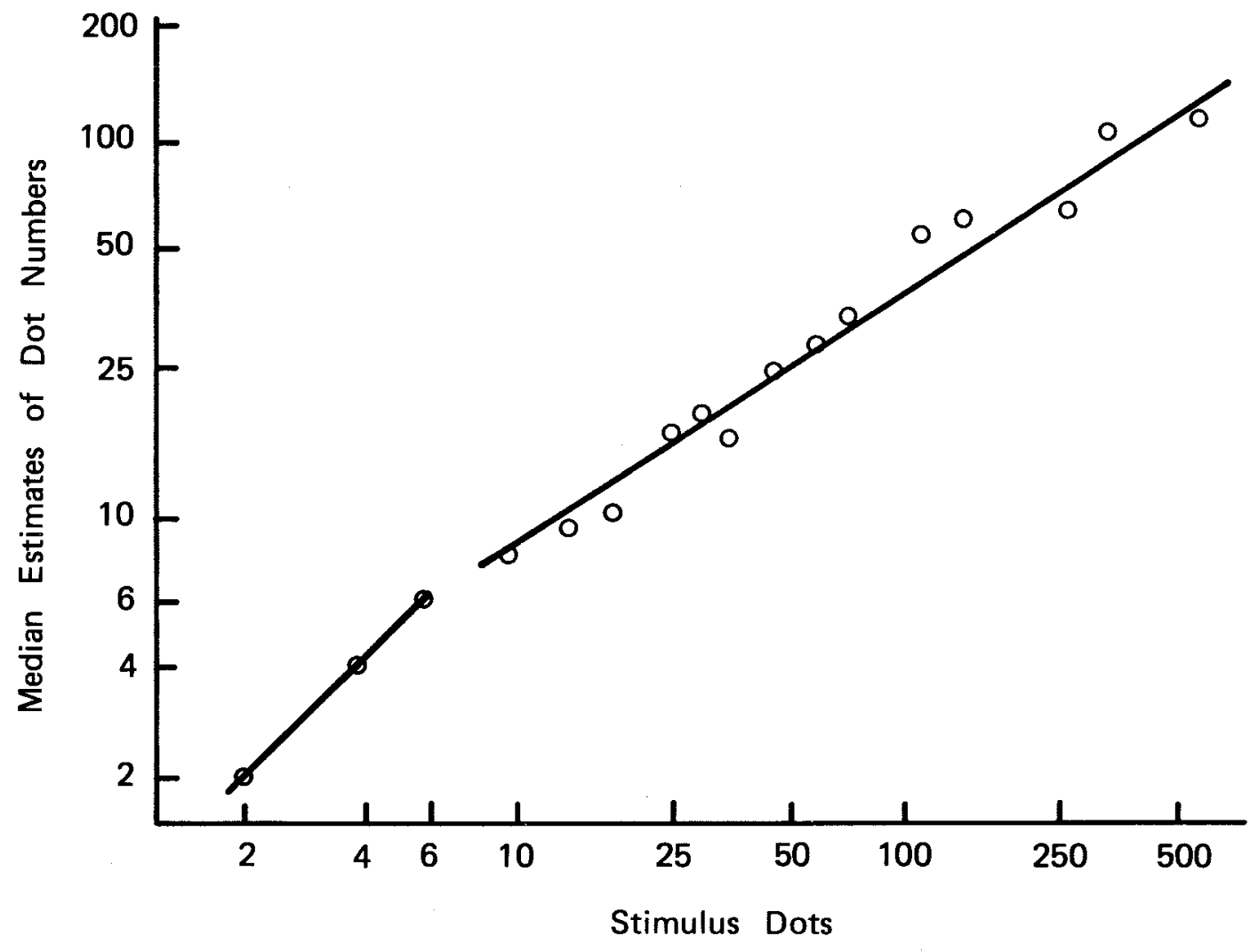

Figure 7. The relationship between the actual number of dots and the estimated number of dots. The discontinuity in the plot defines the two mechanisms of perceived numerousness. (After Taves) 
variable sample fields. Results from this test indicated that area and density are perceived independent of number, but as with perceived number, reports tend to be underestimated. 7

Taves also examined the effect of dot pattern on the perception of number. Again, the testing procedure was basically the same except that the fields were limited to four, containing $10,20,40$, and 60 dots respectively. The dots in these fields were arranged into compact circles rather than random distributions. The subjects were instructed to select from a group of variable random fields one that appeared to equal one-half the number of dots in the stimulus field (circle configuration). The results indicate that with the circle configuration of dots, and presumably with other regular configurations, the degree of underestimation is greater than that with random distributions of the same stimulus value. 8

In a similar study, Saltzman and Garner attempted to establish the magnitude and direction of perceptual error as affected by such variables as knowledge of the range of dot numbers, practice, regularity in the spacing of the dots, distance from which the dot fields are observed, brightness of the background on which the dot fields appear, and the size of the dots. 9 Both the tachistoscopic (flash for a fraction of a second) and the reaction time (field shown until subject responds with an 
answer) methods were used for displaying dot fields, and the subjects were instructed to emphasize accuracy rather than speed. In all of the experiments the visual stimuli included from one to ten open circles or dots. All fields were of equal density.

The results of the experiments were identical for both dots and circles. Generally there was an increase in reaction time and decreased accuracy with increased numbers of stimulus objects. All of the variables were found to have some effect on reaction time and accuracy. The knowledge of the numerical range, increased brightness of the background and increased size of the dots all reduced reaction time and improved accuracy.

Kaufman, and his co-workers, in their further study of the perception of dot number investigated the relationship between accuracy and speed. 10 In their experiments, subjects were shown 35 different dot fields, one at a time. The number of dots in each field'ranged from 1 to 210 and were displayed to the subjects for one-fifth of a second. One group of subjects was instructed to emphasize accuracy while another was instructed to emphasize speed.

The results support Taves's findings in that there appeared to be two mechanisms at work in the perception of number. The authors indicate, however, that the two mechanisms not only are distinguishable in terms of accuracy of perceived number but also by differences in 
speed and confidence in the subject's reports. With between one and six stimulus dots, regardless of instructions for speed or accuracy, the accuracy, speed, and confidence of reports remained relatively unchanged. However, with stimulus dots of six and above, accuracy instructions produced slightly more accuracy and speed instructions resulted, to a greater extent, in more speed.

In addition to the commonly used terms estimating and counting, Kaufman, et al., suggest the new term, subitizing, to describe a newly encountered mechanism by which people perceive numbers of objects. The authors found that estimating, a relatively fast, inaccurate, and low confidence means by which people discriminate numbers could only be applied to the discrimination of objects where the total number is six or above. Counting, in contrast, is slow, accurate, and high in confidence. With counting, however, the objects must be visible for a long enough period of time for the process to take place. Subitizing is very high in accuracy, more rapid than estimating, and is high in confidence. However, the process only applies when the number of objects in the stimulus field is less than or equal to six. In a practical sense, subitizing can be characterized as an instantaneous recognition of the number of objects shown to a subject. However, the authors emphasize that the difference between subitizing and estimating is actually statistical in nature as it is defined only by a 
discontinuity in the slopes of confidence, reported number, and speed versus actual number (of dots).

Another study by Minturn and Reese was conducted to establish the effects of differential reinforcement on the perception of dot number. ${ }^{11}$ Fields of dots ranging from 1 to 210 were shown to the subjects with an exposure of one-fifth of a second. The subjects were divided into two groups. One group simply reported numbers with each exposure, while the second group was told the correct number after each report was made. The second group then was subject to differential reinforcement which is a form of anchoring stimulus. Anchors generally serve as standards by which other similar stimuli can be judged. ${ }^{*}$ Both groups were instructed to be as accurate as possible. The test results indicate that differential reinforcement decreases the amount of underestimation in reporting number and decreases the variability between the subjects. In addition, it was found that differential reinforcement had no effect on the tendency for people to subitize when the number of stimulus objects was six or

* An anchor or anchoring stimulus is any stimulus that establishes a standard by which other stimuli can be judged, or in some way alters judgment of like or unlike stimuli. On a dot map a box in the legend containing 200 dots, and labeled as such, would be considered an anchoring stimulus as the legend would serve as a standard for judging numbers of dots over various areas on the map. 
below; also reinforcement did not as might be expected, increase the range of subitizing to higher levels.

Other important variables that affect the perception of dot number are examined by Bevan and Turner's paper entitled: "Assimilation and Contrast in the Estimation of Number." Assimilation and contrast are two perceptual effects that are observed in subjects that are given anchoring stimuli of various kinds. The assimilation effect is described briefly as follows:

In judgments of graded stimuli ranging from low to high in some dimension, the introduction of anchors at the end points of the series will cause displacement in the distribution of judgments of series stimuli in the direction of the anchor. Thus the judgments will be pulled toward the end points of the graded stimuli, extending their range.

and the contrast effect is described thusly:

As the anchors are placed at increasing distances away from the end points of the series, the distributions of judgments will be displaced in the direction away from the anchor and the whole judgment scale will be constricted. Thus the judgments will be pulled toward the center of the graded stimuli decreasing their range.13

These two concepts are illustrated in Figure 8 .

To see how these effects manifest themselves in the perception of dots, Bevan and Turner constructed an experiment in which five random arrays of dots numbering 21,42 , 84,168 , and 336 dots on a gray field were shown to 150 subjects. For one group of subjects the dots were surrounded by a large frame well separated from the dot field, while for another group the frame was small and closely fitted the field. In addition, one more variable was added 


\section{ASSIMILATION}

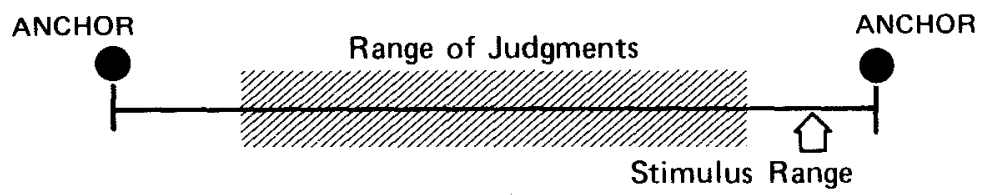

\section{CONTRAST}

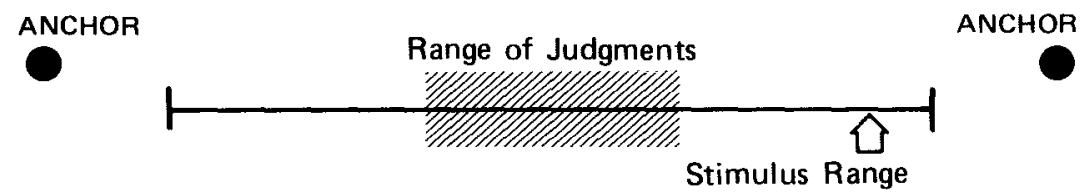

Figure 8. The effect of anchors under conditions of assimilation and contrast. Anchors at the end points of a range of graded stimuli produce assimilation effects which extend the range of judgments. Anchors placed at increasing distances from the end points produce contrast effects which constrict the range of judgments.

Figure Instructions (Assimilation Effect)

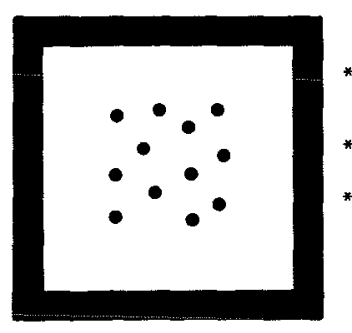

A 1

* Large frame (figure)

* Enlarge field

* Increase estimated number
A2

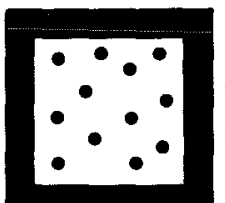

Small frame (figure)

* Reduce field

* Lower estimated number

\section{Ground Instructions (Contrast Effect)}

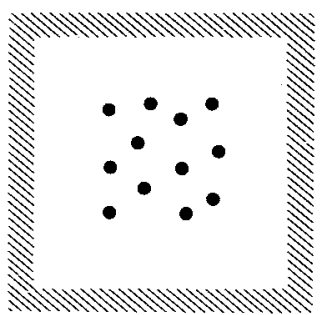

\section{B 1}

Large frame (ground)

* Reduce field

Lower estimated number
B 2

Small frame (ground)

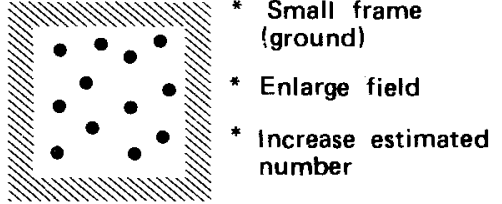

Figure 9. A simplified diagram showing the basic design of the experiment on assimilation and contrast. In judgments of dot number, with large and small frames, figure instructions (A) produce assimilation effects and ground instructions (B) produce contrast effects. 
by telling other subjects to associate the frames, large or small, with either being part of the figure or part of the ground. The subjects given figure instructions were told to associate the frame conceptually with the dot field, while the subjects given ground instructions were told that the frame was to form the background for the dots. Figure and ground refer to the basic components of a visual field. Figure is the primary object of visual and conceptual interest in a field, while ground is of secondary interest, serving mainly as a frame of reference for the figure. On a dot map, the distribution of dots would be the figure and base map would be the ground. The idea behind these tests was that relative to the control group, figure instructions would produce assimilation effects and ground instructions would create contrast effects (Figure 9).

The logic of the test design was based on certain assumptions on how figure-ground relationships affect the perception of dot number. First it was assumed that any added stimulus (in this case a frame associated with the figure or the ground) may display anchor properties. It was further assumed that a large frame regarded as part of the figure by an observer would enhance the perceived area of the field and thus increase estimation of dot number (Figure $9 \mathrm{~A}_{1}$ ). With the same situation only with ground instructions given, the differentiation of the separate identities of the field and frame would reduce the 
perceived area of the dot field and lower the estimation of dot number (Figure $\left.9 \mathrm{~B}_{1}\right)$. The opposite effect can be expected with a small frame relative to the dot field. Under figure instructions, it was assumed that an observer would judge the frame to be small and thus would tend to compress the area of the dot field, lowering the estimation of dot number (Figure $9 \mathrm{~A}_{2}$ ). If the ground instruction was stressed, according to the authors, there would be a tendency on the part of the observer to compensate for compression by an overestimation of the field area along with dot number. (Figure $9 \mathrm{~B}_{2}$ ).

By examining Figure 10, one can see that the hypothesis put forth by the authors was confirmed in the results of the test. It is obvious from the graph that large and small frames with figure or ground instruction do exert a considerable effect on the perception of dot number. More important to this study, however, is the observed effect of figure and ground alone on the perception of number, as it would apply to.dot maps. It can be seen that figure (assimilation) effects tend to be greater than those observed for ground (contrast). ${ }^{14}$ Thus on dot maps, anchors associated with the figure (dots) should modify the estimation of number to a greater degree than anchors associated with the ground (base data). An interesting study by Lechelt and Nelson ${ }^{15}$ investigated the problem of number perception under varying conditions of background brightness and length of viewing 


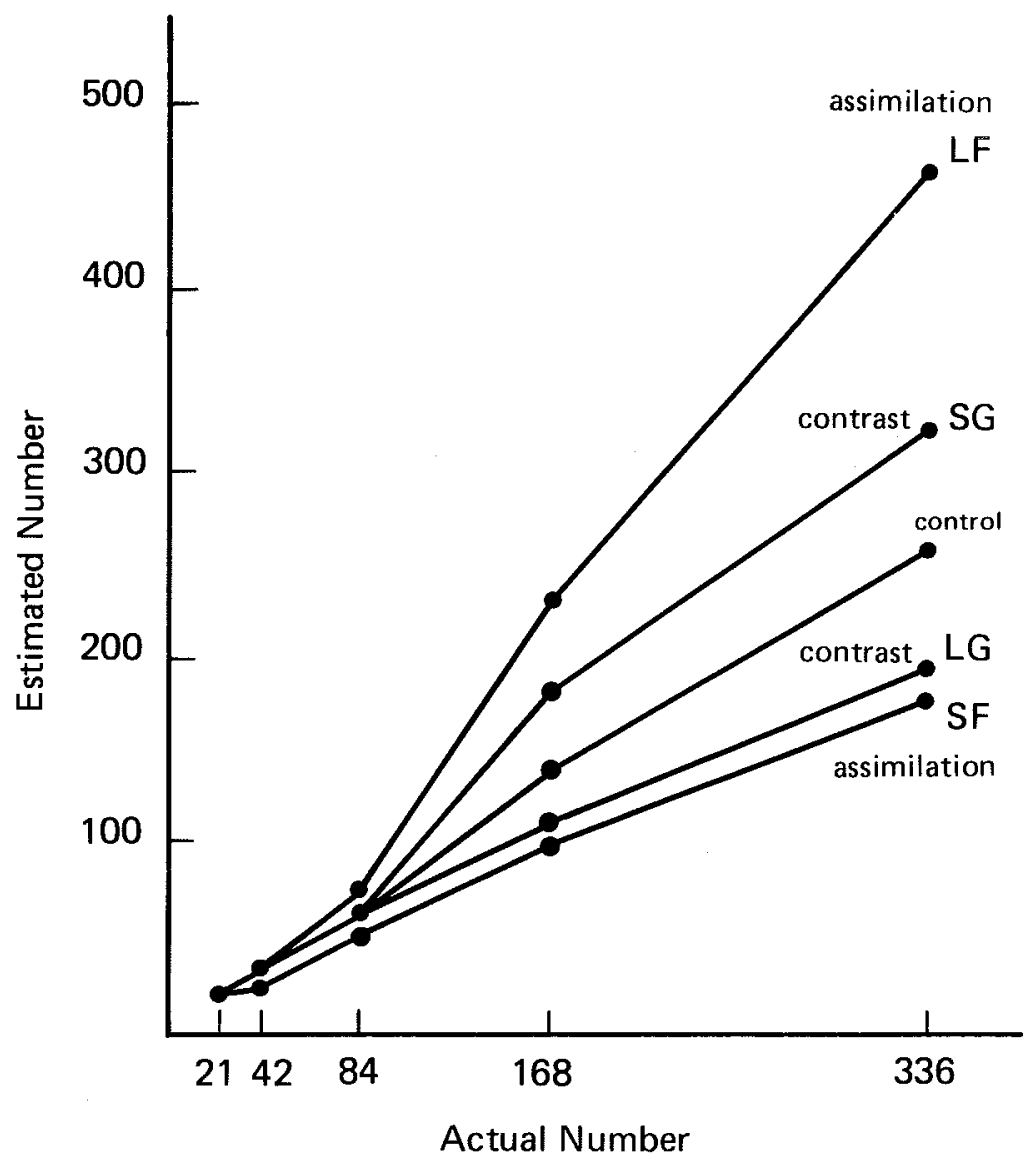

Figure 10. Estimations of the number of dots in a series of random arrays, when bordered by large (L) or small (S) frames, and when made under figure $(F)$ or ground $(G)$ instructions. (After Bevan and Turner) 
time. The study concentrated mainly on perceived number with more than six dots. This study then is particularly applicable to dot map problems. In their experiment, subjects were shown fields (through projection) that ranged from 2 to 128 dots. In addition, the fields were projected with a variable light intensity ranging from 3 to 30 foot candles and durations of between .04 and 3.5 seconds. After each field was shown the subjects were asked to report directly their estimations of the number of dots.

The results show that both increased exposure duration and background brightness improves perceptual accuracy. All of the estimates, regardless of the condition of the two variables, were underestimations of the stimulus values, but the degree of underestimation was lessened with longer durations and increased brightness. It was found, however, that exposure duration has a much greater influence on perceptual accuracy than does background brightness. Examination of the test results reveals that perceptual accuracy improves with each increase in viewing time (Figure 11). More important, however, is the fact that the degree of improvement increases with each increase in stimulus number. Similar results are evident with increases in background luminance, but improvement is not so great. Regarding the dot map, background luminance is probably of greater importance than viewing duration because viewing time is seldom limited 


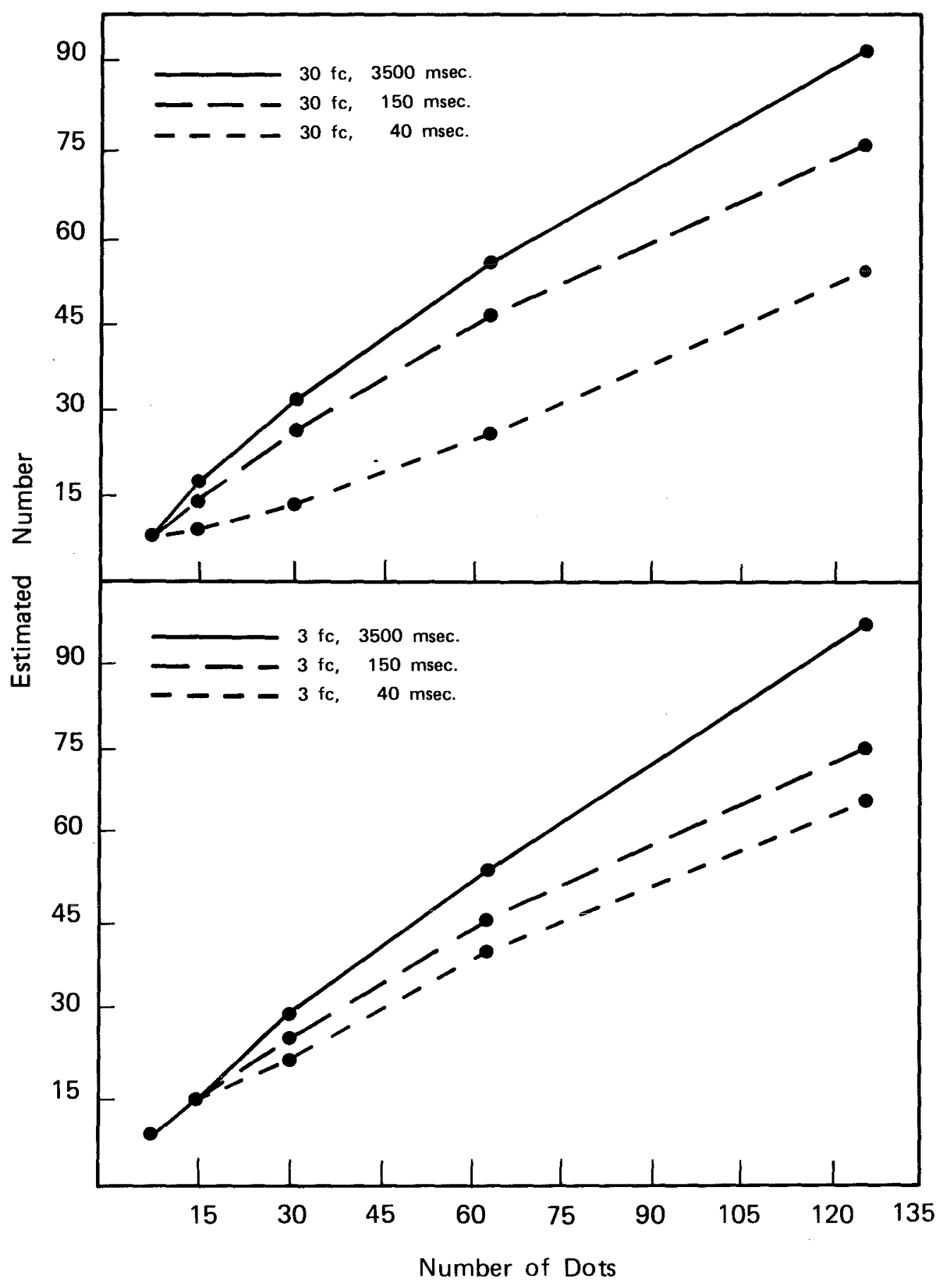

Figure 11. Numerousness shown as a function of time and background brightness. (After Lechelt and Nelson) 
in map study. Background luminance as presented in this study may possibly be analagous to figure-ground problems in cartography, in that variable luminance would alter the visual contrast between subject and base data (figure and ground) on maps.

Another problem in the perception of dot number was examined by Krueger in his paper "Perceived Numerosity."i6 In this study Krueger tested whether or not dot fields of varying densities would affect the perception of their numbers. In several separate experiments, fields of $25,50,75,100$, and 200 dots were distributed randomly on four display boards measuring 56, 225, 900 , and 2,025 square centimeters in size (there were a total of 20 different dot fields). Although subjects were not given a time limit, they were instructed to estimate the number of dots present on each sheet without counting or otherwise computing the number. The response time for the most part ranged between three and five seconds among the sixty-two persons that participated.in the experiments. The results of all the experiments indicate that the size of the display board (variation in dot density) had considerable influence on the perception of number. In all cases only the smallest display board (dot field of greatest density) appeared to have fewer dots than all other sizes with an equal number. Krueger suggests that there was perhaps a ceiling effect involved, with the maximum effect of area being achieved with the smallest- 
sized, 56 square centimeters. In addition to this ceiling effect, the subjects were found to underestimate numbers under almost all conditions and regardless of variables. The differences in perception with variable densities are, of course, one of degree; in this case greater densities result in a high degree of underestimation than with lesser densities. Looking at the results of this study, it may be assumed that very dense areas on dot maps may be perceived in a different manner than other areas where densities are not as great.

\section{Summary}

The primary purpose behind the reviewed psychophysical studies is to define those parameters that govern the way people perceive numbers of objects. Specific among those parameters is the number function itself (stimulus number), density, configuration, viewing time, figure-ground, and anchors. While some of these variables are more applicable to dot map problems than others, all of the studies are of value for they indicate the strong interrelationships existing between the various factors. Among the findings brought out in these studies, one is shared by nearly all. Regardless of any variables applied, underestimation is universal among subjects making judgments of dot number. The various parameters that control perceived number generally only affect the degree of underestimation in that there seems to be little mention 
of overestimation cited in the literature.

The investigations into the role of stimulus number agree that the degree of underestimation increases as stimulus number increases. Similar results have been reported with density variation. The application of anchors, however, whether they be directly or only conceptually related to the stimulus object, tend to improve the accuracy of estimation. In a similar fashion, figure-ground relationships have been found to create similar results. This is probably due to the fact that both figure and ground stimuli possess anchoring properties.

The other parameters, viewing time and configuration, while not important from a cartographic viewpoint, are reviewed here because of their importance in defining basic properties of number perception. Viewing time is' of little importance to cartographers because it is assumed that map study is not time limited. It is important to know, however, that with large stimulus numbers, the perception of dot number improves with increased viewing time, an indication that perceptual accuracy is highest in map study situations. Although it has been found that regular dot configurations are perceived with less accuracy than those that are random, few dot maps exhibit distributions with regular configurations. 
1. Subjects tend to underestimate dot numbers, with the degree of underestimation being directly proportional to the magnitude of the stimulus.

2. Anchors improve perceptual accuracy in the estimation of dot numbers, except when related to the ground under contrast conditions or when related to the figure under conditions of assimilation.

3. Both increased viewing time and increased background brightness improve perceptual accuracy in the estimation of dot numbers.

4. Regular configurations of dots are underestimated to a greater degree than are random configurations.

5. There are two mechanisms in the perception of visual number in addition to counting. Subitizing is active with six stimulus objects or less, while estimating is active when there are more than six stimulus objects. 


\section{REFERENCES}

${ }^{1}$ S. H. Oberly, "The Range for Visual Attention, Cognition, and Apprehension," American Journal of Psychology XXXV (Ju1y 1924): $3 \overline{32-352 .}$

${ }^{2}$. F. Freeman, "Experiments on the Perception of Number in Children and Adults," Psychological Bulletin VIII (December 1911): 43-44.

3 M. D. Vernon, A Further Study of Visual Perception. (Cambridge: University Press, 1952), 56.

${ }^{4}$ T. H. Taves, "Two Mechanisms for the Perception of Visual Numerousness," Archives of Psychology XXXVII

(September 1941): 8 .

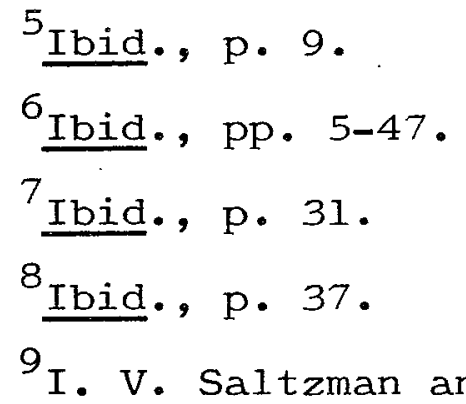
a Measure of Span of Attention," Journal of Psychology XXV (April 1948): 237 .

10E. L. Kaufmann, M. W. Lord, T. W. Reese, and J. Volkman, "The Discr mination of Visual Number," American Journal of Psychology LXII (October 1949): 502.

${ }^{11} \mathrm{~A}$. L. Minturn and $\mathrm{T}$. W. Reese, "The Effect of Differential Reinforcement on the Determination of Visual Number," Journal of Psychology XXXI (April 1951): 230.

${ }^{12}$ M. Sherif, D. Taub, and C. I. Hovland, "Assimilation and Contrast Effects of Anchoring Stimuli in Judgments," Journal of Experimental Psychology LV (January 1955): 151 .

\section{${ }^{13}$ Ibid., p. 151 .}

${ }^{14} \mathrm{~W}$. Bevan and E. Turner, "Assimilation and Contrast in the Estimation of Number," Journal of Experimental Psychology LXVII (May 1965): $4 \overline{58-467 .}$ 
${ }^{15}$ E. C. Lechelt and T. M. Nelson, "Numerosity Discrimination Under Varying Conditions of Steady Illumination: A Temporal Analysis of a Spatial Factor," Journal of General Psychology LXXIV (January 1971): 121-131.

${ }^{16}$ L. E. Krueger, "Perceived Numerosity," Perception and Psychophysics XI (January 1972): 5-9. 
CHAPTER III

\section{EXPERIMENTAL DESIGN}

Within the psychophysical literature some studies have a more direct bearing than others on the primary perceptual problems associated with the dot map. Those dealing with questions of over and underestimation of dot numbers, anchors, dot size-density relationships, and figure-ground are pertinent to cartographic problems. Most psychophysical studies, however, serve only as indicators of the perceptual mechanisms at work with dot map users. These experiments are general in character and are intended to be foundations on which more specific studies can be based.

The purpose of the experimental studies presented here is to examine the perception of dots in a mapping context. The primary problems that will be studied are the perception of numerousness, the effects of anchors, dot size, and figure-ground relationships. This experiment consists of four tests. The first, second, and third test sections were made in the specific areas of investigation mentioned above. The fourth section was intended to deternine if there was any bias in the map design or 
sampling procedure that could possibly affect the results in the other test sections. All of the maps used in the four categories were made identical in every respect except where changes were needed to accommodate the purposes of each specific test. It was felt that this would improve the possibilities for making comparisons between the results. of the different testing areas.

Purpose of the Tests

The first test was to determine the relationship between stimulus and response on dot maps and the effects of anchors on these relationships. Nearly all of the psychophysical studies cited in the last chapter have dealt to some degree with the problem of dot number estimation, and many have looked into the effects of anchors, but little is directly applicable to the dot map because of the testing methods. Unlike the studies done by psychophysicists, which present simple dot fields projected tachistoscopically, the tests presented here provide each subject' with a map that can be studied, just as maps are used in real situations. The first test was designed so that a more accurate appraisal of a map user's ability to differentiate variations in numerousness can be made. This is probably the most critical test in that this aspect of perception is basic to the usefulness of the dot map. Additional work with anchors will measure their effects on perceptual error and will serve as a practical 
method by which any observed error in the first part of the test may be reduced.

The second test is designed to measure the effects of variation in dot size on the perception of dot numbers. The psychophysical literature only hints at some of the mechanisms that may be useful in this aspect, which is of considerable importance from the cartographic viewpoint. Because the dot size-unit value relationship is such an important element of the dot map, it was felt that one test should employ this aspect as a variable. According to convention, with a proper dot size and unit value, the dots should just coalesce in those areas where the distribution has the greatest density. This convention, so far as the author knows, is based purely on esthetic principles rather than on tested functions based on map user perception. Thus, with the second test the dot size convention will be examined along with the effects of deviating from that convention.

The third test is designed to measure the effect of figure-ground relationships on the perception of the dot number. Specifically this test will look into the results of variation in background tints on the base data of dot maps. This problem is of primary importance to cartographers because of the fact that with nearly every kind of map subject data (figure) is plotted over some kind of base data (ground). The psychophysicists were first to suggest that background may exert some influence 
on perceived numerosity, when they examined the effect of background brightness in a projected image. In other studies these results were confirmed, although qualified by the fact that brightness effects were reduced through prolonged exposure. Further work, while mainly concerned with anchors, did shed some light on the perceptual changes that take place through the manipulation of figure-ground concepts. But again, while these experiments are valid, the methodology makes the results somewhat questionable when applied to dot map problems. Most dot maps have varying degrees of base complexity which in turn can affect figure-ground contrast. The question of whether or not this contrast variation affects perceptual accuracy will be the primary subject of the third test.

The last test in the series is designed mainly to check for bias in design or selection of subjects in the previous tests. Specifically, this test will attempt to detect any influences exerted by the shape of the stimulus areas and establish if level of education or area of study can bias results.

A summary of tests making up this study is shown in Table 1. 
TABLE 1

SUMMARY OF TESTS MAKING UP THIS STUDY

\begin{tabular}{|c|c|c|c|}
\hline & Purpose & $\begin{array}{c}\text { Number of } \\
\text { Maps }\end{array}$ & $\begin{array}{l}\text { Number of } \\
\text { Subjects }\end{array}$ \\
\hline Test 1 & $\begin{array}{l}\text { Measurement of } \\
\text { perceived numerous- } \\
\text { ness, effects of } \\
\text { anchors }\end{array}$ & 5 & 165 \\
\hline Test 2 & $\begin{array}{l}\text { Effect of variation } \\
\text { in dot size }\end{array}$ & 3 & 99 \\
\hline Test 3 & $\begin{array}{l}\text { Effect of variation } \\
\text { in background tint }\end{array}$ & 3 & 99 \\
\hline Test 4 & $\begin{array}{l}\text { Bias in stimulus area } \\
\text { shape, subject's } \\
\text { background }\end{array}$ & 4 & 121 \\
\hline
\end{tabular}

The areas of investigation described above repre-. sent important problems to be examined in a cartographic study. The definition of perceptual error and the effects of anchors on this error along with the effects of variation in dot size and figure-ground relationships are examined in the context of the dot map. The results of this study should help delineate, from the perceptual viewpoint, the strengths and weaknesses of this form of statistical map. 
Map Design and Rationale

All of the tests in this study incorporate dot maps showing identical distributions plotted over political boundaries. Both the distribution and the base information on all of the maps are artificial in that neither reflects real situations. The dot distribution used on the maps was constructed so as to offer no interference from irregular size and shape of the dots. To insure this result, all of the maps, with the exception of two in the dot size test, were dotted with press-on dots (Chartpak \#45I). Although the dot size varied slightly from sheet to sheet, the amount was considered small enough to not noticeably affect the results of the test. The two maps that were not dotted in this manner were dotted with Leroy pen. The dots were applied with care to maintain uniform size and shape.

Linework for the maps was executed with Rapidograph pens of various line widths. All art work was photographically reduced and then reproduced by offset lithography. This step was taken to insure maximum resolution with dark uniform blacks throughout the dot distribution, something that xerox reproduction could not accomplish.

All of the tests in dot map perception described in this study incorporated the same testing method. By placing equally sized delineated areas at various locations 
on what was hoped were fair representations of a dot map, and asking subjects to estimate the number of dots contained in those areas, it was expected that an accurate appraisal could be made regarding the way people perceive and use the dot map.

With tests one, two, and three, six horizontal rectangles lettered $A, B, C, D, E$, and F, were placed over the distribution of each map. The rectangles contained 13, 29, 100, 64, 85, and 47 dots respectively and were positioned identically on all of the test maps. The number of rectangles placed over the distribution was limited to six because certain studies indicate that people cannot readily distinguish quantitative differences in more than six or seven objects of similar quality. ${ }^{1}$ With test four, in the section concerned with stimulus shape, a vertical rectangle, a circle, and an oval were included with the horizontal rectangle as stimulus areas. In addition to variation in shape, the delineated areas were also positioned differently with respect to the dot distribution on each map.

Test one consisted of five maps, each distinguishable from the others only by differentiation of anchoring stimuli in the upper left corner (see Figures 12, 13, 14, 15, and 16). Specifically, one map had no anchoring stimulus, (this map served as the control group), while the remaining four maps had anchoring stimuli consisting respectively of 10 dots, 50 dots, 100 dots, and a full 
range of $10,50,100$ dots inclusive. The anchors take the form of a legend with the dots placed in boxes equal in size to those placed on the distributions. The range of anchoring stimuli was chosen to reflect the range of dot numbers found in the boxes placed over the distribution on the maps.

With the second test, which was made up of three maps, dot size was the distinguishing variable (see Figures 17, 18, and 19). The first map in the series was constructed according to standard practice in that the dots begin to coalesce in the areas of greatest density. The dot size required for the distribution used was approximately .035 inches in diameter. For the other two maps used in the test the dots were .025 and .020 inches in diameter respectively and were placed so as to create identical distribution patterns on each map. The dot sizes chosen for the last two maps were arbitrary, in that selection was not made on the basis of any mathematical relationship in dot diameters or area, but rather on the subjective judgment of what constituted good visual separation. In the end it only mattered that each of the three maps were readily distinguishable on the basis of dot size alone.

The third test consisted of three maps with distinguishable background tints. While the first map in this test was identical in all respects to the first map in both tests one and two, the other two maps differed in 
that both had screened backgrounds with black political boundaries rather than white grounds and screened boundaries. The screened tints on the two maps were printed at values of 10 per cent and 30 per cent respectively. These screened tints were intended to simulate in a mapping context, those experiments done by psychophysicists in which the brightness of projected images were varied (see Figures 20, 21, and 22).

In the fourth test both the shape of the stimulus areas and the subject's backgrounds served as distinguishing variables. The four maps used in this test were identical to those used in the first three tests except the lettered stimulus areas vary in position and in shape. The same maps were used for both the stimulus area shape test and for the test dealing with class rank and area of study of the subjects (see Figures 23, 24, 25, and 26).

It is probably safe to say that most people when using a dot map seldom actually count the dots. The real situation is probably closer to a comparison of relative densities with a determination to the effect that there are more of something in one area and less in another. If, however, a determination beyond this is attempted, (i.e., how many more are there in one region versus another), then a question arises as to the ability of a map user to make such a determination. 
In designing the tests it was felt that the

easiest and most direct method for evaluating dot map perception would be to have the subjects estimate the number of dots rather than the density. When a subject is asked to determine density, (even relative density), he is in reality being asked to make a determination for both number and area. It is for this reason that density is a more difficult concept for most people to grasp than number, besides being more difficult to test in a consistent manner. To insure comparability between the tests and to allow evaluation of density perception, the stimulus areas were standardized in shape and size.

Subjects and Testing Procedures

Subjects participating in tests one, two, and three were all students at California State University, Northridge. A total of 165, 99, and 99 subjects took part in the three respective tests. Thirty-three subjects made up the control sections for each of the three tests. Data for these control sections were derived from a single testing of one group of thirty-three subjects. * Thus the control section data for each test is identical. Ninetysix subjects, all student employees of Los Angeles City Schools Youth Services Section, took part in test four.

*This group of thirty-three subjects was part of the 165. subjects participating in test one. 
In addition, twenty-five Geography majors at California State University, Northridge, participated in an additional test segment dealing with area of study. The total sample for the four tests was fairly well balanced in the distribution of class ranks but at the same time the sample was heavily weighted with Geography majors. Out of a total of 418 subjects, there were 66 freshmen, 57 sophomores, 110 juniors, 122 seniors, and 63 graduates. However, Geography majors made up 40 per cent of the sample when divided into area of study. Whether or not this imbalance affected the results of the tests was examined in test four. The area of study and class rank of the subjects participating in each of the four tests can be found in Appendix 1.

It was considered important that each individual map be examined by independent groups of thirty-three subjects, thus no single subject examined more than one particular map. The reason for this lies in the fact that it has been demonstrated by Saltzman and Garner that practice improves the perceptual accuracy of many subjects. 2 For this study it was felt that if a subject participated in more than one section of a particular test or in more than one test, that this would constitute practice and therefore could affect the results. The primary purpose then in limiting each subject to only one test section was to insure that the only variables influencing test results would be those that were designed 
into the maps.

Al1 of the subjects were given instruction sheets on which spaces were provided for answers to the test. The subjects were asked to estimate the number of dots contained in each box without counting. No time limit was set, but most of the subjects completed the test within three to four minutes. Examples of the instruction-answer sheets can be found in Appendix 2 . 
MAPS USED IN TEST ONE

FIGURE 12. Control map

FIGURE 13. 10 dot anchor map

FIGURE 14. 50 dot anchor map

FIGURE 15. 100 dot anchor map

FIGURE 16. Full range anchor map 


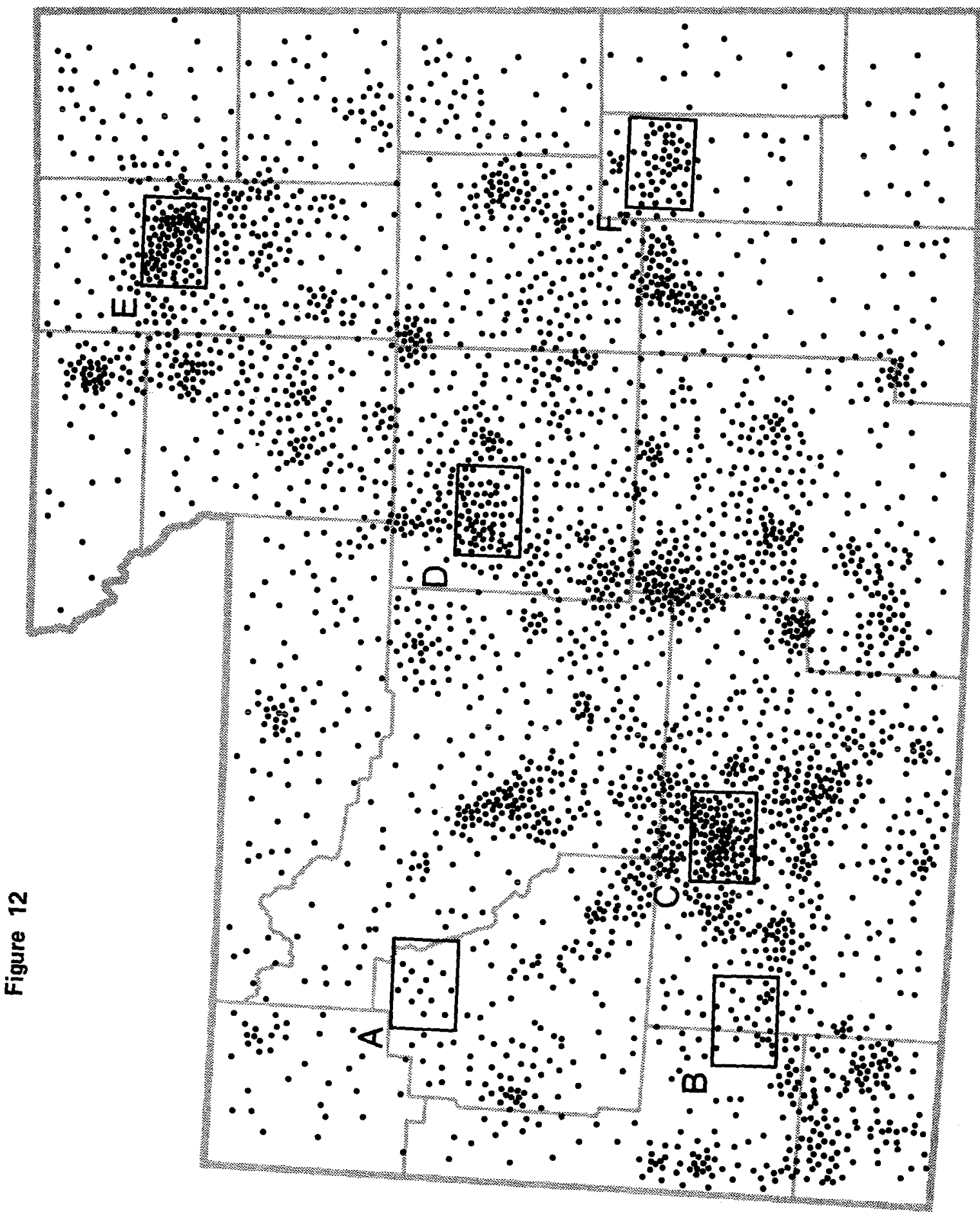




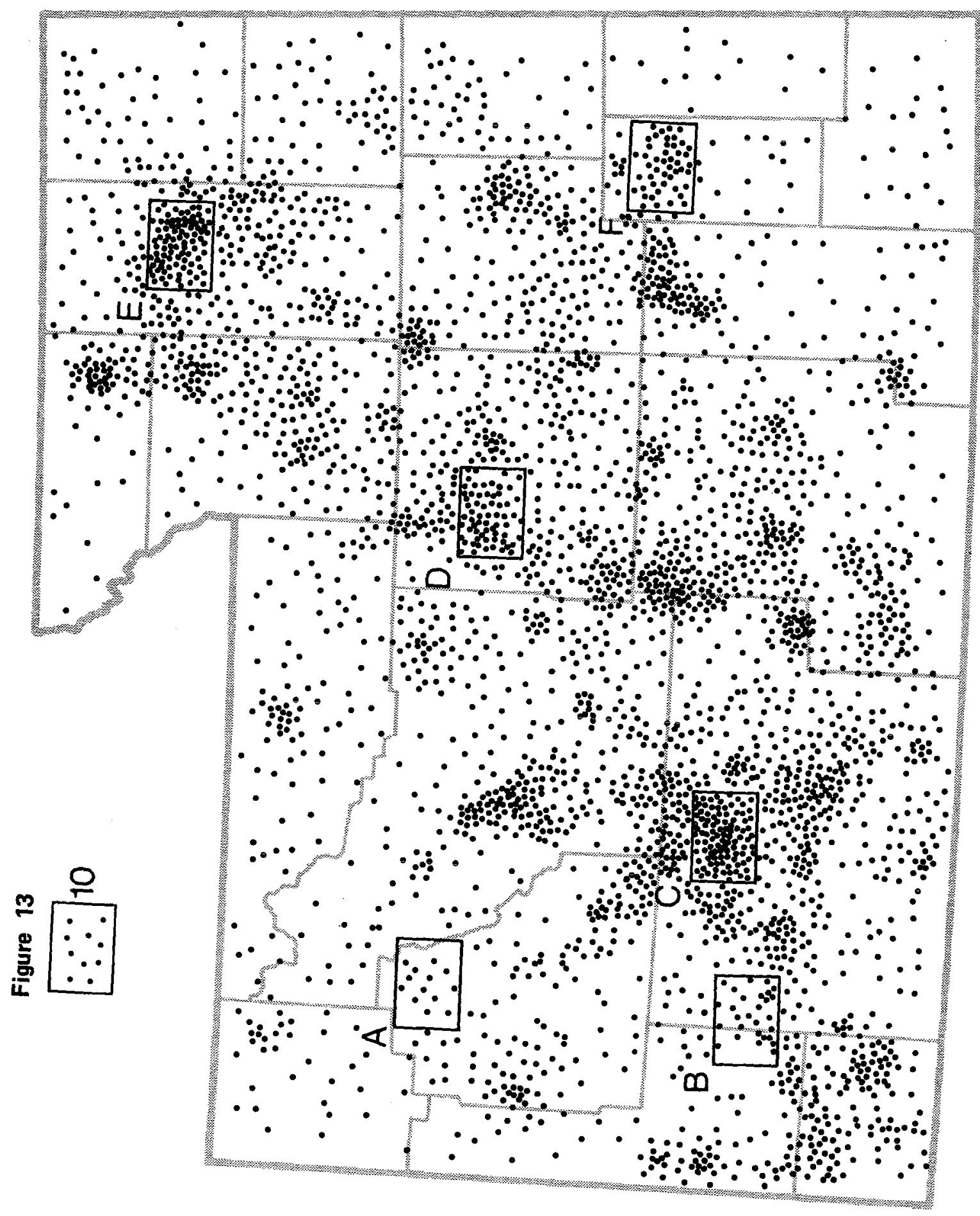




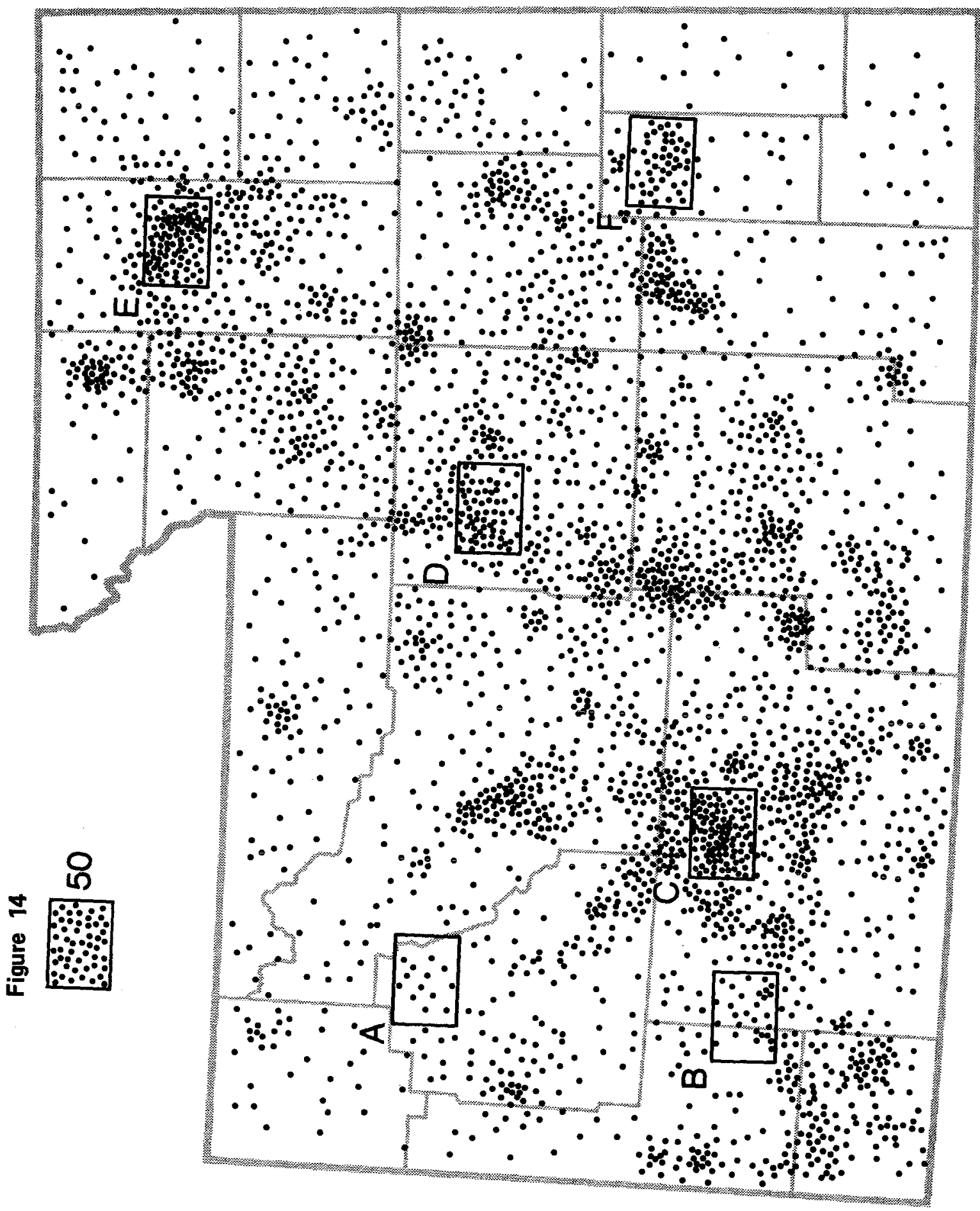




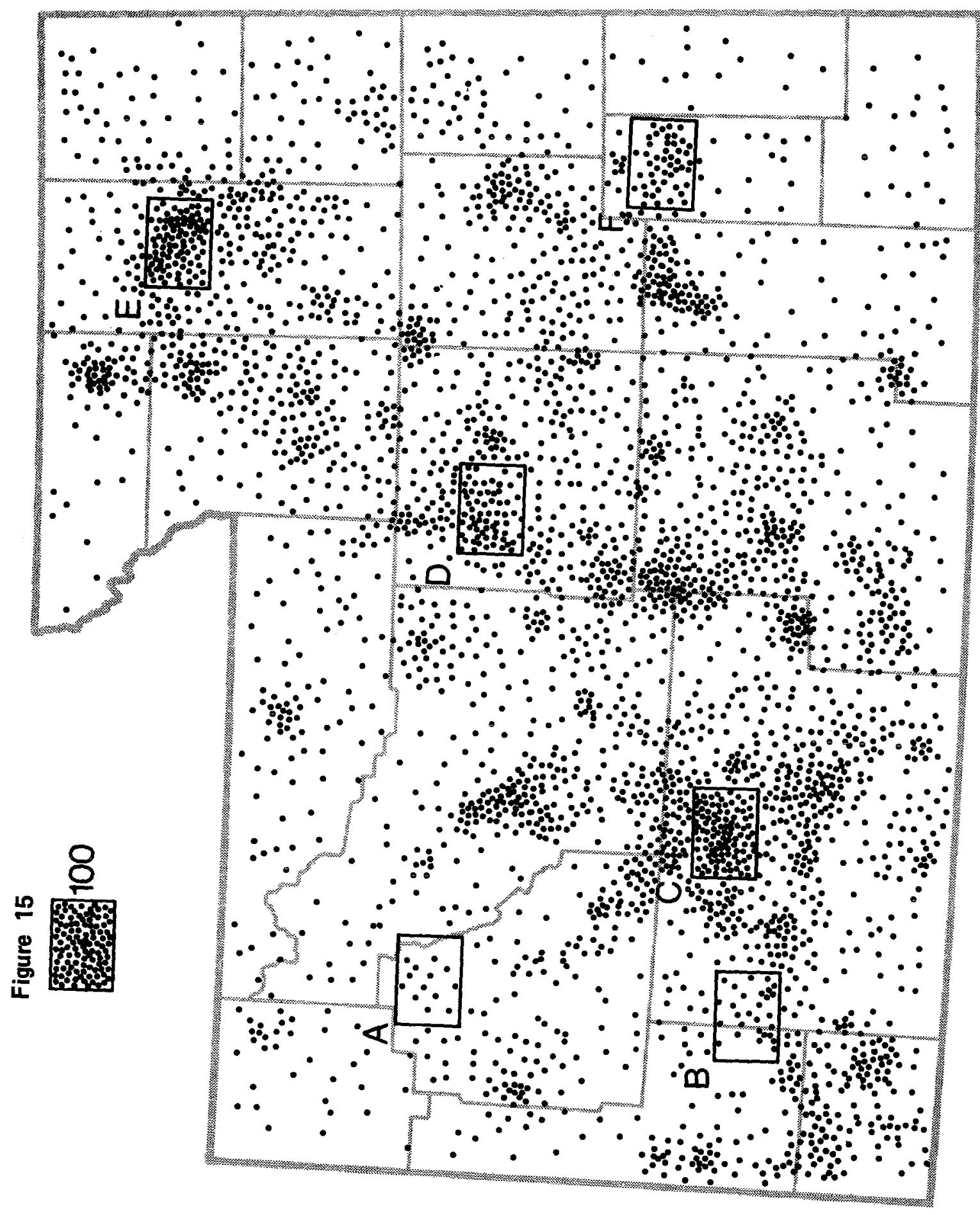




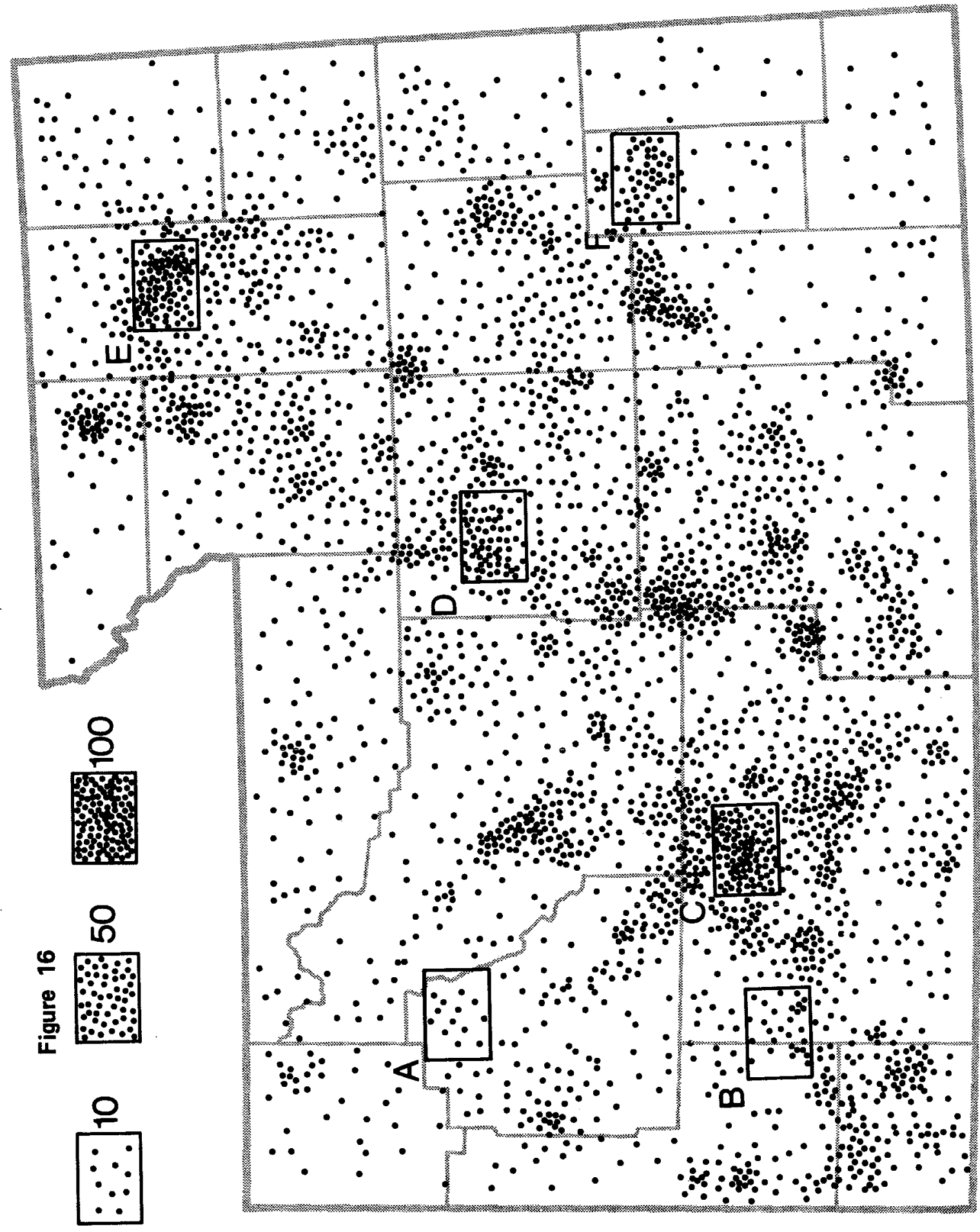


MAPS USED IN TEST TWO

FIGURE 17. Control map

FIGURE 18. Medium dot map

FIGURE 19. Small dot map 


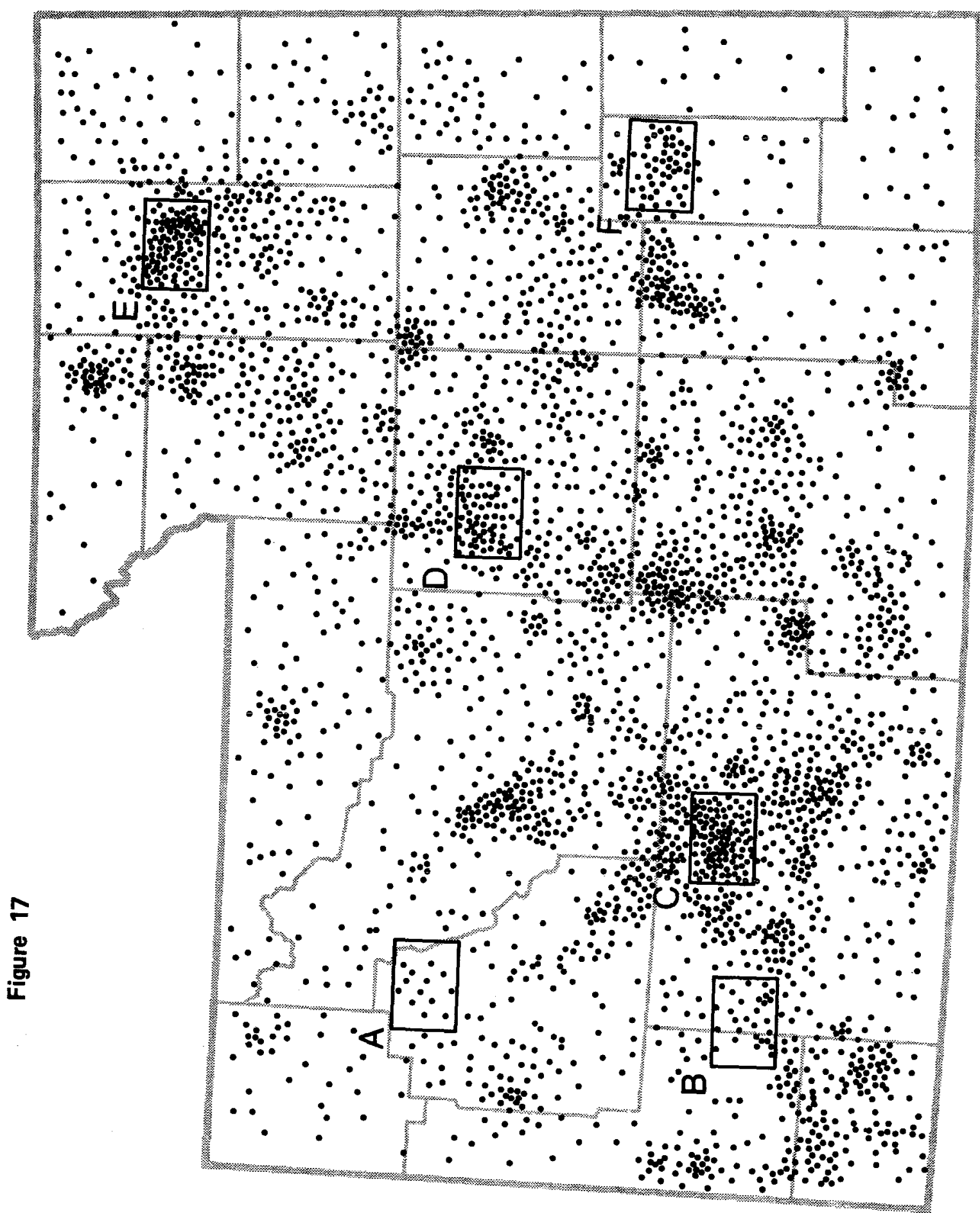




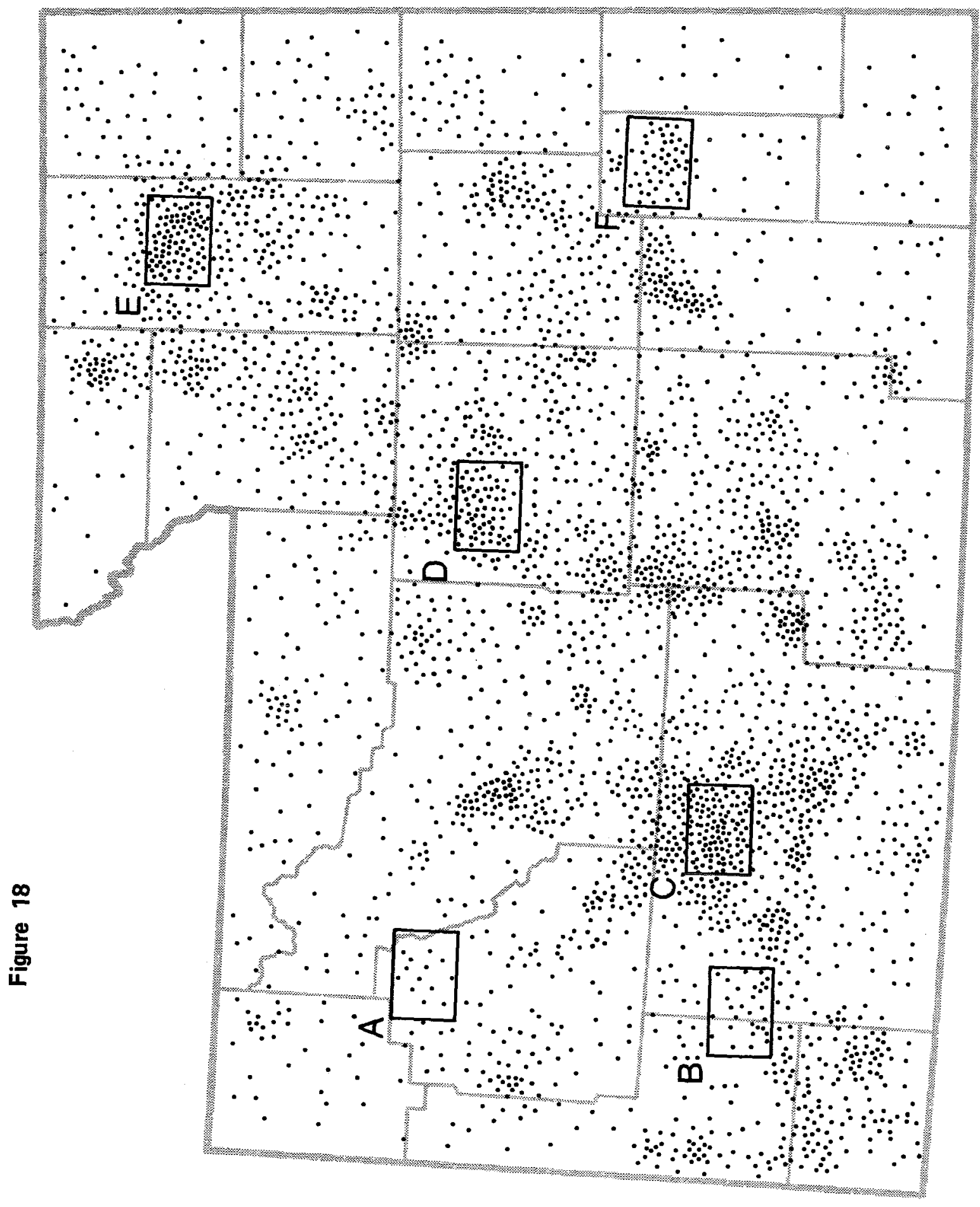




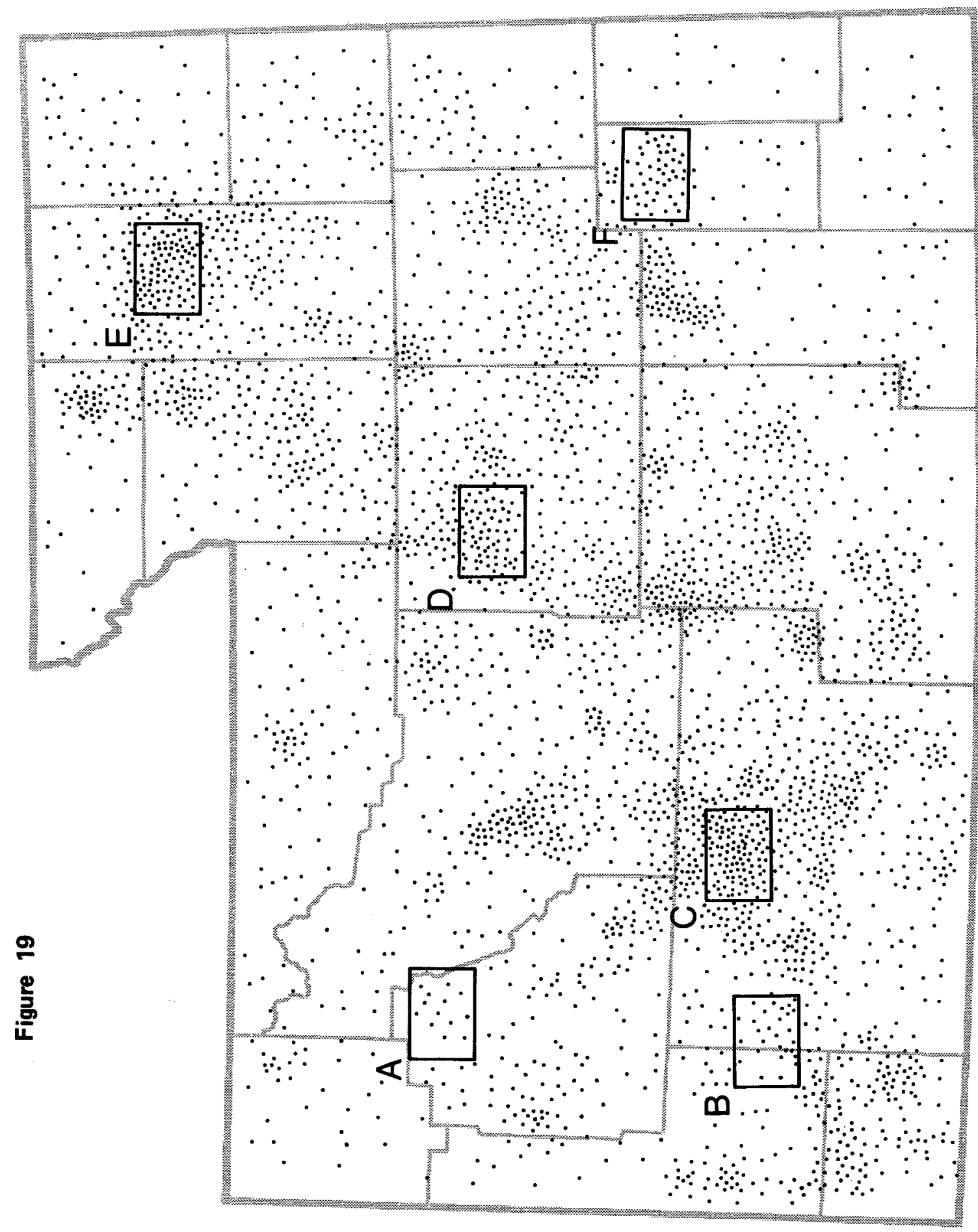


MAPS USED IN TEST THREE

FIGURE 2O. Control map

FIGURE 21. 10 per cent screen tint map

FIGURE 22. 30 per cent screen tint map 


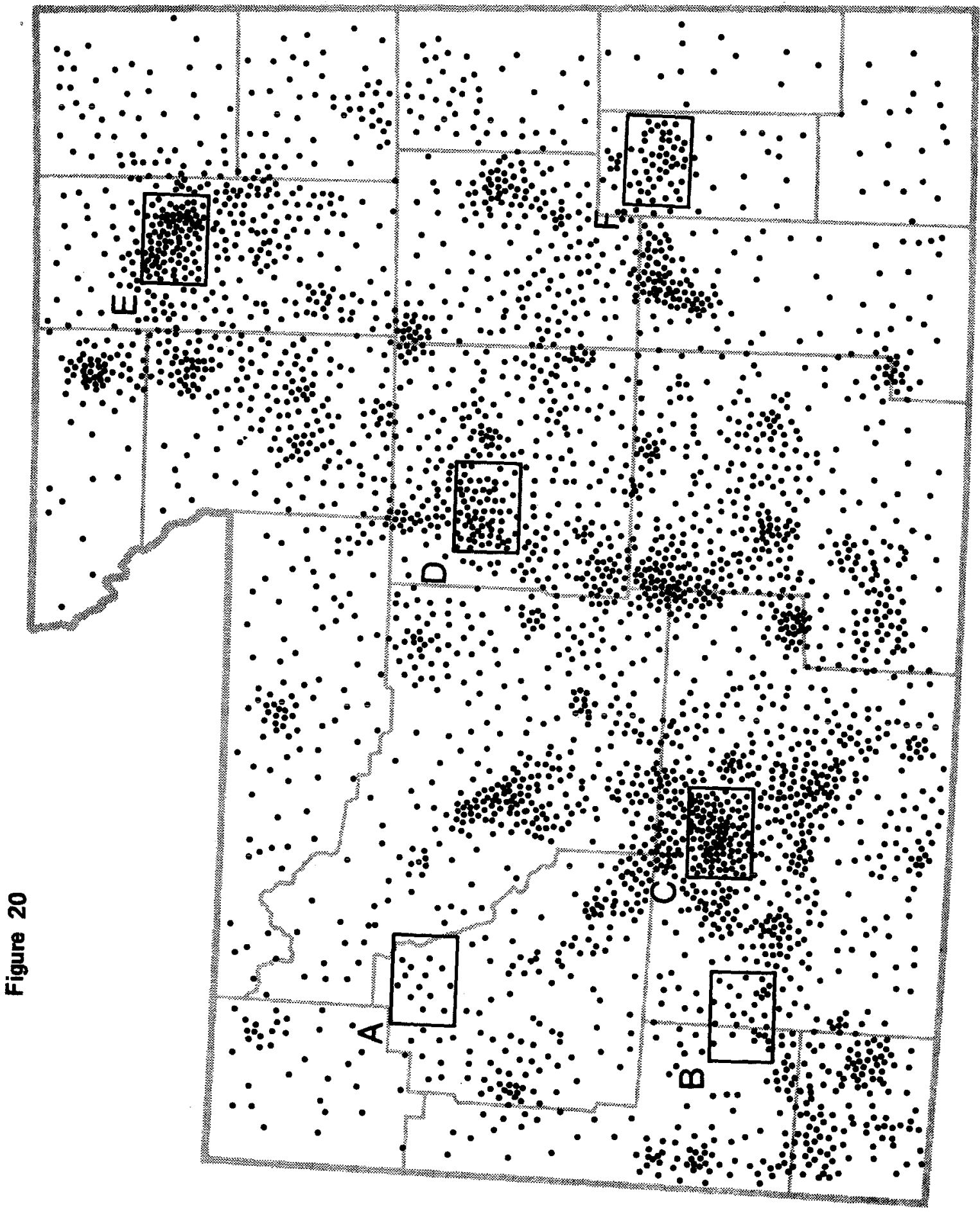




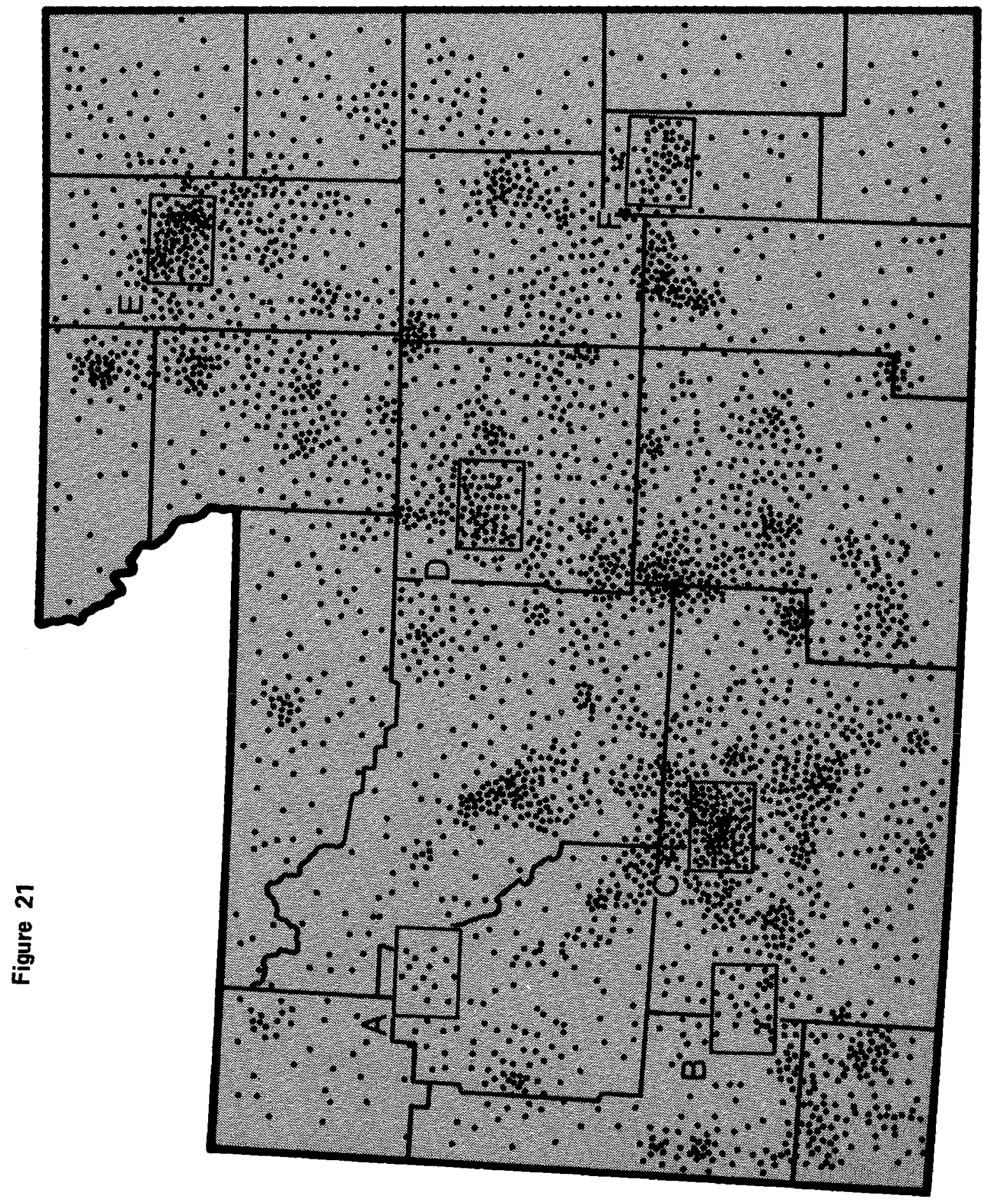




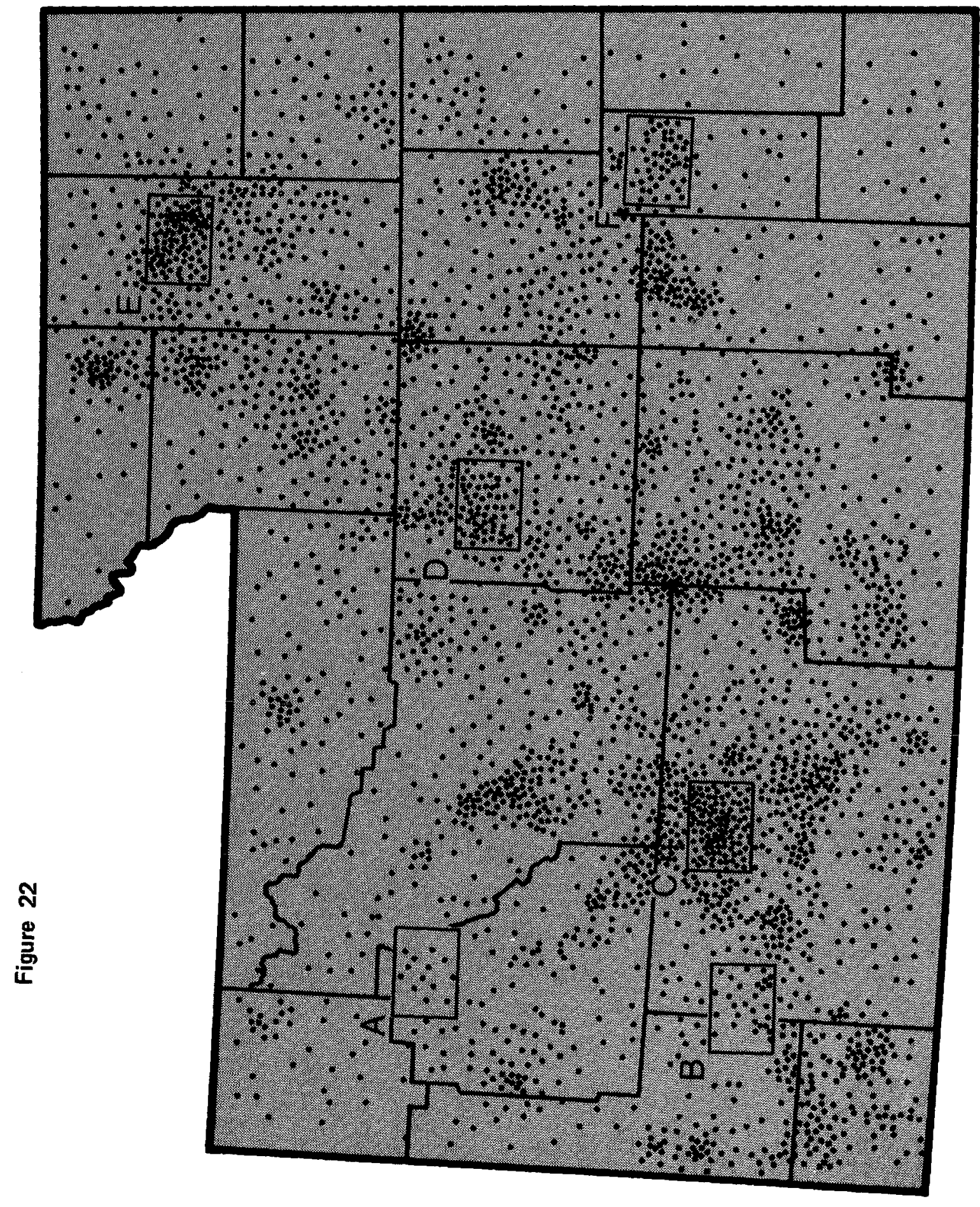


MAPS USED IN TEST FOUR

FIGURE 23. Horizontal rectangle

FIGURE 24. Vertical rectangle

FIGURE 25. Circle

FIGURE 26. Oval 


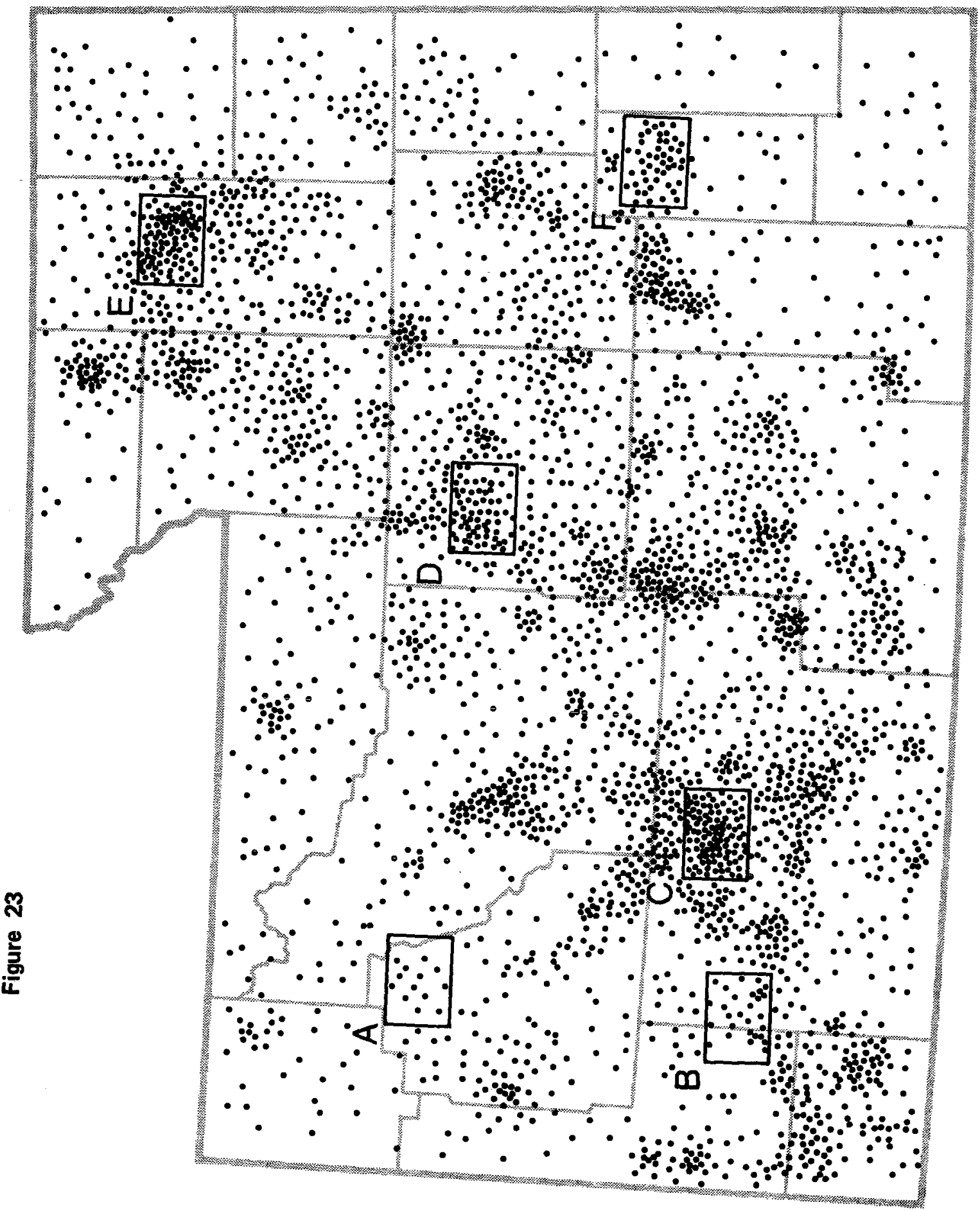




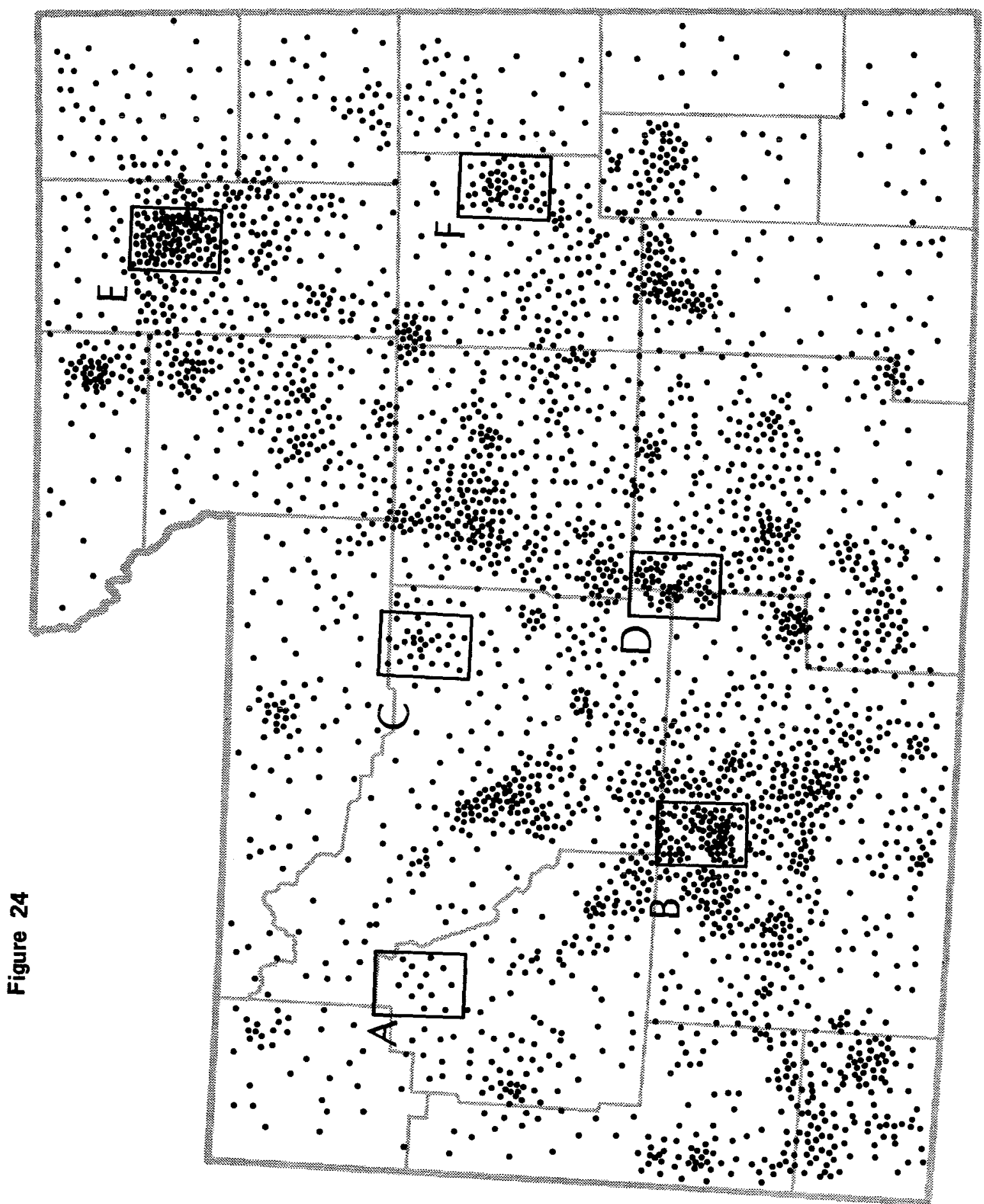




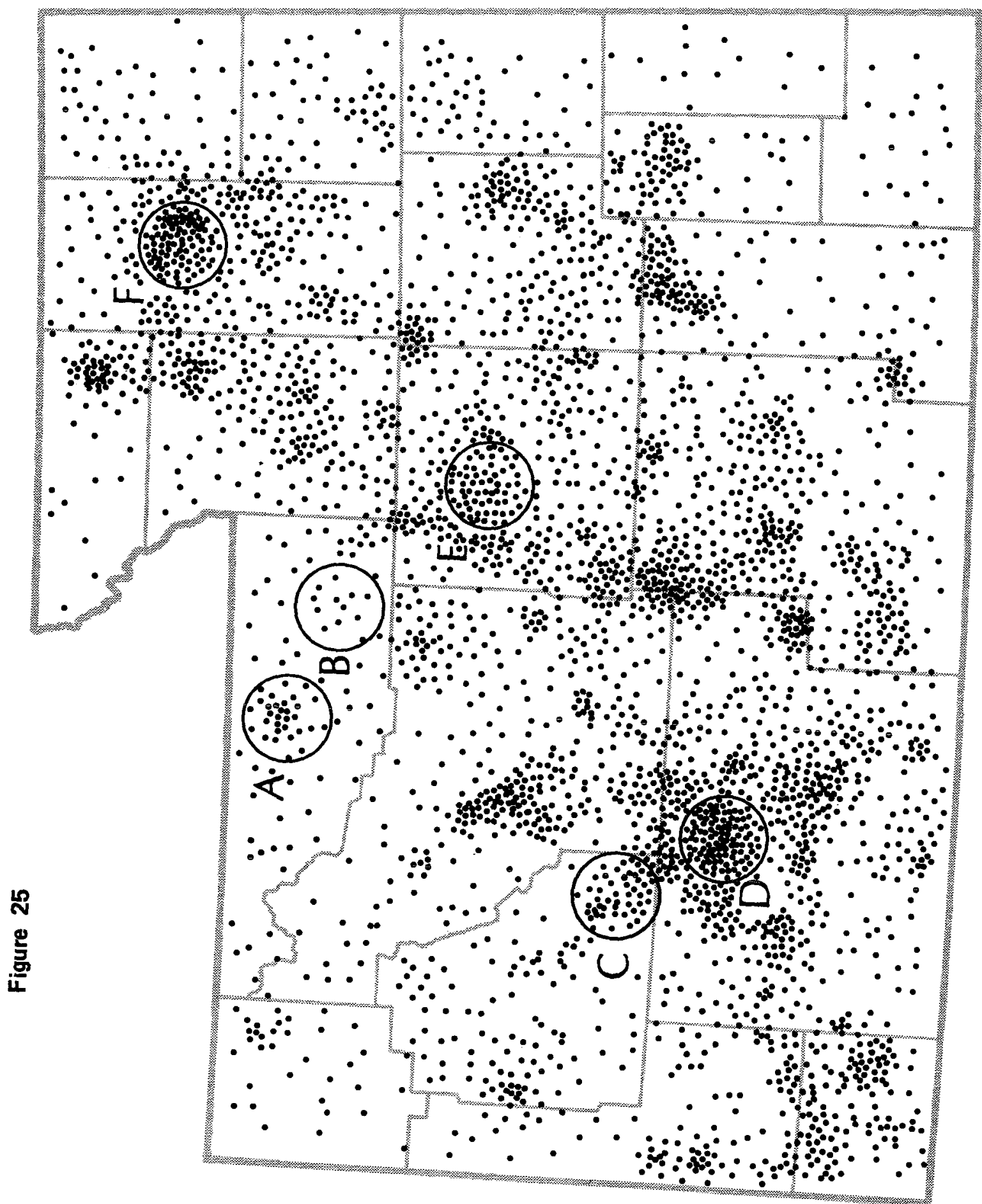




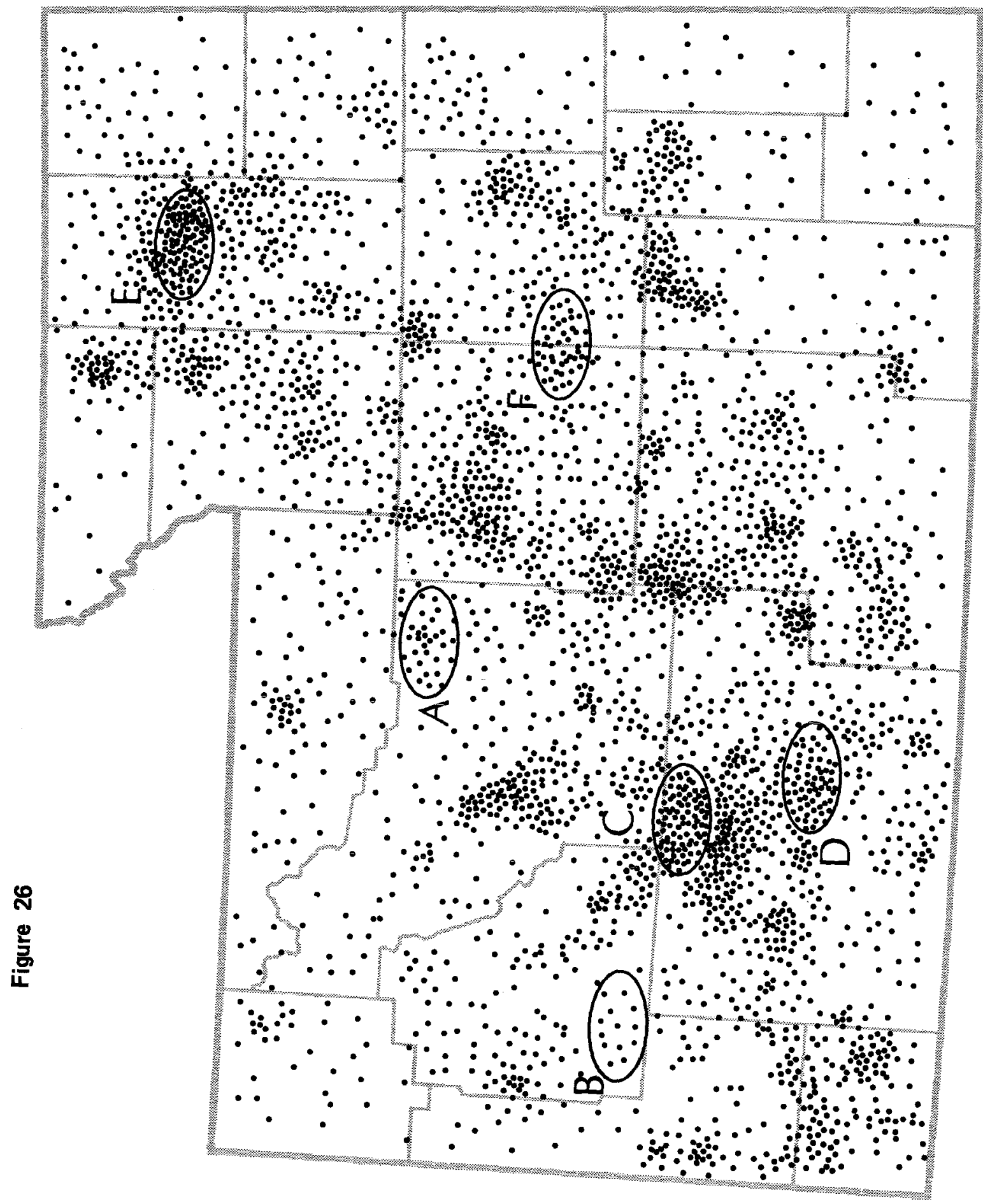




\section{REFERENCES}

${ }^{1}$ G. S. Miller, "The Magical Number Seven, Plus or Minus Two," Psychological Review LXIII (March 1956): 81-97.

${ }^{2}$ Saltzman and Garner, "Reaction Time as a Measure of Span of Attention," Journal of Psychology XXV (April $1948): .234$. 


\section{CHAPTER IV}

\section{FINDINGS}

The findings from the four tests in this study have answered some fundamental questions. The basic characteristics of perceived numerousness are explored, and several of the dot map's limitations are revealed. While it is demonstrated that the dot map does not communicate information as effectively as once thought, its value is that it portrays distributional pattern as no other statistical map can. The findings discussed here not only help define some of the perceptual aspects of the dot map, but also serve as mechanisms by which dot maps can be improved.

Test One

The purpose of test one is to determine the direction and amount of perceptual error in judging dot number. In addition, this test attempts to establish if anchoring stimuli will significantly affect any observed error. The findings from test one indicate that most map users underestimate dot numbers. The $Z$ scores for all reports from the five sections show that in nearly every case the 
means and modes of the sample estimates are lower than the stimulus values (see Figures 27 and 28). Of the thirty means derived from the test data only three equaled or exceeded the value of the stimulus. Likewise, ten modes exceeded the stimulus values, but only three of these contained over one-third of the observations. The map with no anchor in the test (control section) exhibited underestimated mean values for every stimulus. Underestimation ranged from a high of 33 per cent for the largest stimulus ( 100 dot stimulus) to a low of 1 per cent for the smallest stimulus (13 dot stimulus). The results of this test clearly indicate that people tend to underestimate in their perception of numbers on dot maps and that the error increases in a consistent manner with larger stimulus values.

The four maps with anchoring stimuli, with the exception of that with the low end anchor, all showed marked improvement in both the means and modes for the estimates when compared to the stimulus values. The map with the low end anchor (10 dots) actually showed greater underestimation than did the map with no anchor. Underestimation ranged from a high of 40 per cent ( 100 dot stimulus) to a low of 8 per cent ( 13 dot stimulus). The low end anchor section gives poorer results than the central section; probably because the anchor pulls the estimates toward itself, lowering the mean values (assimilation effect). 
The map with the middle anchor (50 dots) exhibits mean estimates that are much improved over both the map with no anchor and the map with the low end anchor. All of the mean estimates are approaching the actual stimulus values as the maximum error shrinks to 20 per cent. The mean estimates for the high end anchor (100 dots) reach the highest degree of accuracy; higher even than those estimates using anchors covering the whole range of stimulus values. Perhaps this can be explained by the same factors that seem to be operating in the low end anchor test. While the high end anchor pulled all of the estimates upward (end anchor tendency), which improves them markedly because of the tendency to underestimate to begin with, the full range anchor was moderated to some extent in its upward shifting influence by the presence of the low and middle anchors. By way of concrete comparison, the range of mean percentage error for the high end anchor was 14 per cent and 1 per cent while the full range anchor ranged from 28 per cent to 2 per cent. Figure 29 shows the relationships between the stimulus values, the control section, and the various anchoring stimuli.

One peculiarity in the results for test one is the overestimation in the means for box E (85 dot stimulus) with the middle, high, and full range anchors (Figure 28). The best explanation seems to be that of all the boxes, box $E$ has the least uniform distribution of dots 
(Figure 12, stimulus E). Perhaps this unevenness of the distribution causes the estimates to shift in an upward direction. Taves indicated that there might be a direct relationship between the degree of irregularity in configuration and accuracy in the perception of number. I It is interesting to note, however, that this effect is totally absent in the control group and low end anchor tests.

Another intriguing revelation is the change in the range of estimates and standard deviations about the means caused by the various anchoring stimuli. As pointed out previously, improvement in the mean estimates do not follow in the expected sequence (i.e. control, low, middle, high, and full range anchors); but the range of the estimates along with the standard deviations do generally decrease in the expected order. This stands out strongly when comparing the plots of data range and standard deviations for each individual test (Figures $30,31,32,33,34$, and 35$)$. Not only do the ranges progressively contract with the application of anchors in the given order, but generally the modes become stronger. As expected, the most pronounced improvements occur in the estimates of high stimulus values.

Test one indicates that people generally underestimate in their perception of numbers on dot maps, with the degree of underestimation being directly proportional 
to the magnitude of the stimulus. Anchoring stimuli improve this situation, especially if the anchor is at the high end of the stimulus range. The anchors in addition to improving the accuracy of estimation also greatly reduced both the range in the estimations and variability in estimates. While the sequence of anchoring stimuli used in the test did not result in the expected sequence of improvement with regards to errors of estimation, the expected order did present itself with respect to the improvement in range of estimates and in the standard deviations throughout the test sections. Given the test results, dot maps employing a simple high end anchor or a full range anchor should give considerably improved accuracy for the average map user.

\section{MAJOR FINDINGS FROM TEST ONE}

1. Most subjects underestimate the number of dots on dot maps. The degree of underestimation is directly proportional to the magnitude of the stimulus.

2. Low end anchors increase underestimation of dot numbers.

3. High end anchors and full range anchors greatly improve the accuracy of estimates of dot numbers.

4. Middle, high and full range anchors decrease the range and the variability in estimates of dot numbers. 

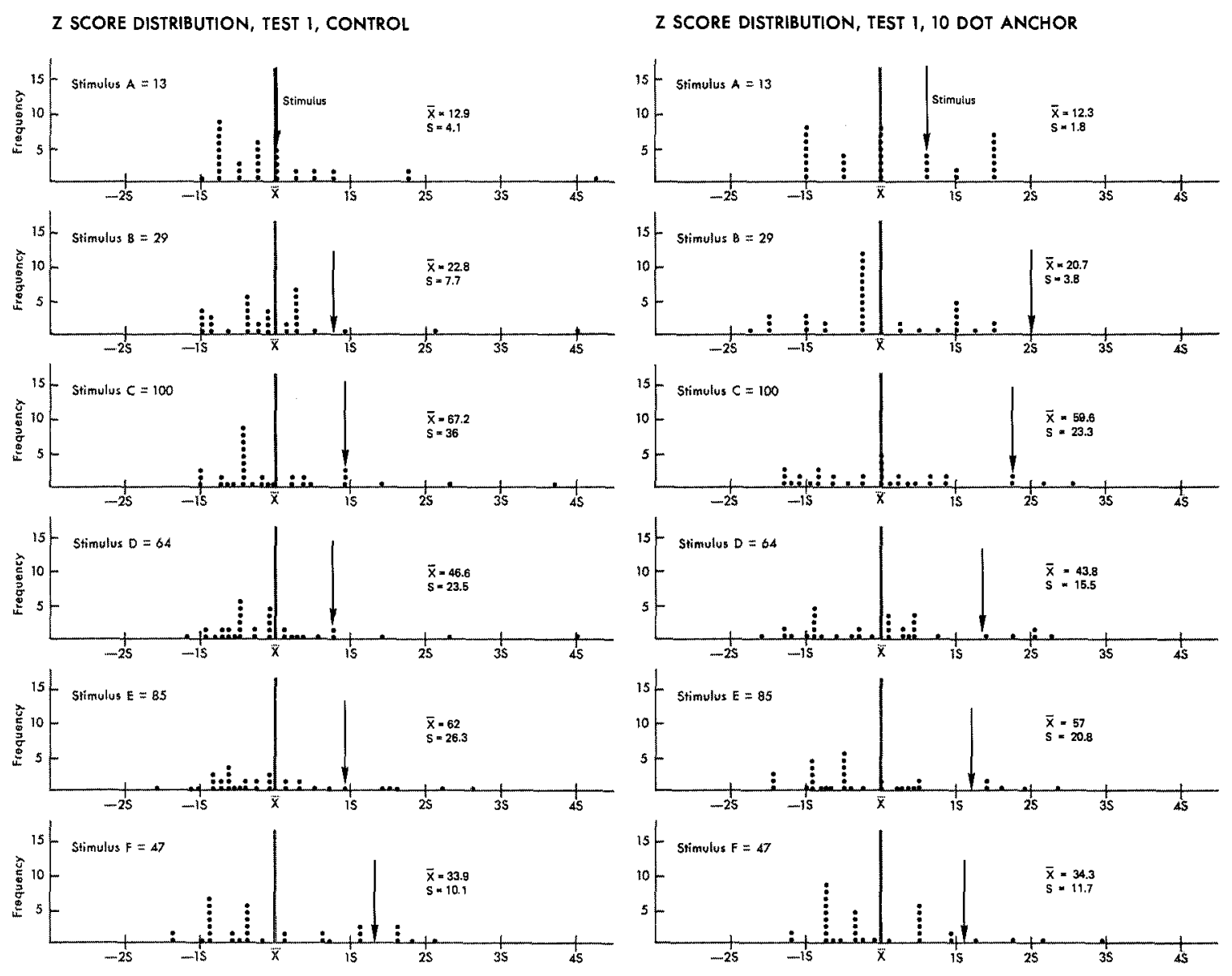

Figure 27. $Z$ score distribution for Test 1 , sections 1 and $2 . \bar{X}$ is the mean and $S$ is the standard deviation. 
Z SCORE DISTRIBUTION, TEST 1, 50 DOT ANCHOR
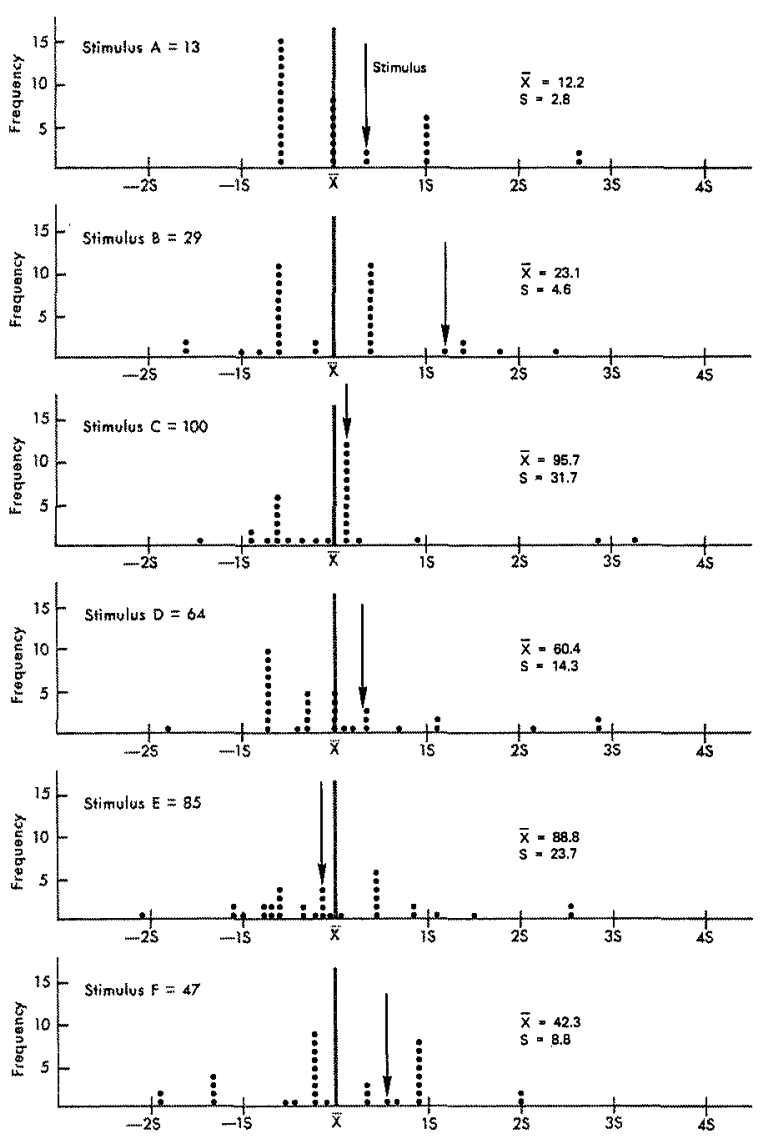

Z SCORE DISTRIBUTION, TEST 1, 100 DOT ANCHOR
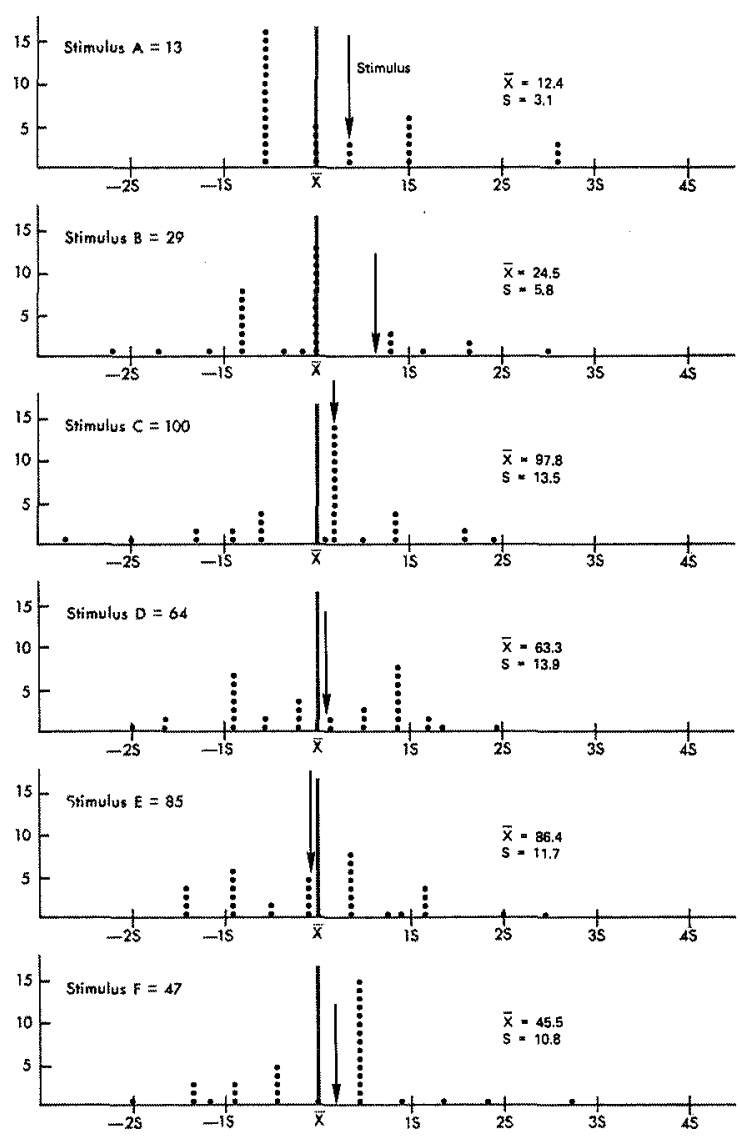

7 SCORE DISTRIBUTION, TEST 1, FULL RANGE ANCHOR
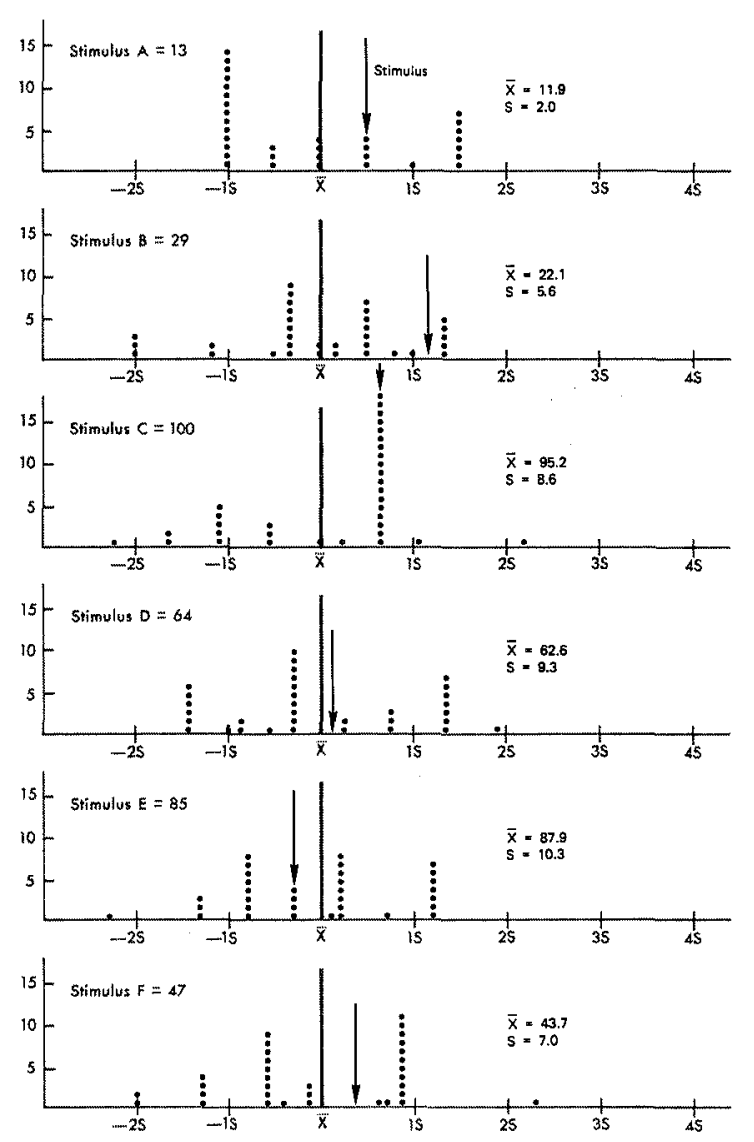

Figure 28. $Z$ score distribution for Test 1 , sections 3,4 , and $5 . \bar{X}$ is the mean and $S$ is the standard deviation. 


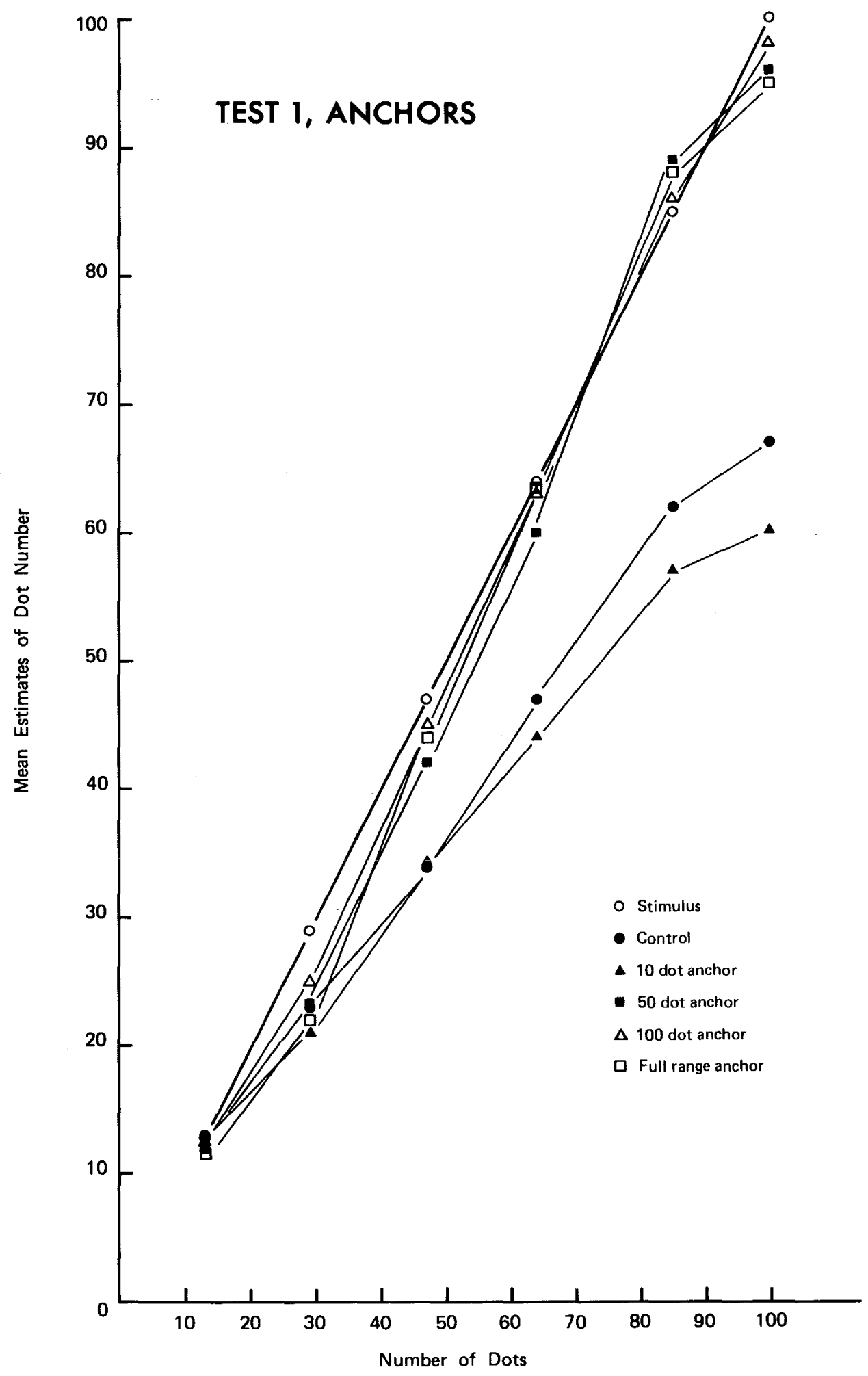

Figure 29. The relationship between the mean estimates and stimulus value for Test 1 with no anchor (control) , 10 dot anchor, 50 dot anchor, 100 dot anchor and full range anchor. 


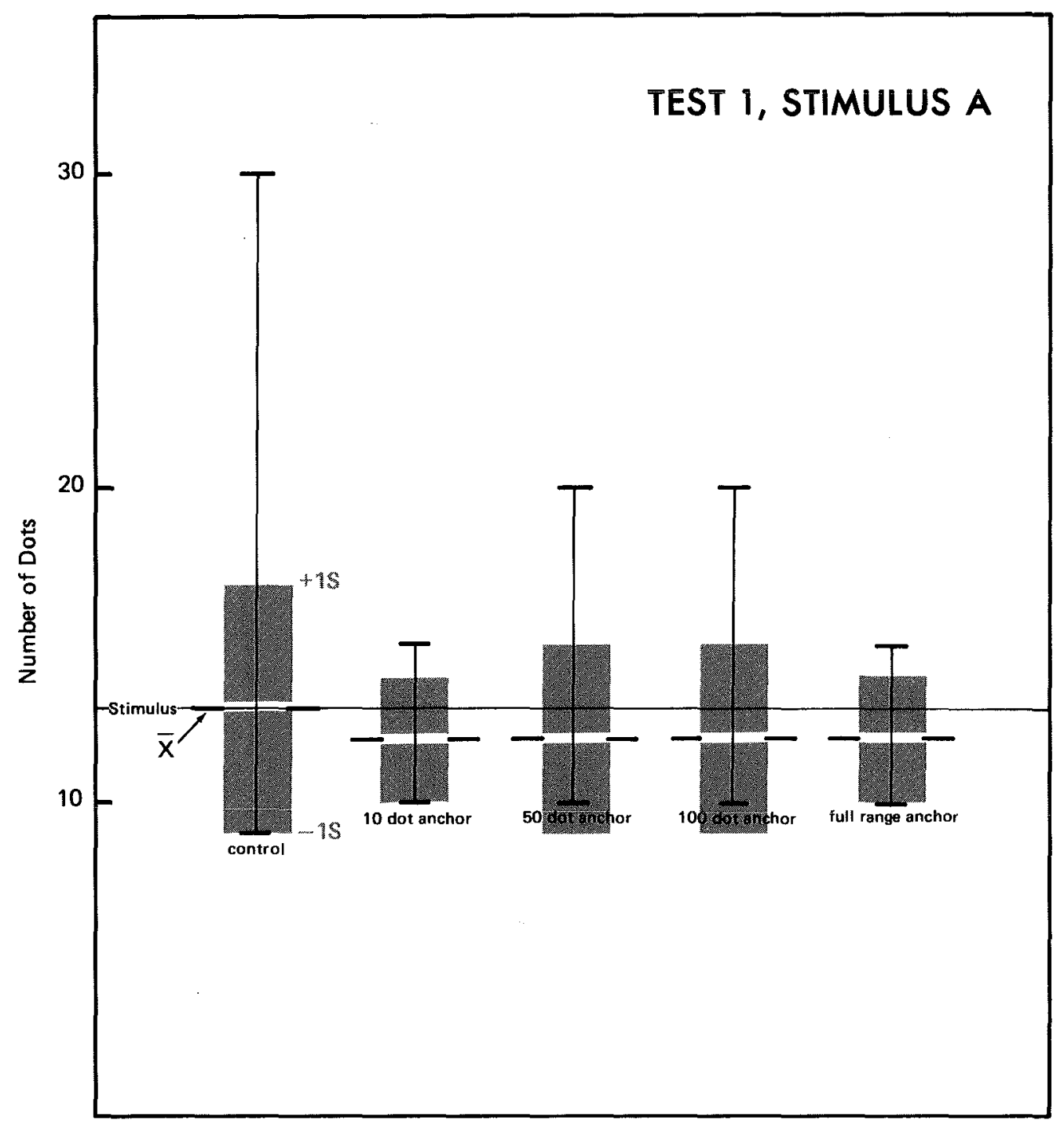

Figure 30. Range of response and standard deviations for Test 1, stimulus A. Vertical lines show range of response, $\bar{X}$ is the mean and $S$ is the standard deviation. 


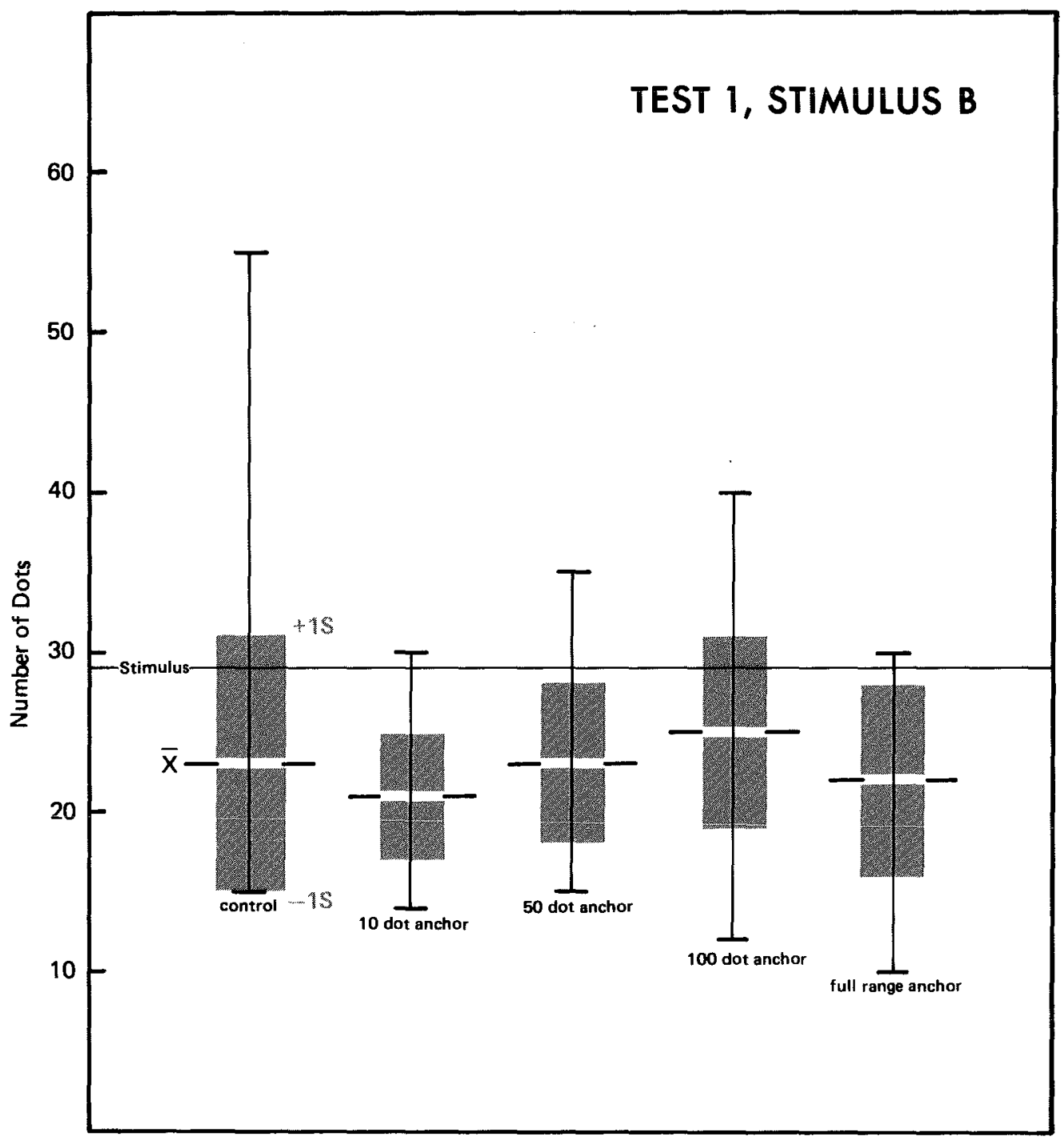

Figure 31. Range of response and standard deviations for Test 1, stimulus B. Vertical lines show range of response, $\bar{X}$ is the mean and $S$ is the standard deviation. 


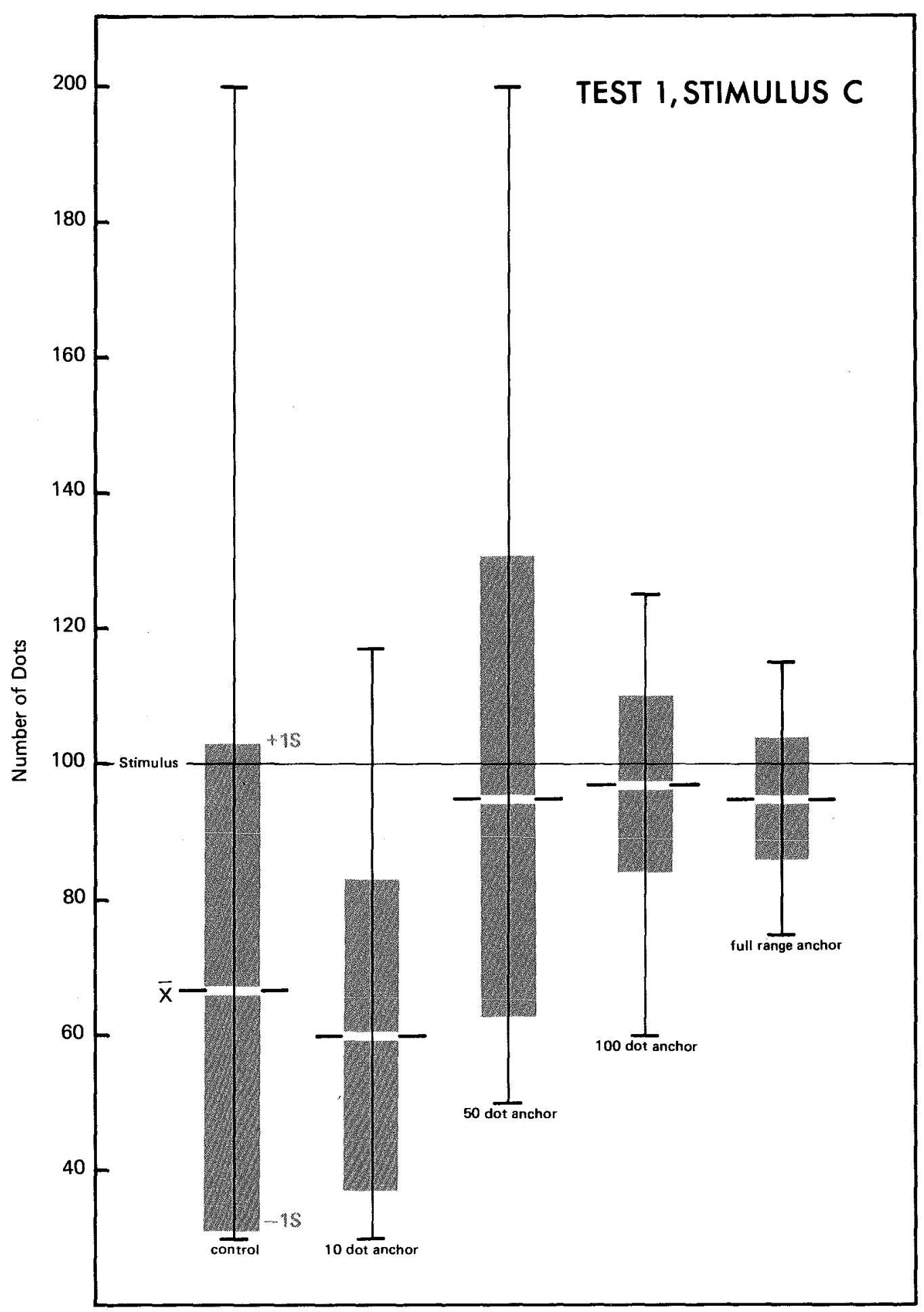

Figure 32. Range of response and standard deviations for Test 1 , stimulus $C$. Vertical lines show range of response, $\bar{X}$ is the mean and $S$ is the standard deviation. 


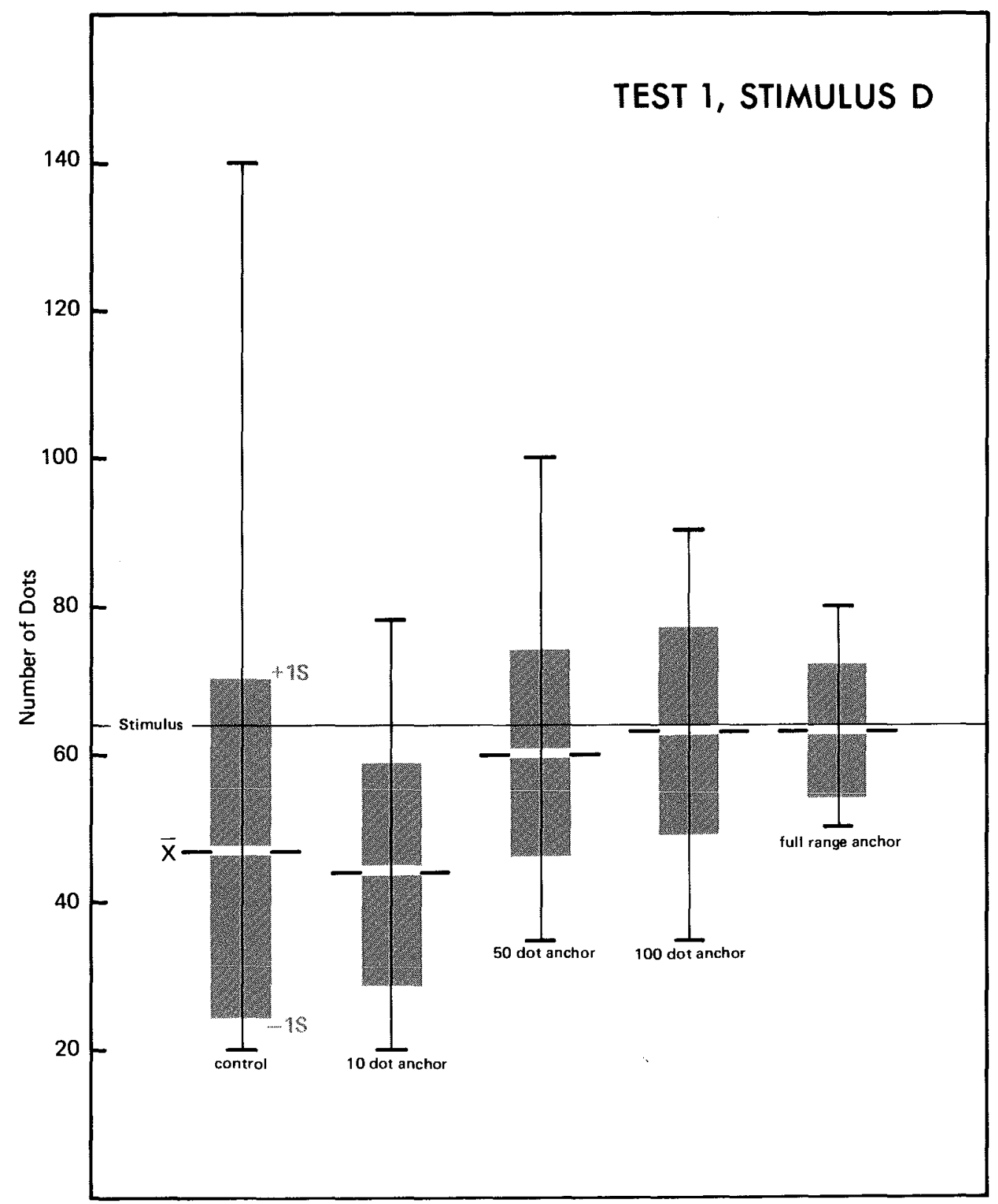

Figure 33. Range of response and standard deviations for Test 1, stimulus $D$. Vertical lines show range of response, $\bar{X}$ is the mean and $S$ is the standard deviation. 


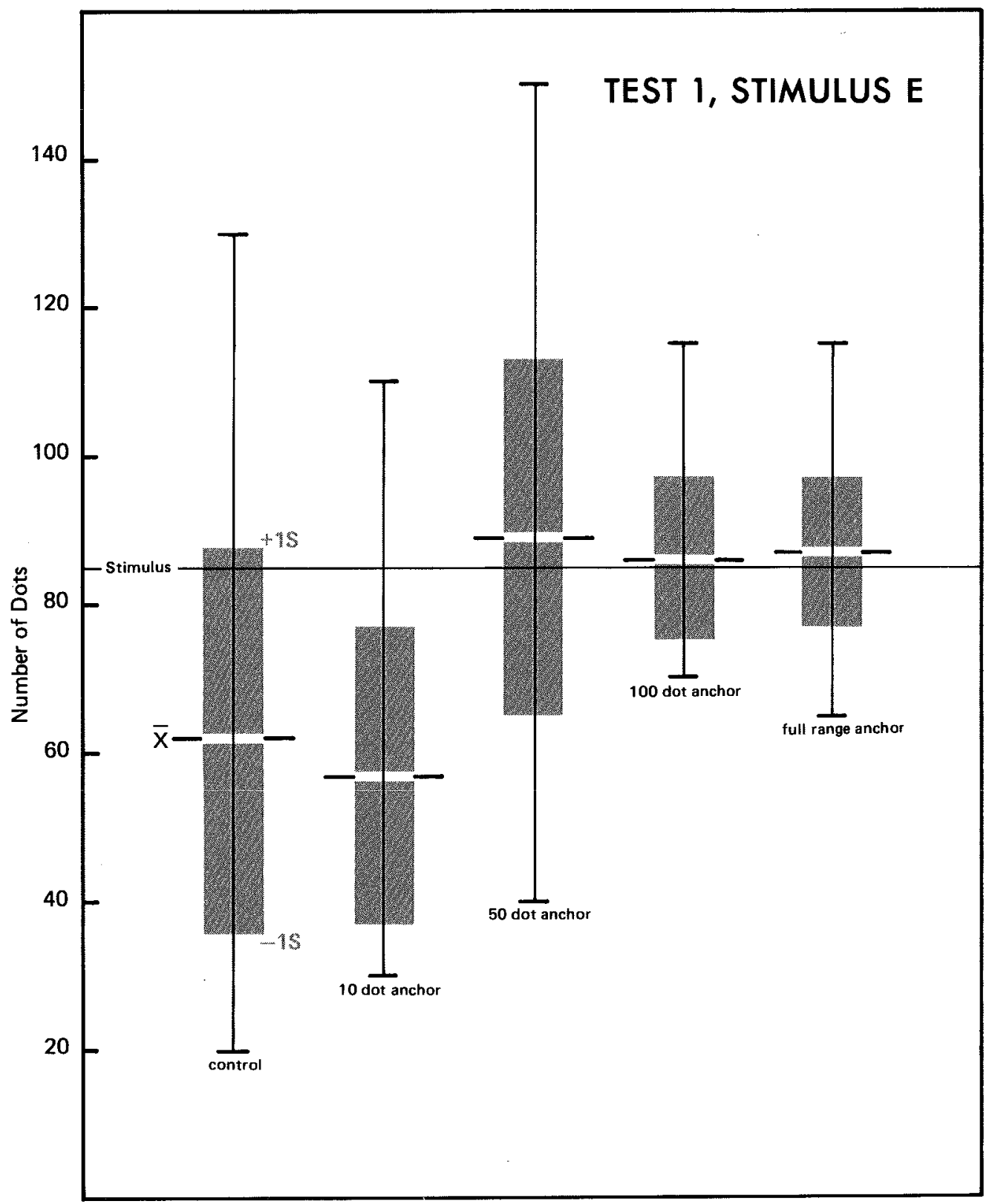

Figure 34. Range of response and standard deviations for Test 1, stimulus E. Vertical lines show range of response, $\bar{X}$ is the mean and $S$ is the standard deviation. 


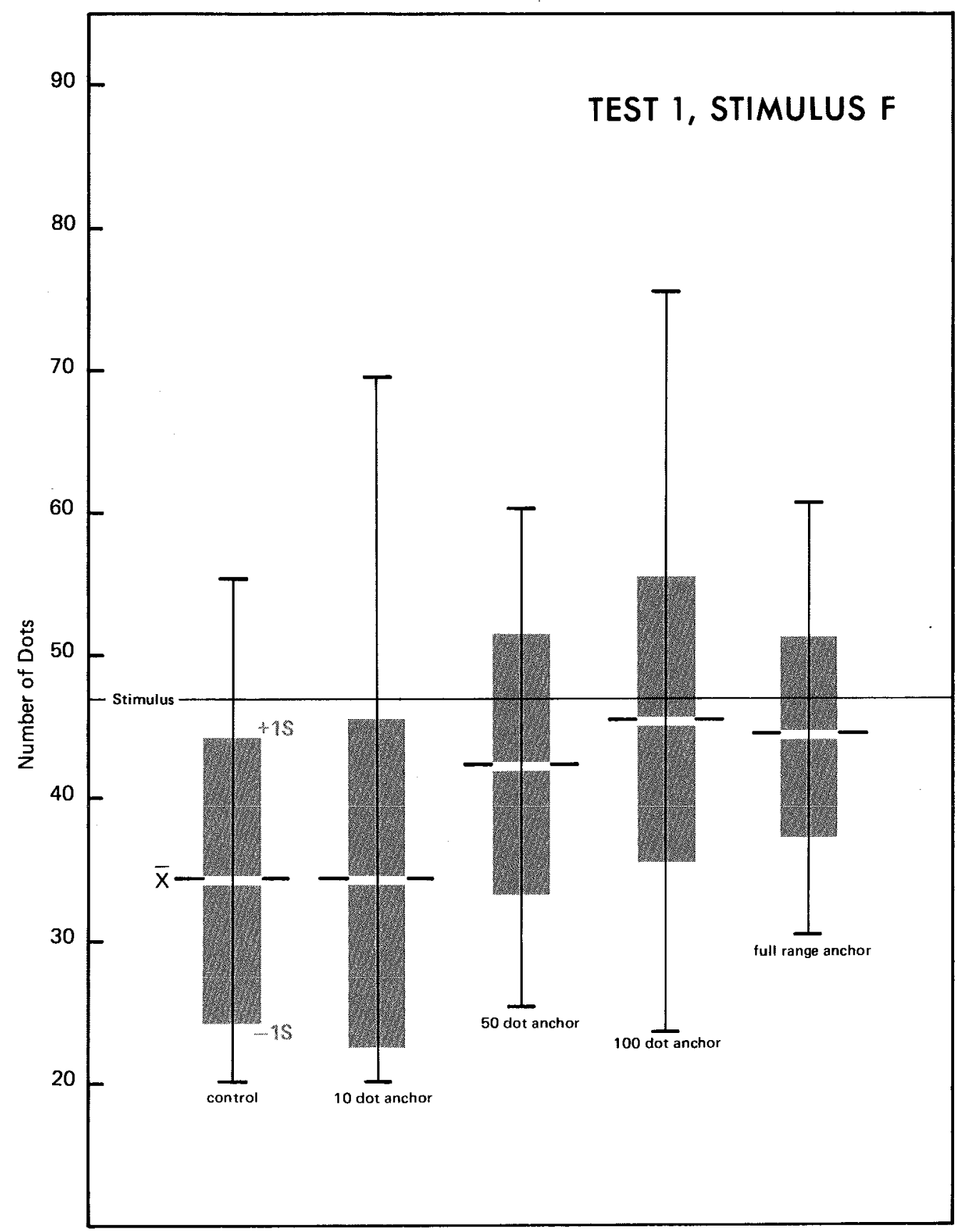

Figure 35. Range of response and standard deviations for Test 1 , stimulus $F$. Vertical lines show range of response, $\bar{X}$ is the mean and $S$ is the standard deviation. 
Test Two

The purpose of test number two is to establish if variation in dot size affects the perception of dot number. In addition, it attempts to indicate how apparent density conditions number perception. The findings from test two indicate that dot size does influence the percep- : tion of dot number to some degree. Examining the $Z$ score distribution for all reports shown in Figure 36, it can again be seen that in every case the mean estimates are lower than the stimulus values. The range in percentage errors for the means are from $O$ per cent to 33 per cent for section one, 7 per cent to 29 per cent for section two, and 5 per cent to 32 per cent for section three. In all cases the smaller errors are associated with the 13 dot stimulus, while the larger errors are associated with the 100 dot stimulus. Although all of the mean estimates for test two are below the stimulus values, when one compares the amount of error for all of the mean estimates in each section, it can be seen that there is an inverse relationship between dot size and amount of error (Figure 37). The map that was constructed by convention (dots just coalesce in the most dense areas) and which had the largest dots, was perceived with the least accuracy. Although the differences in the degree of error between the three test sections is small, it is of some significance, especially when one looks at some of the other statistics 
that describe the test results.

The findings from test two also indicate that the smaller dot sizes result in a decrease in the range of response and in the standard deviations. The first section (dot size selected by convention) displays the greatest ranges in response and the highest values in standard deviation for each stimulus. The other two sections show a considerable degree of improvement in these respects, being nearly identical in their mean values for range of response and standard deviation (Figures 38, 39, $40,41,42$, and 43). To explain this phenomenon, it is suggested that the dichotomy in the response ranges and standard deviations between section one and sections two and three is a direct result of the coalescing of dots in the first section. Perhaps what is happening is that confusion is introduced into the perceptual process as each dot loses its individuality in the more heavily populated areas of the map. As might be expected, when the dots are given more separation (made smailer) the number of individual dots is made more apparent to the map reader. Smaller dots seems to decrease the degree of uncertainty in estimating dot numbers but only slightly improve the accuracy of the estimates in terms of mean responses.

Probably the most interesting finding from test two comes when one compares apparent density with the mean estimates of number. If one compares the small difference 
in mean responses with the extreme difference in apparent density in the stimulus areas on maps one and three (largest and smallest dots), it must be concluded that apparent density has very little influence on perceived numerousness. Specifically, for example, the large dots in box $C$ on map one (Figure 17), cover approximately 44 per cent of. the total area of the rectangle, while the smaller dots on map three (Figure 19) cover approximately 14 per cent of an equal area, yet the mean estimates of the two boxes were 67.75 and 67.21 respectively. Assuming that the dots are uniform in size on each of the three maps, then it is probably safe to assume that the proportion of density differentiation is equal among all of the stimulus areas of each map in the test. Returning to Figure 37, it is apparent that the differences in the mean estimates for all of the boxes (between test sections one and three) is insignificant when compared to the vast difference in apparent density from box to box on the two individual maps.

In conclusion, test two demonstrates that dot sizes smaller than those dictated by convention tend to improve the estimate of number to a small degree. More important, however, is the fact that the smaller dots greatly reduce the range of responses and standard deviations in the estimation of number on dot maps. Finally, this test suggests that apparent density has very little to do with the perception of numerousness. 
1. The accuracy of dot number estimation is slightly improved with dot sizes smaller than those dictated by convention.

2. The smaller dot sizes decrease the range in response and the variability in estimates of dot number.

3. Apparent density has little effect on judgments of dot number. 
Z SCORE DISTRIBUTION, TEST 2, CONTROL
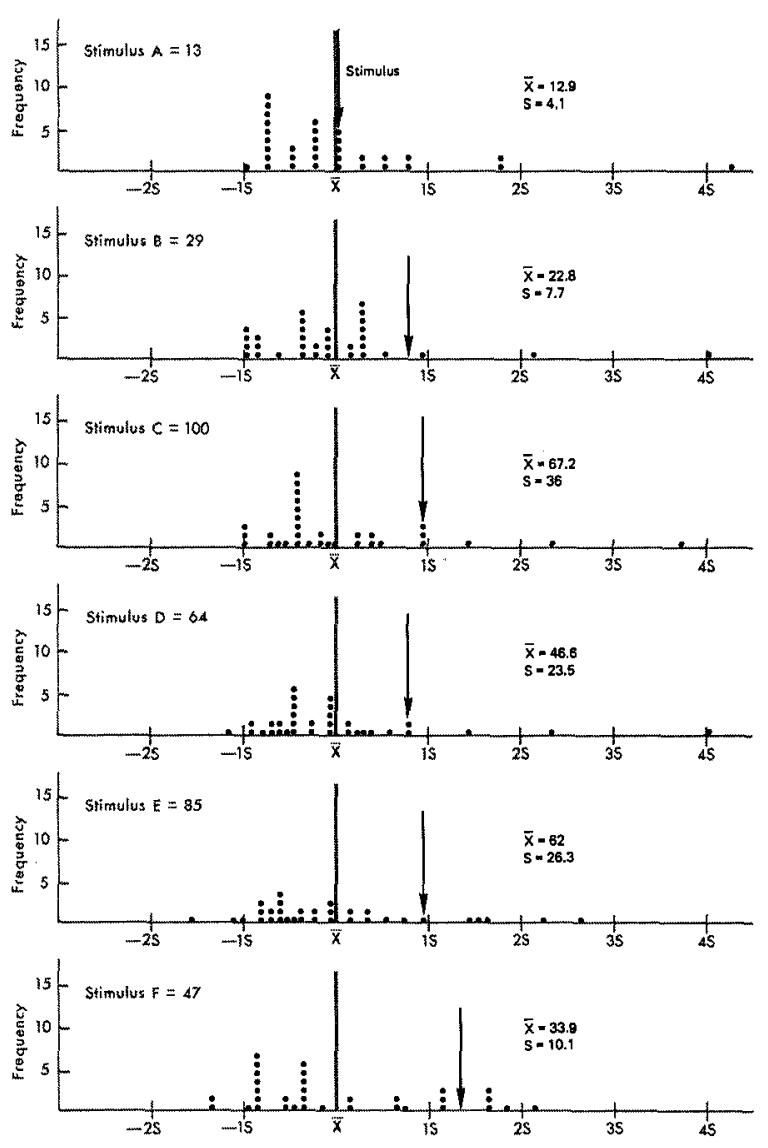

Z SCORE DISTRIBUTION, TEST 2, MEDIUM DOT
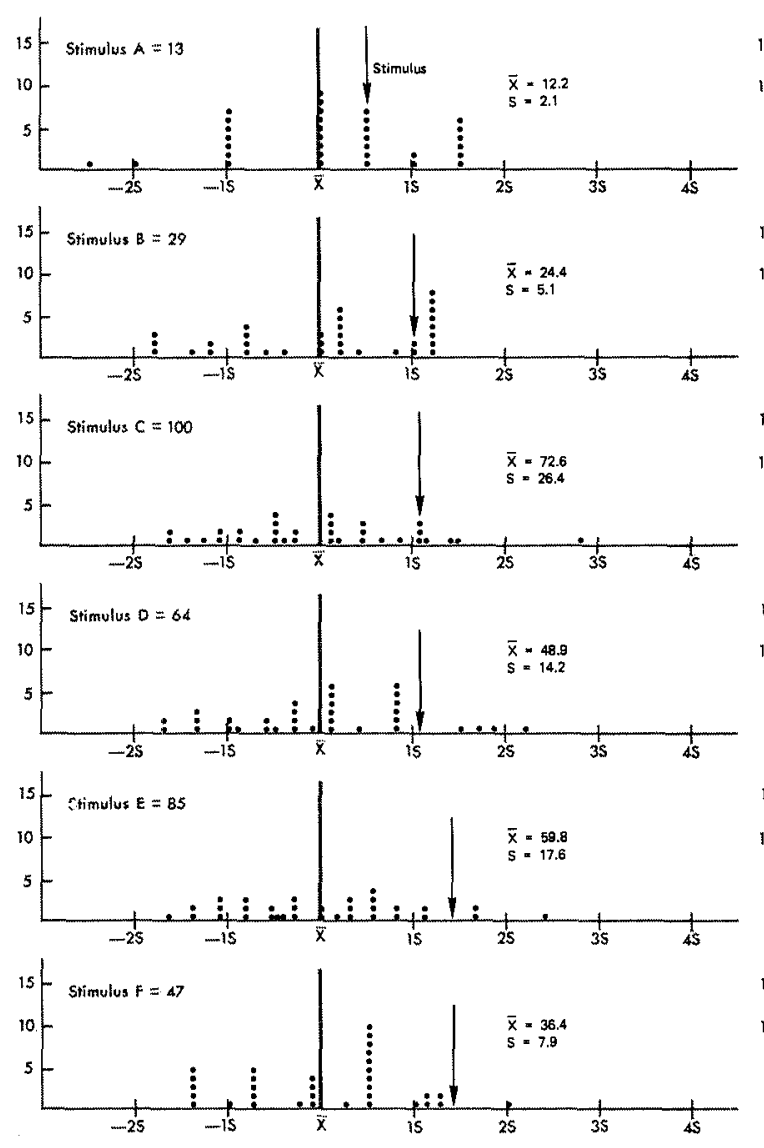

Z SCORE DISTRIBUTION, TEST 2, SMALL DOT
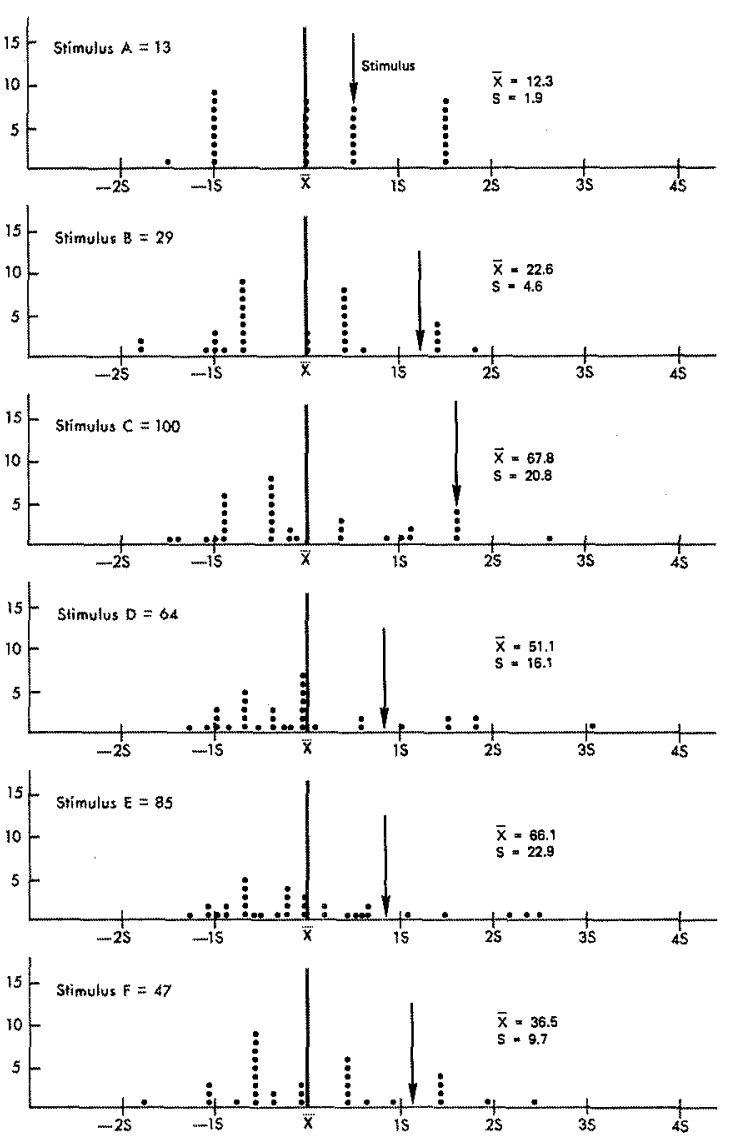

Figure 36. $Z$ score distribution for Test $2 . \bar{X}$ is the mean and $S$ is the standard deviation. 


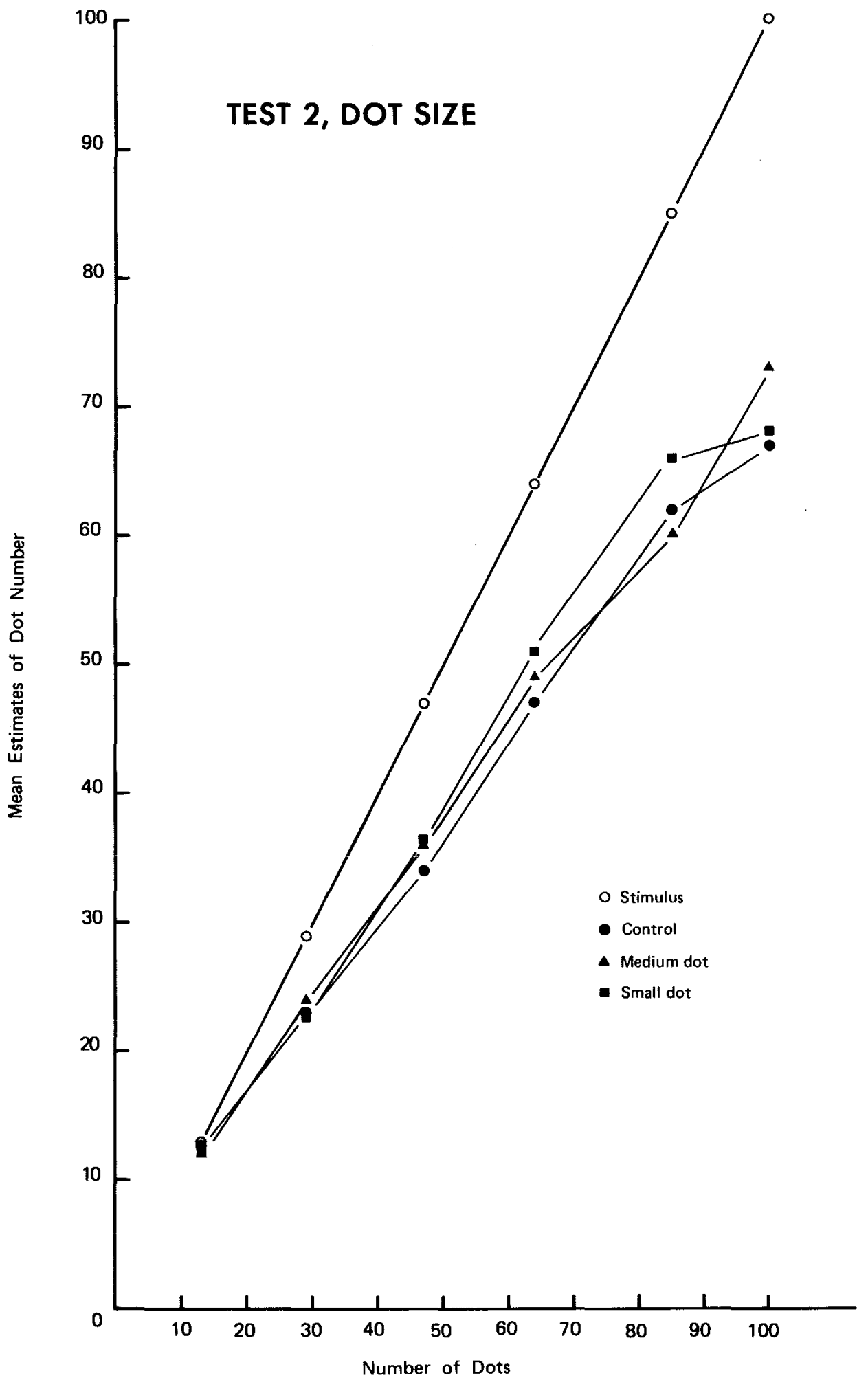

Figure 37. The relationship between the mean estimates and stimulus value for Test 2 with conventional dot size (control), medium dot and small dot. 


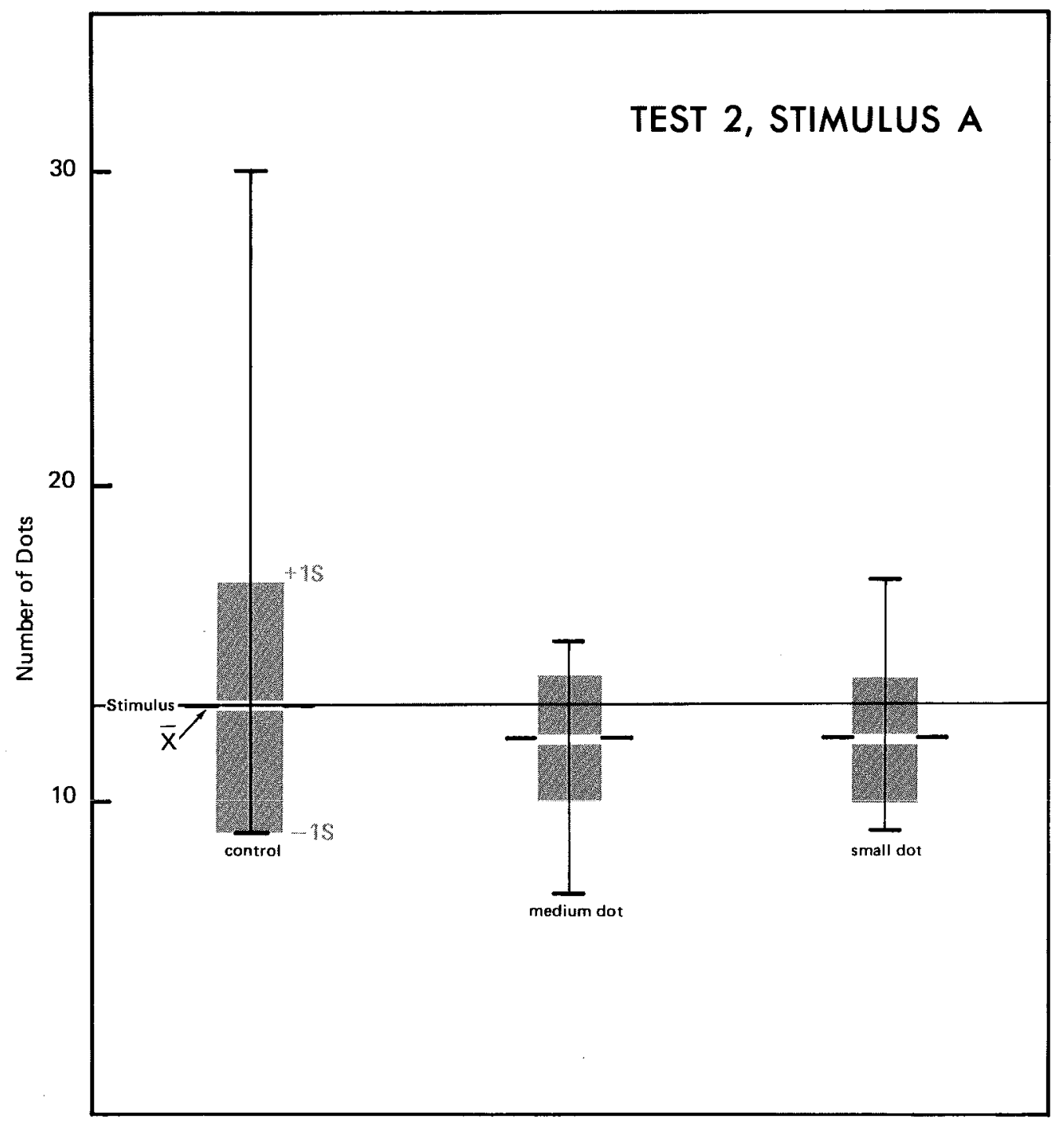

Figure 38. Range of response and standard deviations for Test 2. stimulus A. Vertical lines show range of response, $\bar{X}$ is the mean and $S$ is the standard deviation. 


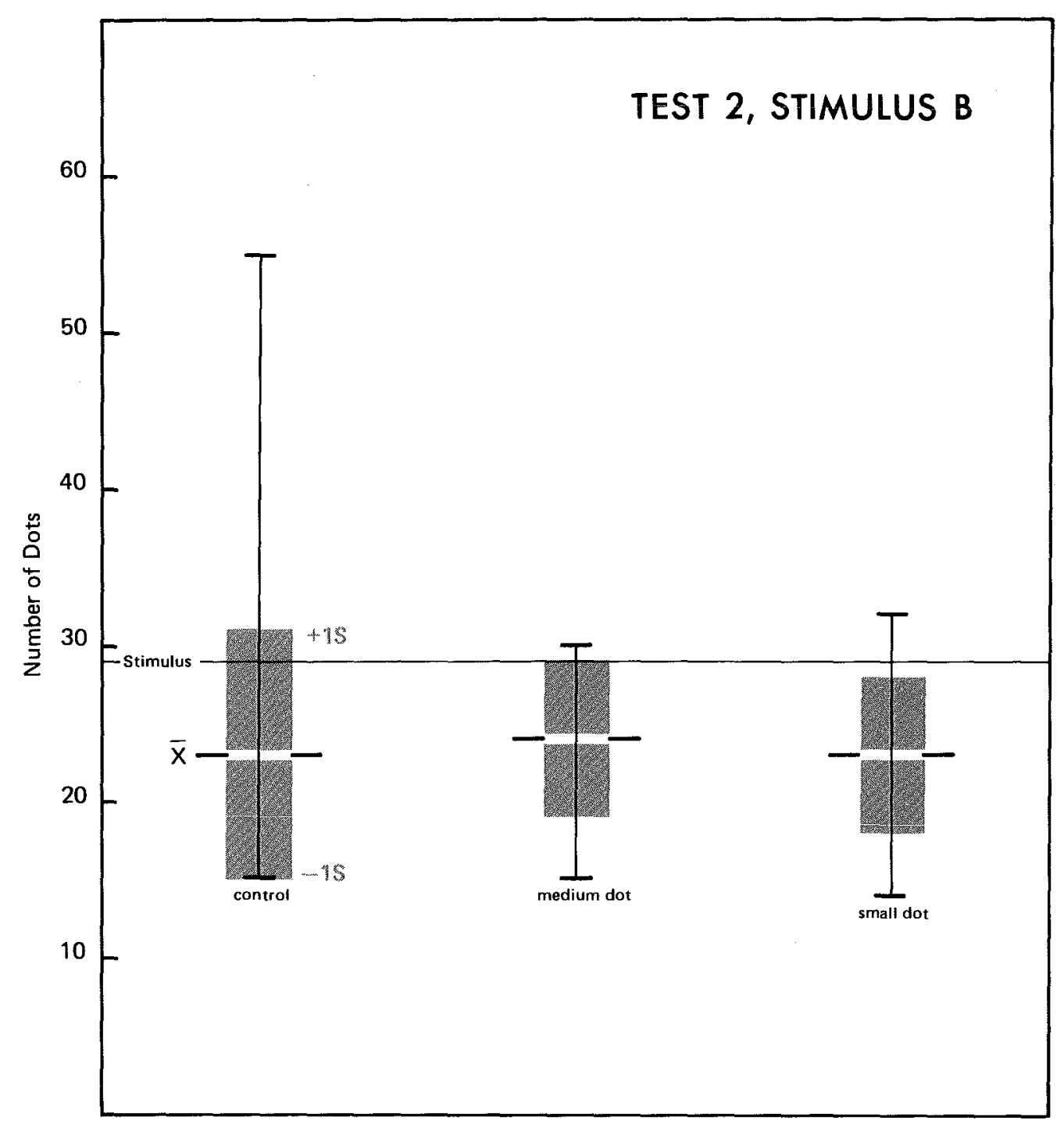

Figure 39. Range of response and standard deviations for Test 2, stimulus B. Vertical lines show range of response, $\bar{X}$ is the mean and $S$ is the standard deviation. 


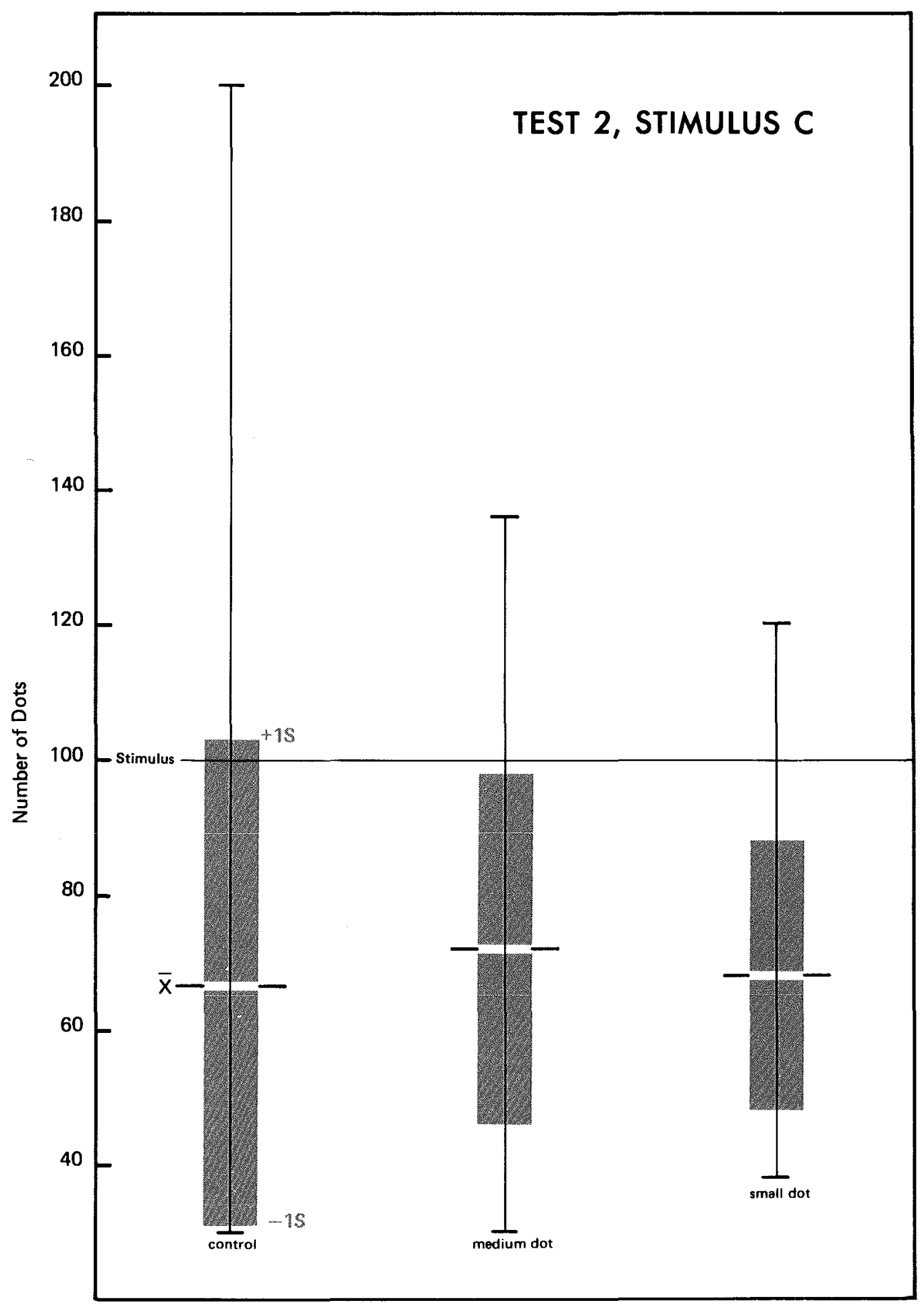

Figure 40. Range of response and standard deviations for Test 2, stimulus $\mathrm{C}$. Vertical lines show range of response, $\bar{X}$ is the mean and $S$ is the standard deviation. 


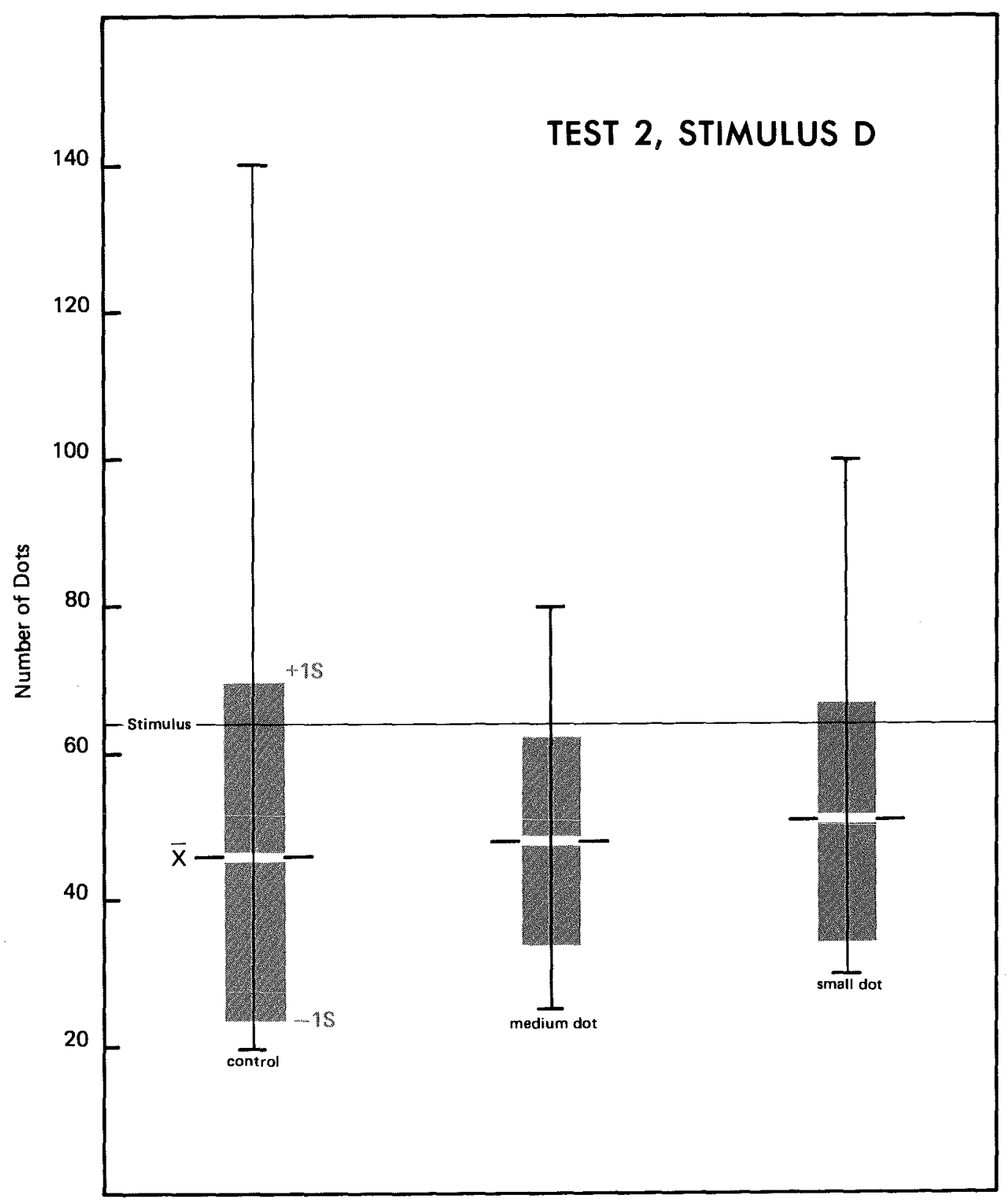

Figure 41. Range of response and standard deviations for Test 2, stimulus D. Vertical lines show range of response, $\bar{X}$ is the mean and $S$ is the standard deviation. 


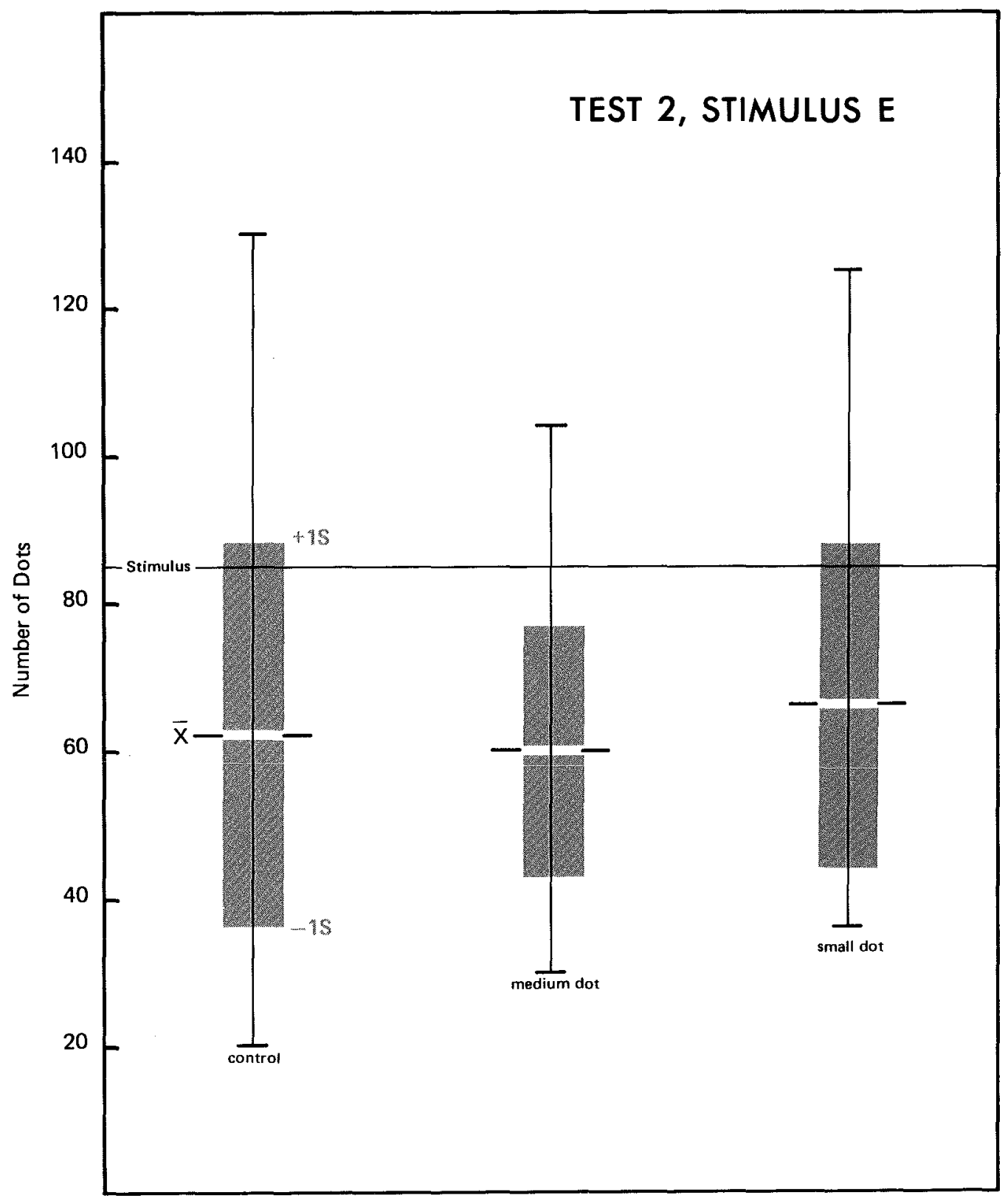

Figure 42. Range of response and standard deviations for Test 2, stimulus $E$. Vertical lines show range of response, $\bar{X}$ is the mean and $S$ is the standard deviation. 


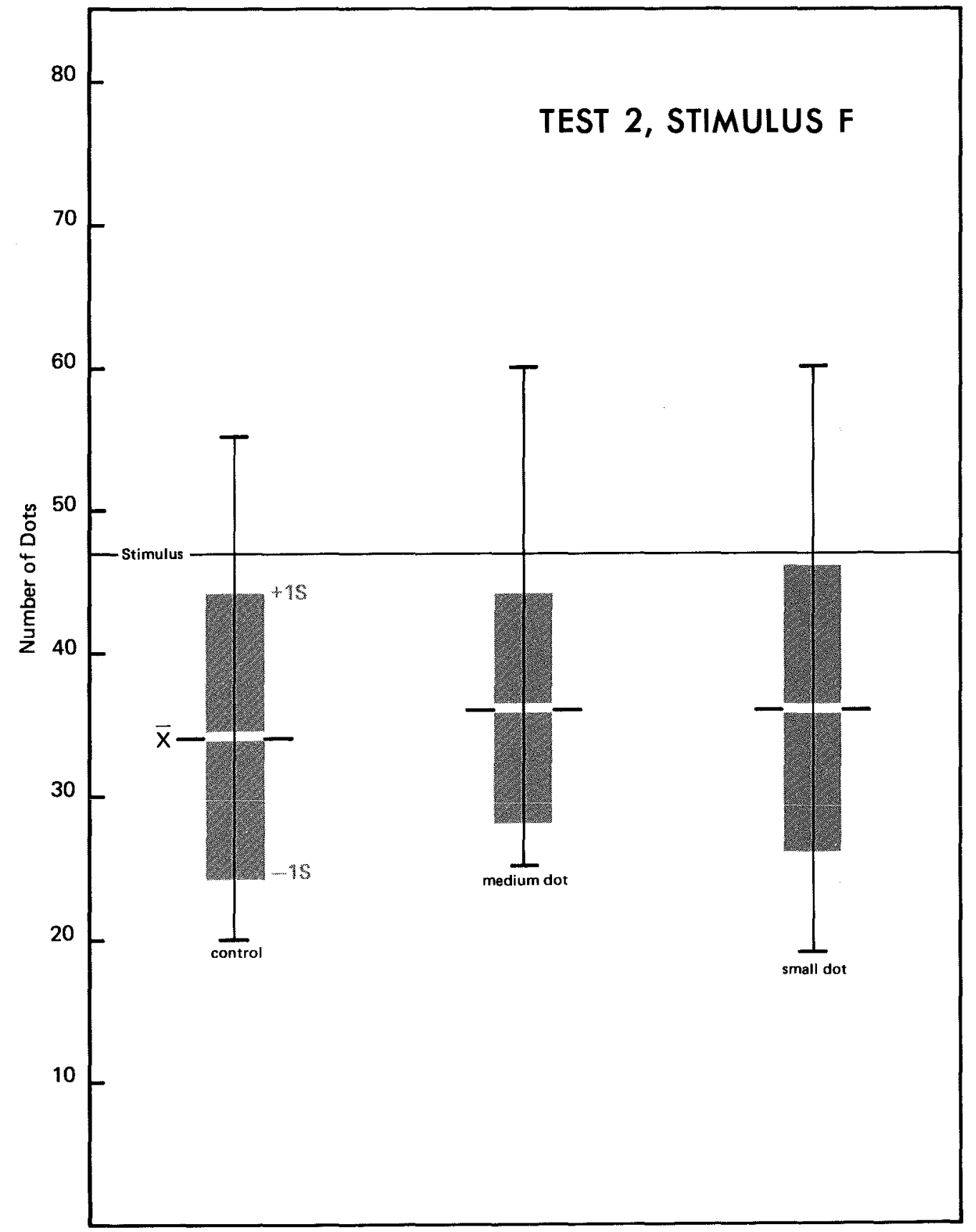

Figure 43. Range of response and standard deviations for Test 2, stimulus $F$. Vertical lines show range of response, $\bar{X}$ is the mean and $S$ is the standard deviation. 
Test Three

The purpose of test three is to determine the effect of figure-ground relationships on the perception of dot number. Specifically, this test will concern itself with contrast effects between subject and base data. The results of test three support partially the findings of the first two tests in that consistent underestimation has again been recorded. Examination of the $Z$ scores shows that all the means and modes are lower than the stimulus values for each section of test three (Figure 44). Quite unexpected, however, was the fact that compared to the control group the two maps with screened backgrounds displayed smaller errors in the mean estimates for all reports, with the exception of the 13 dot stimulus (Figure 45). The ranges of percentage error are as follows: from 1 per cent to 33 per cent for section one (contro1), from 1 per cent to 23 per cent for section two (10 per cent screen), and from 10 per cent to 29 per cent for section three (30 per cent screen). As with previous tests the amount of error increases with the stimulus magnitude. According to the psychophysical literature, there is an inverse relationship between background brightness and perceptual accuracy in the judgment of dot number. Although at least one of these studies indicates that with prolonged exposure time (a situation duplicated in map study), the influence of background brightness is 
considerably reduced, no investigator has ever indicated that a tinted background could improve perceptual accuracy. Apparently some other mechanism is at work with respect to test three.

In an attempt to explain the results of test three, the study by Bevan and Turner may be of some help. ${ }^{2}$ It is suggested that the improved perceptual accuracy is a result of assimilation or contrast effects (see Chapter II for discussion of assimilation and contrast). The authors pointed out that anchors associated with a figure will display assimilation characteristics, while anchors associated with the ground will display contrast characteristics. In order to account for increased perceptual accuracy, the authors indicated that the anchor must either be large and associated with the figure (assimilation) or small and associated with the ground (contrast). It is important to stress that anchors in this respect have only to be related conceptually to the stimuius and therefore need not be of the same form as the stimulus object. Thus background tints can display anchoring characteristics. With section two of test three it is assumed that the light (10 per cent) screen exerts some sort of anchor effect that increases the estimates of number relative to the control group (section one). At the same time, the darker ( 30 per cent) screen of section three must also be exerting anchor effects, but to a lesser degree. Referring back to the study by Bevan and Turner, it can be 
seen that this combination of results can be explained as a simple contrast effect. In this case the 10 per cent screen is acting as a small anchor associated with the ground while the 30 per cent screen acts as a large anchor also associated with the ground (Figure 10, Chapter II). Although according to this model, the degree of overall error for section three ( 30 per cent screen) should be larger than that for section one (which it is not); the two values are so close that the situation could easily reverse with another sample. Another aspect of this problem lies in the fact that in Bevan and Turner's study, large and small anchors are not defined quantitatively, but only relative to each other. It is quite possible that the 30 per cent screen in test section three was not a large enough anchor relative to the control group (section one) to display the same relative effects described by Bevan and Turner.

The findings from test three indicate that the background tints also reduce the ranges in response and the standard deviations. Both section two (10 per cent screen) and section three (30 per cent screen) show considerable improvement in this respect when compared to section one (control). Although section two displayed the best results for estimation of dot number, section three had the lowest values for range of response and standard deviations (Figures 46, 47, 48, 49, 50, and 51). 
Although the test only dealt with background brightness, it is conceivable that other forms of base information could display similar anchoring properties. The important finding here, however, is that base information need not lower perceptual accuracy, but may improve it in some cases.

\section{MAJOR FINDINGS FROM TEST THREE}

1. The accuracy of estimation of dot numbers is slightly improved with the addition of gray tints to the base data on dot maps. Lighter tints seem to work the best.

2. The range in response and the standard deviations are decreased with the addition of gray tints to base data. 
Z SCORE DISTRIBUTION, TEST 3, CONTROL
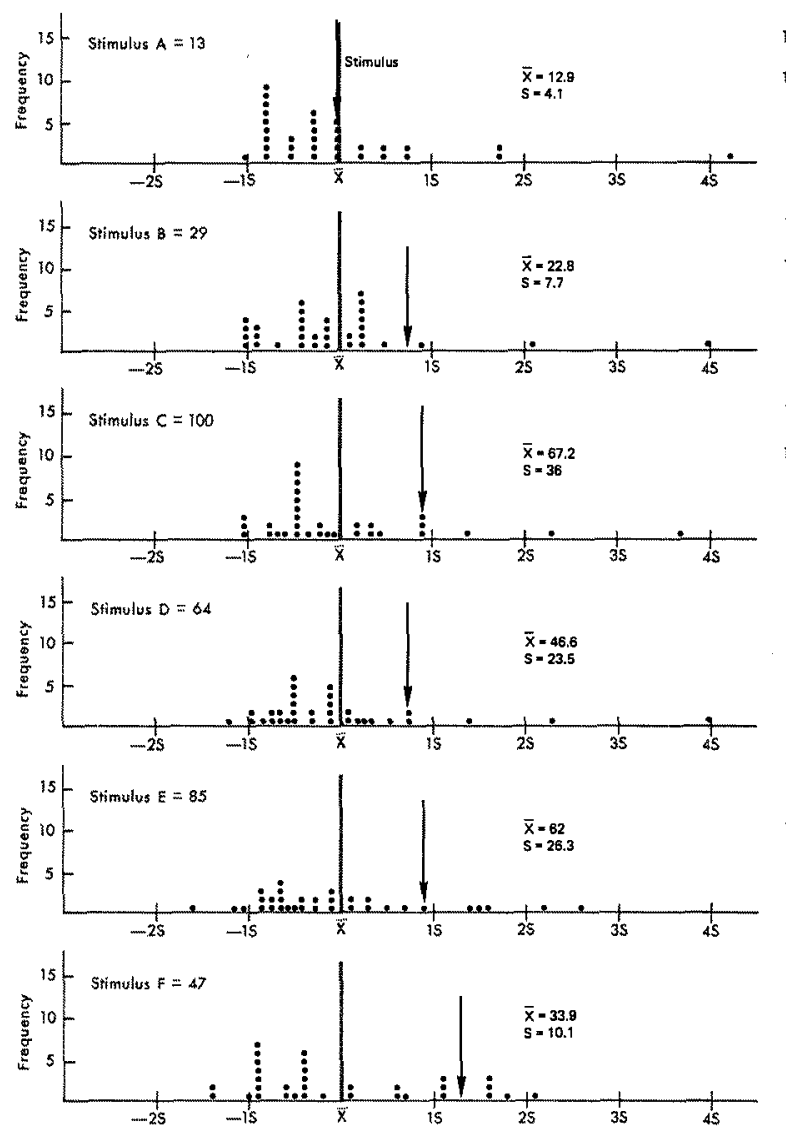

Z SCORE DISTRIBUTION, TEST 3, 10\% SCREEN
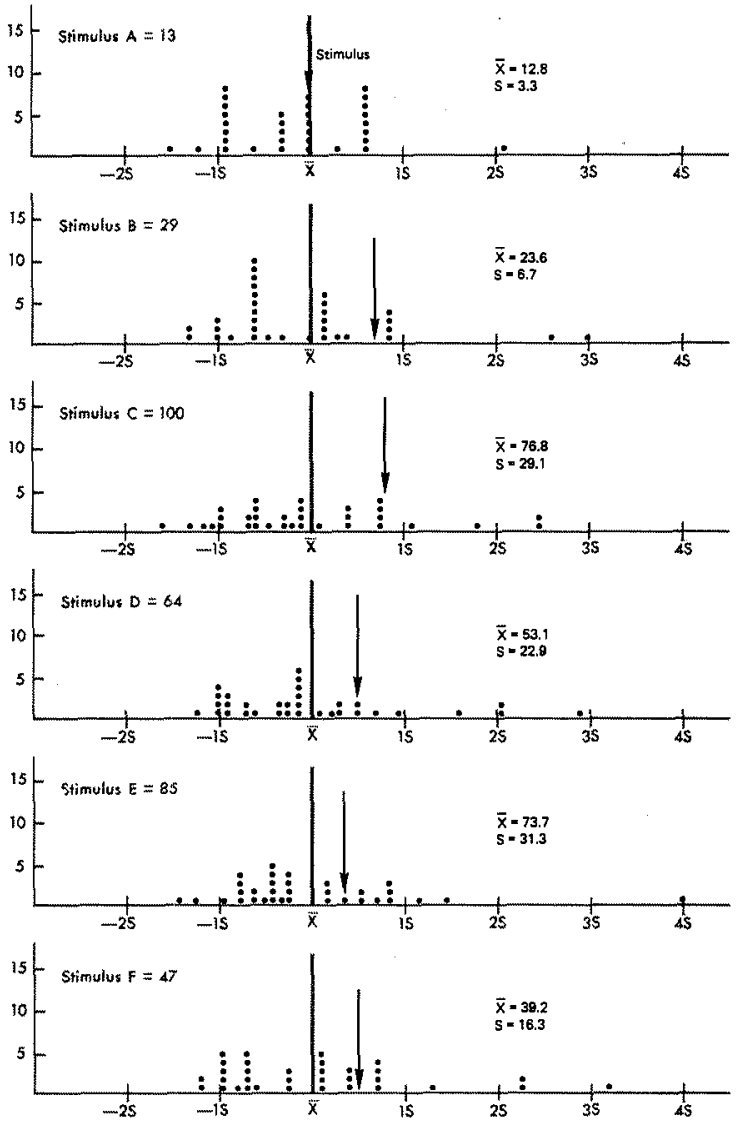

Z SCORE DISTRIBUTION, TEST 3, 30\% SCREEN
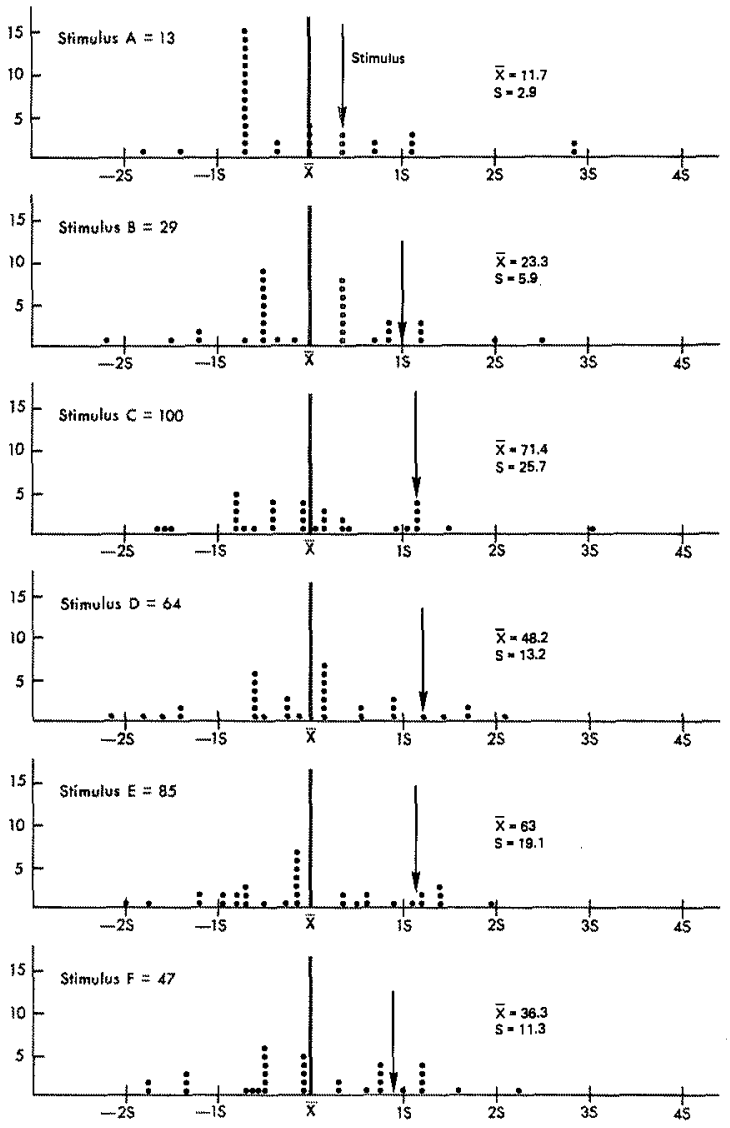

Figure 44. $Z$ score distribution for Test $3 . \bar{X}$ is the mean and $S$ is the standard deviation. 


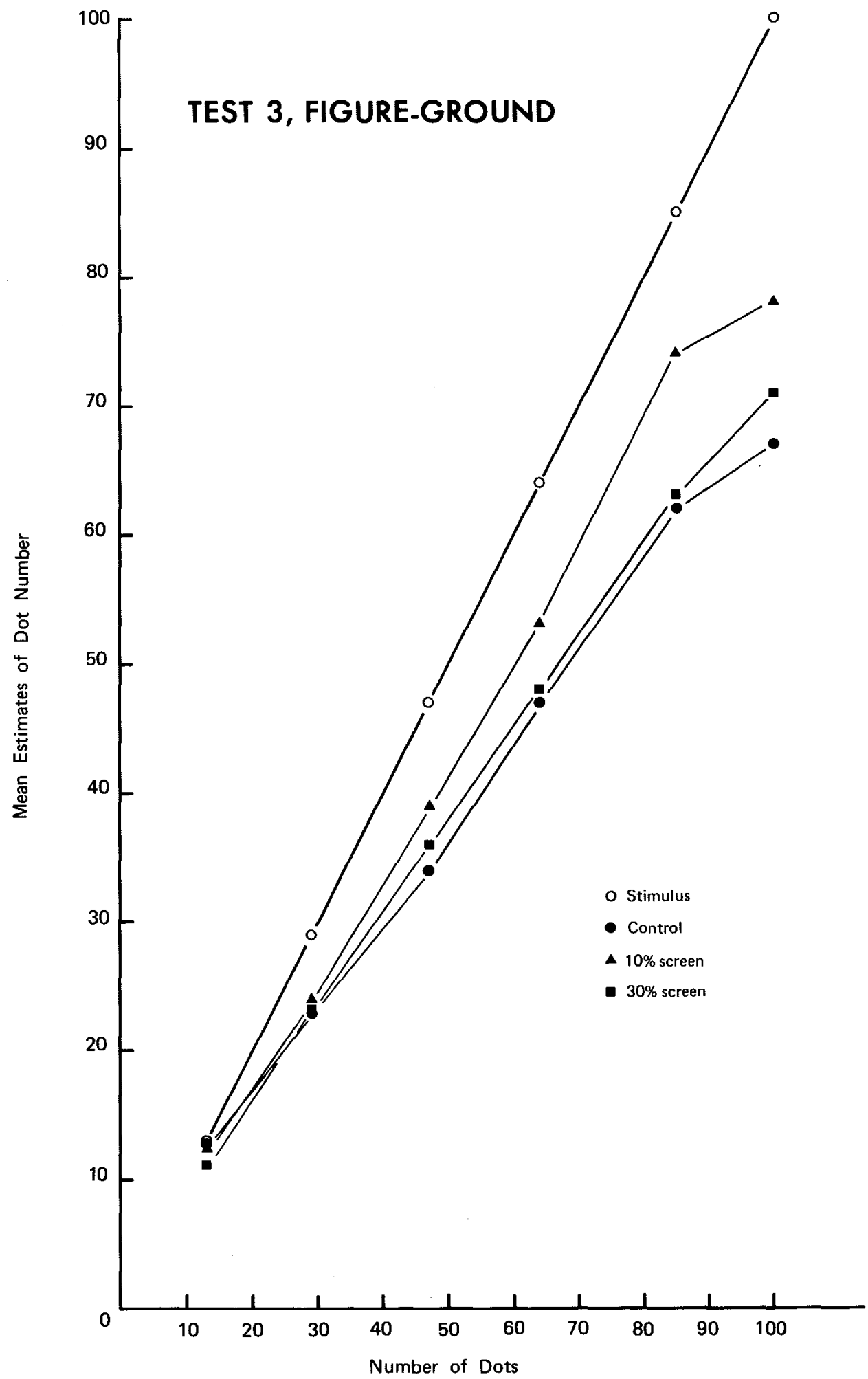

Figure 45. The relationship between the mean estimates and stimulus value for Test 3 with white ground (control), $10 \%$ screen ground and $30 \%$ screen ground. 


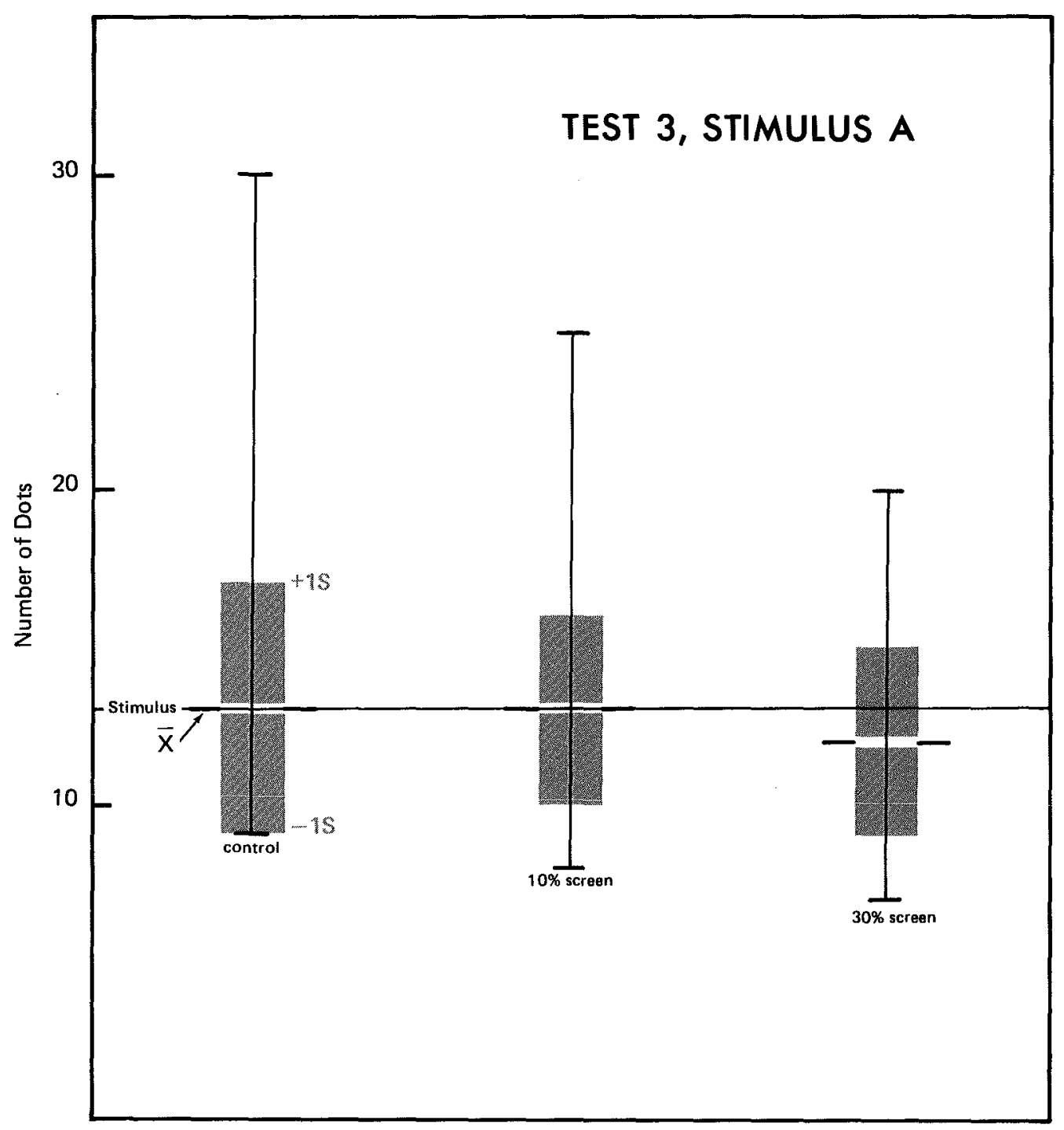

Figure 46. Range of response and standard deviations for Test 3, stimulus A. Vertical lines show range of response, $\bar{X}$ is the mean and $S$ is the standard deviation. 


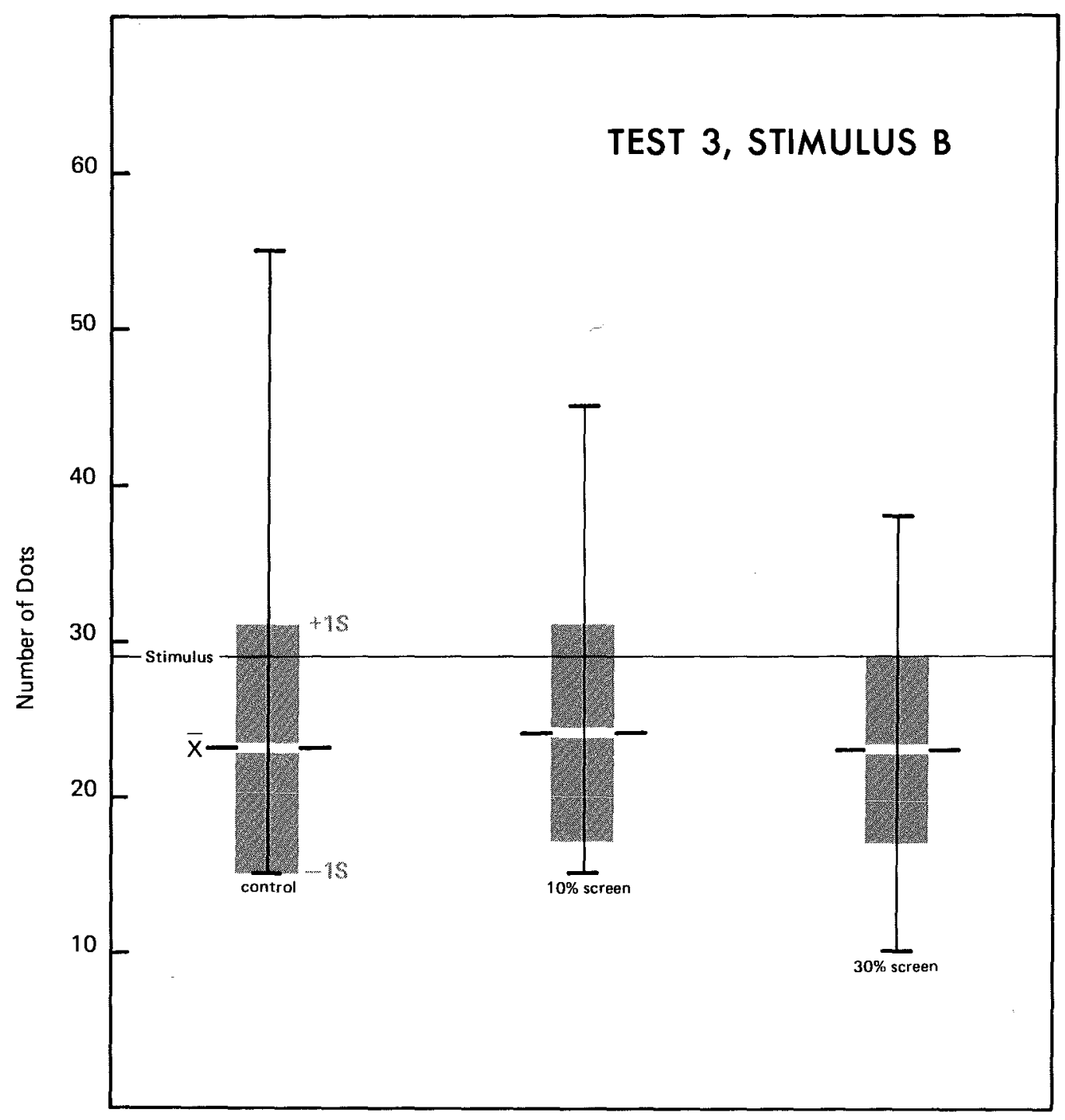

Figure 47. Range of response and standard deviations for Test 3 , stimulus $B$. Vertical lines show range of response, $\bar{X}$ is the mean and $S$ is the standard deviation. 


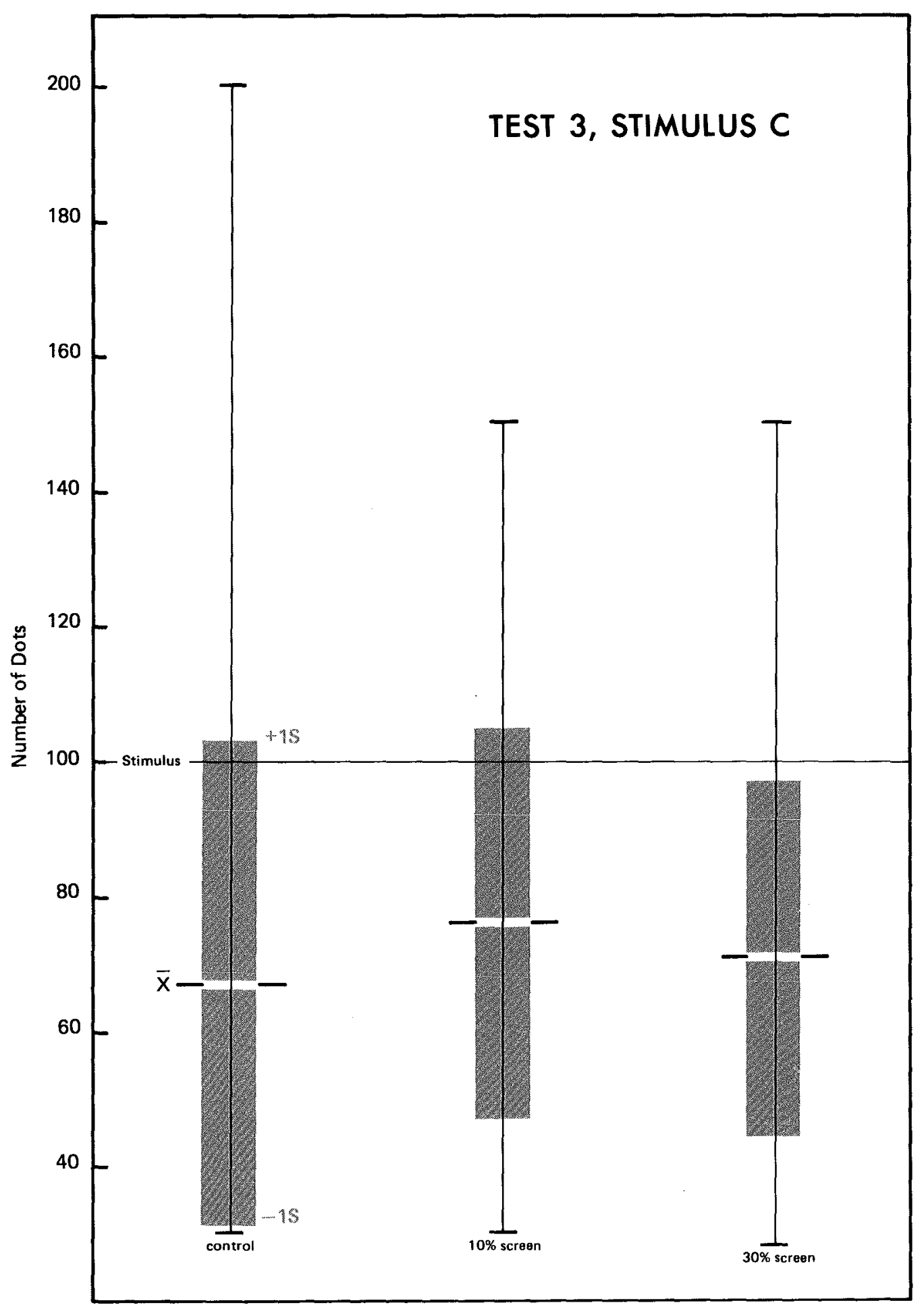

Figure 48. Range of response and standard deviations for Test 3, stimulus $C$. Vertical lines show range of response, $\bar{X}$ is the mean and $S$ is the standard deviation. 


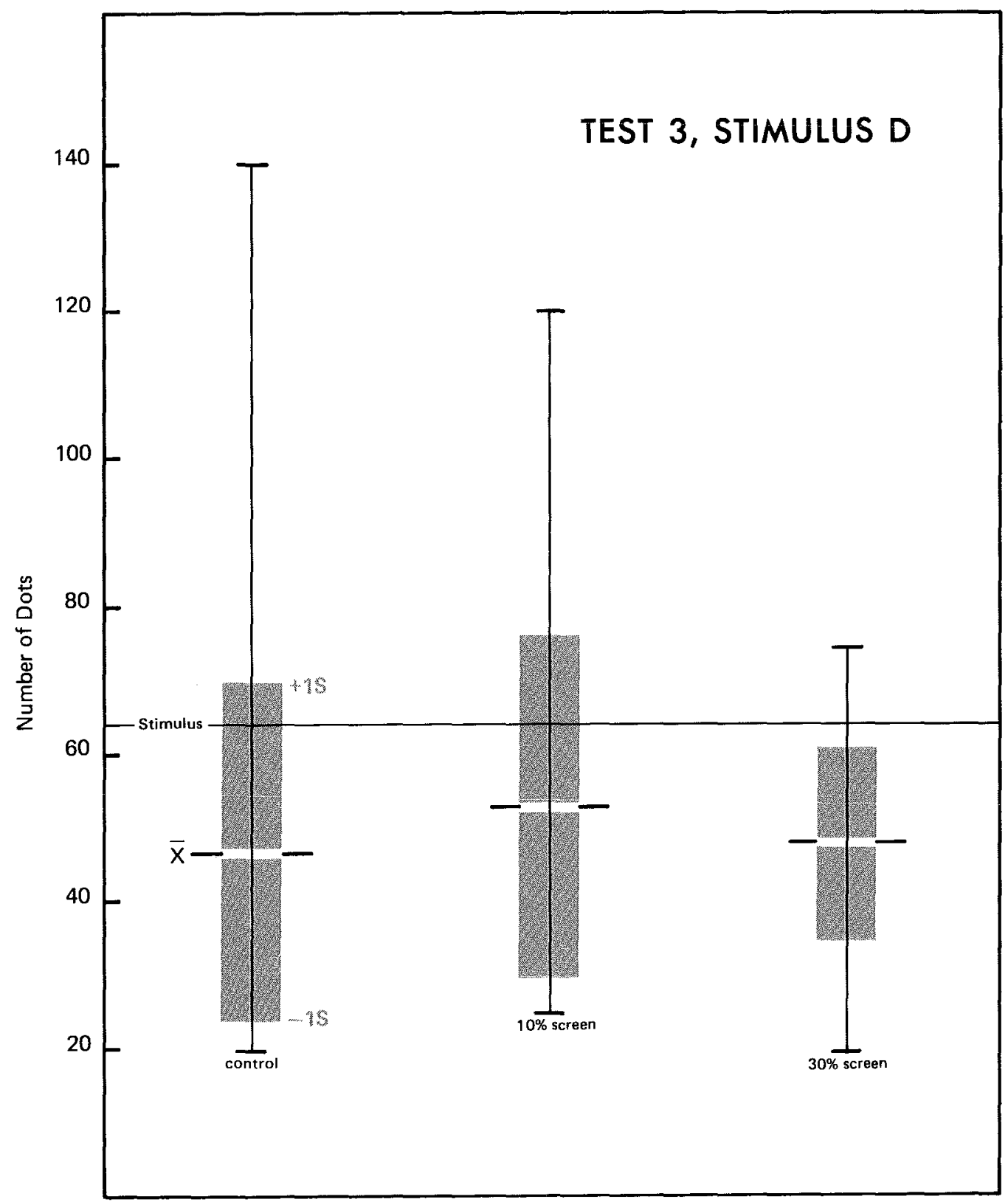

Figure 49. Range of response and standard deviations for Test 3, stimulus $D$. Vertical lines show range of response, $\bar{X}$ is the mean and $S$ is the standard deviation. 


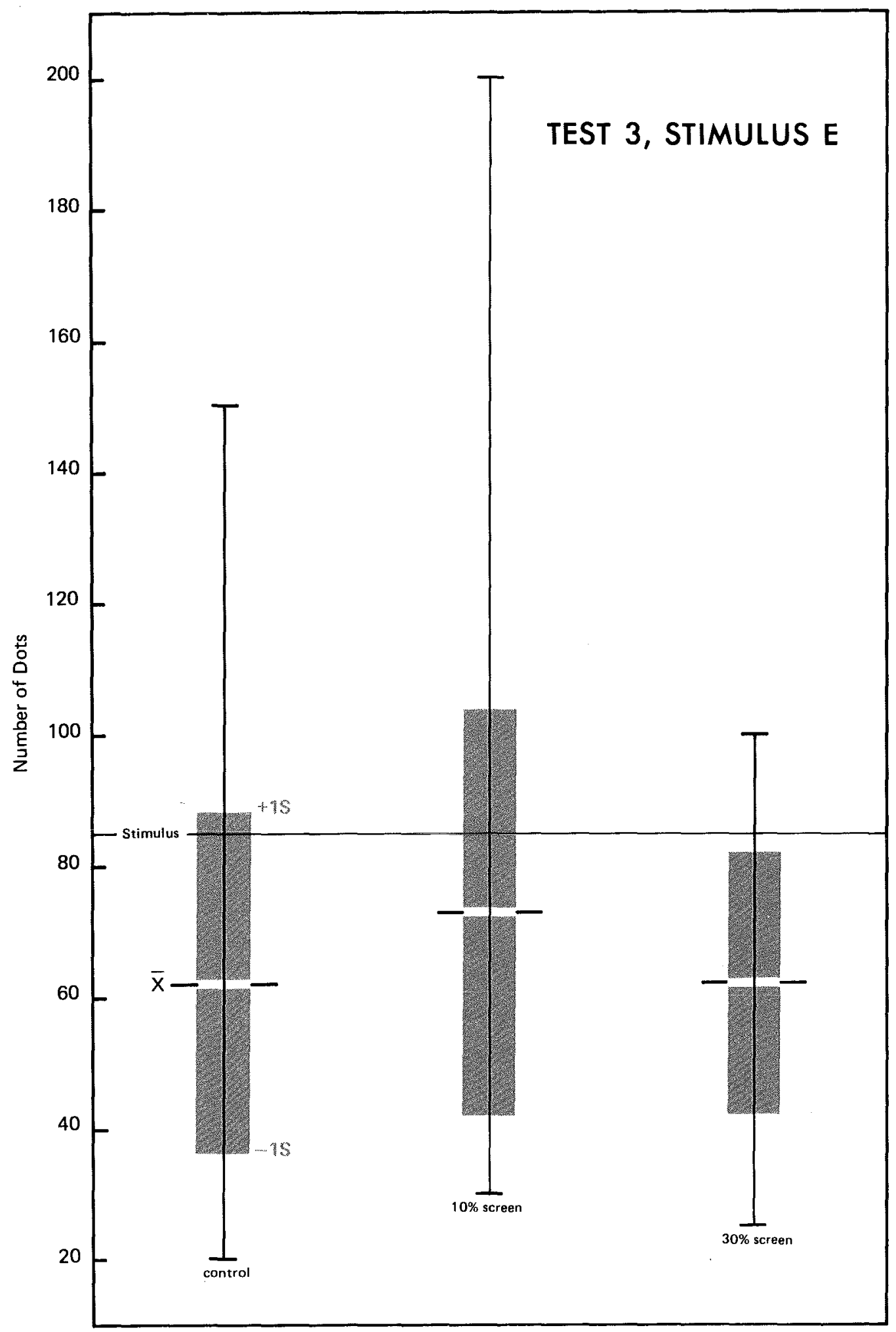

Figure 50. Range of response and standard deviations for Test 3 , stimulus $E$. Vertical lines show range of response, $\bar{X}$ is the mean and $S$ is the standard deviation. 


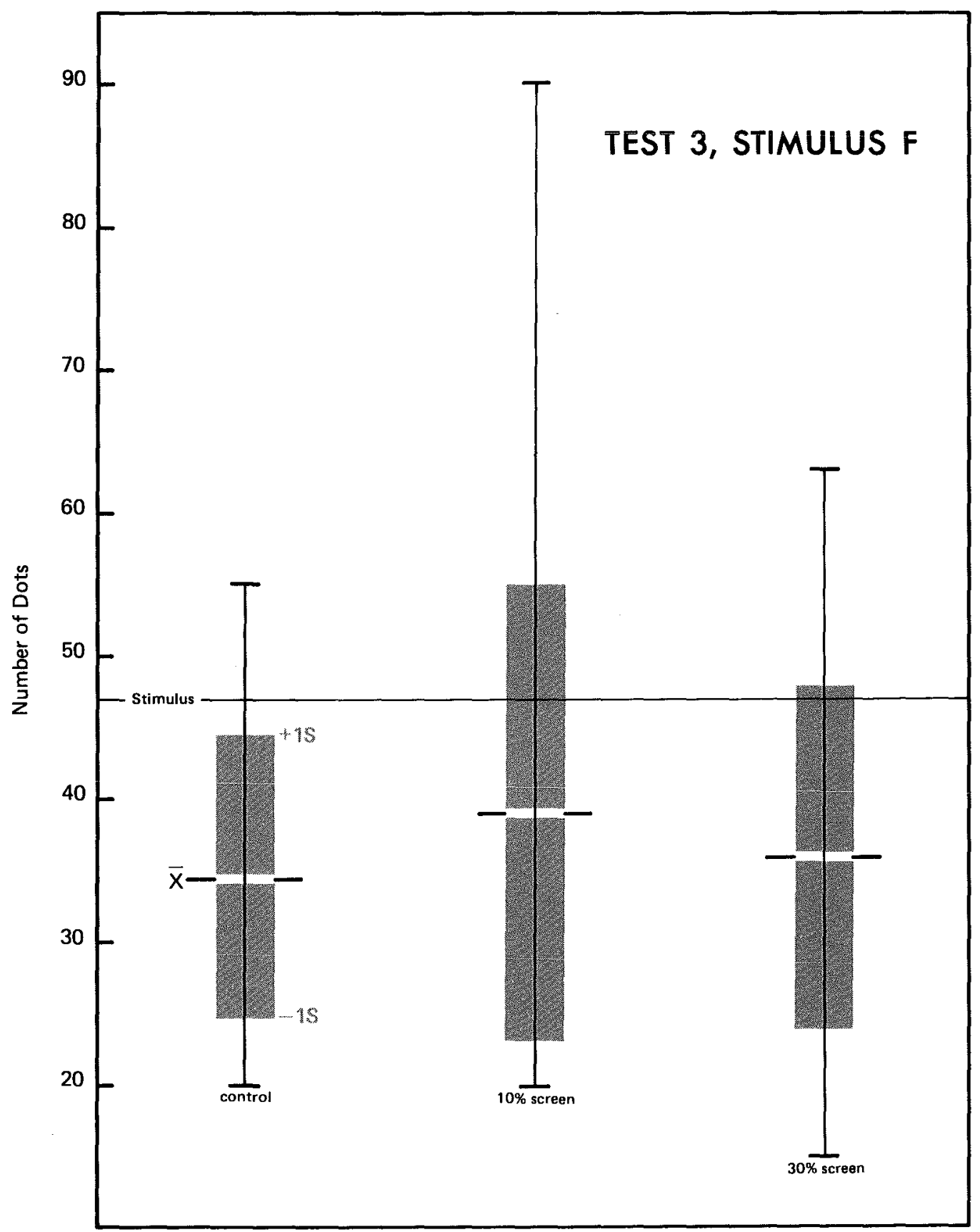

Figure 51. Range of response and standard deviations for Test 3, stimulus $F$. Vertical lines show range of response, $\bar{X}$ is the mean and $S$ is the standard deviation. 
Test Four

The purpose of test four is to determine if there is any design of subject bias that could affect the results of the previous tests. Specifically, the primary concern is with the shape of the stimulus areas and whether or not this is a factor that would influence perception of dot number. Because some of the previous tests were based on samples heavily weighted with both upper classmen and geographers, further tests were made to measure the effect of education level and area of study on previous test results.

Again, as with all of the previous tests, every section of test four shows underestimation for all stimuli. The range in percentage errors for underestimation is very similar to those found in the previous tests, and likewise the degree of error in the mean estimates for each individual section is closely aligned with previous results. Figure 52 reveals that all of the various shapes tested were perceived in very nearly the same way. However, the circle does display a slight edge in overall accuracy. With the ranges in response and the standard deviations, the results are about the same as those for exrors in estimation. Each shape had about the same general range in variation except for the circle, which was considerably better in this respect.

- The reason behind the circle's better performance 
probably lies in the fact that it was the only shape to not have a minor and major dimensional axis. For unknown reasons people estimate numbers more accurately when the stimulus objects are enclosed within an area which has dimensional unity in all directions. Why a more regular shape results in higher accuracy is not known; it is perhaps related to figure-ground complexities that can result in reduced accuracy in the judgment of number.

After reviewing the results of this test, it must be conceded that given more ideal conditions with the previous tests (i.e., the use of circles on the maps) the results would probably have to be revised upward an average of three or four per cent (smaller amounts for smaller stimuli and larger amounts for larger stimuli). Although the use of a circle in the previous tests would no doubt have changed the results as indicated, the basic findings would remain unchanged, as the magnitude of the revision is insignificant when compared to the values obtained in the tests.

Figure 53 shows the plots of mean estimates for the class level test. It is immediately apparent that very little difference exists between freshmen, sophomores, juniors, seniors, and graduates in their perception of dot number. In addition, the ranges of response and the standard deviations for both groups are nearly the same. These results indicate that the perceptual characteristics 
of each population are essentially identical. Thus, one would not expect that a heavily weighted sample in either direction could significantly affect any of the previous test results.

Similar results were realized in the test comparing the performance of geographers and non-geographers. Figure 54 demonstrates that both groups perceive the stimuli in essentially the same manner. It is clear that a sample heavily weighted with geographers would not affect test results. 


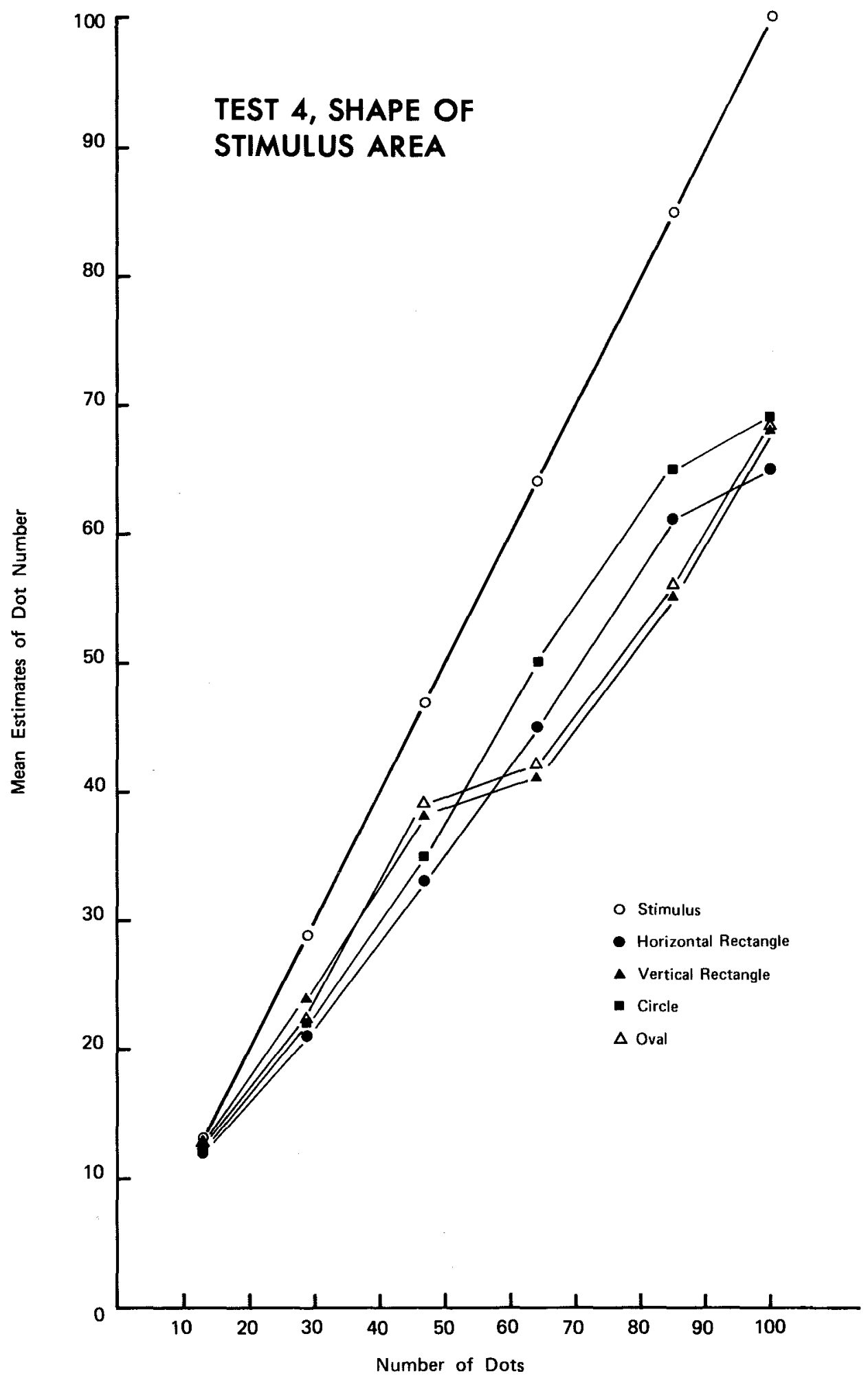

Figure 52. The relationship between the mean estimates and stimulus value for Test 4 with a horizontal rectangle, vertical rectangle, circle, and an oval used to delineate the stimulus areas. 


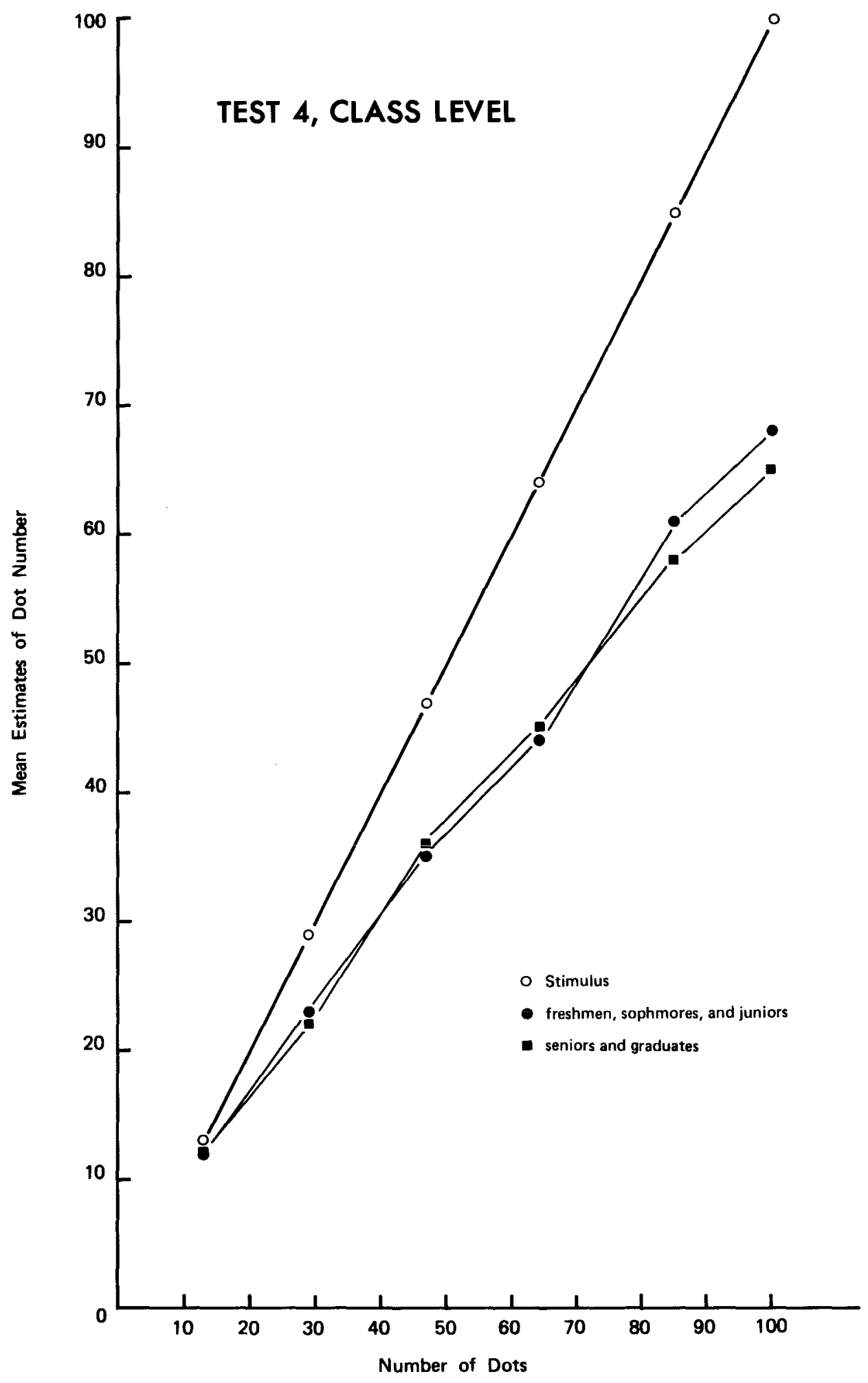

Figure 53. The relationship between the mean estimates and stimulus value for Test 4 , comparing freshmen, sophmores, and juniors with seniors and graduates. 


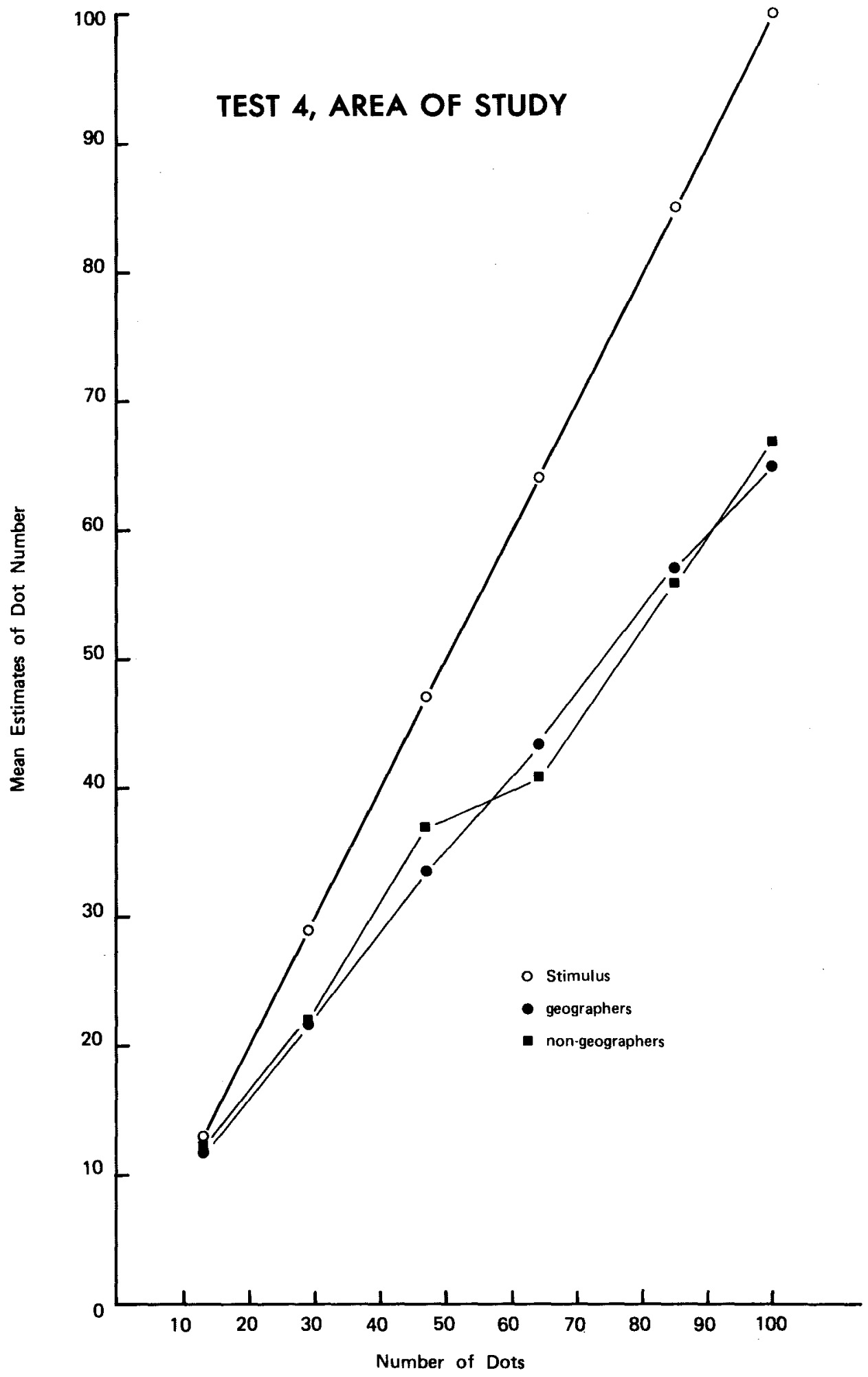

Figure 54. The relationship between the mean estimates and stimulus value for Test 4 comparing geographers with non-geographers. 
Summary and Conclusions

The single most important finding regarding the perceptual characteristics of dot maps is that underestimation of dot numbers seems to be a universal trait among map users. The degree of underestimation is directly proportional to the magnitude of the stimulus. Assuming that dot map users attempt to compare areas on the map to form mental ratios of relative numbers, the implications of the stimulus magnitude versus perceived number problem become quite apparent. To illustrate, consider a case in which a dot map user determined that one area has ten times the population of another. According to the experimental findings described here, a perceived ratio of ten to one is in reality nearer fifteen or sixteen to one! The problem is not hopeless, however, since the findings also reveal mechanisms by which considerable improvement in perceptual accutacy can be realized.

The map user's ability to accurately judge relative numbers and densities is greatly improved with the addition of anchoring stimuli. Because underestimation of dot numbers is so prevalent, high end or full range anchors are the most effective. The experimental studies clearly demonstrate that the inclusion of a legend showing the low, middle, and high density ranges as they exist on a map nearly eliminates the difference between perceived number and the actual stimulus value. When a map user 
perceives a ten to one ratio on a map with such a legend, the actual stimulus ratio will, in reality, probably be around eleven to one. Comparing this degree of accuracy with that achieved without anchors makes the benefits obvious.

Other important variables examined here deal with the effects of variable dot size and figure-ground contrast. The experimental studies concerned with dot size demonstrate that conventional criteria for selecting dot size do not function adequately on a perceptual level. While dot sizes smaller than those dictated by convention do not significantly improve the accuracy of estimation, they do considerably reduce the variability in estimates. Similar results are recorded in the figure-ground experiments, except that a more significant improvement in estimation accuracy is achieved. Not only do screen tints tend to decrease variability in the reports, but the lighter tint also decreased the mean errors of the reports to a considerable degree. Both the symbol size and the background tint functions can serve as additional methods for improving the usefulness of the dot map. To summarize the experimental findings, a hypothetical dot map can be conceived that employs the improvements outlined above. It should include a high end or full range anchor. The full range anchor could be favored since it not only. improves the accuracy of estimation but also reduces variability in estimation 
more than does the high end anchor. addition, a dot size should be selected that is slightly smaller than that dictated by convention. Further improvement can be realized with the addition of a lightly tinted background. Although a dot map with all of these qualities has not been tested, indications from the independent tests seem to point to a much improved map from the perceptual viewpoint.

Although the experiments described here reveal some of the fundamental perceptual characteristics of the dot map, many questions remain unanswered. Because the stimulus range in the experiments described here was limited to a low of 13 and a high of 100 dots, one has to wonder about the perceptual characteristics of stimuli at even higher levels. More specifically, further work should be done toward establishing a power law that would accurately describe the subjective response for any given stimulus number. In addition, more work is needed to define the limits of the anchor effects with background tints. The experimental studies presented here indicate a progression of smaller variance with darker tints, but at some point this must reverse itself. With the application of color an infinite area of investigation is opened up. Figure-ground relationships as modified with color are one area of investigation, along with the effects of coloring the dots themselves. These suggestions represent 
but a few of the possible areas of study that can add to the understanding of the perceptual aspects of the dot map. Although the dot map has been shown to be weak in its ability to communicate some forms of information, basic work in the psychophysics of map perception can do much to improve the situation. 


\section{REFERENCES}

${ }^{1}$. H. Taves, "Two Mechanisms for the Perception of Visual Numerousness," Archives of Psychology XXXVII (September 1941): 37 .

2 Bevan and Turner, "Assimilation and Contrast in the Estimation of Number," Journal of Experimental

Psychology LXVII (May 1964): 458-462. 
SELECTED BIBLIOGRAPHY

118 


\section{SELECTED BIBLIOGRAPHY}

Alexander, John S. "An Isarithmic Dot Population Map." Economic Geography XIX (October 1943):431-432.

Bevan, William, and Turner, Edward D. "Assimilation and Contrast in the Estimation of Number." Journal of Experimental Psychology LXVII (May 1964):458-467.

Birch, T. W. Maps: Topographical and Statistical. Oxford: Clarendon Press, 1949.

Byron, William G. "Use of the Recording Densitometer in Measuring Density from Dot Maps." Surveying and Mapping XVIII (January 1958):41-48.

Casperson, R. C. and Schlosberg, H. "Monocular and Binocular Intensity Thresholds for Fields Containing 1-7 Dots." Journal of Experimental Psychology XL (February 1950):81-92.

Castner, H. W. Dot Area Symbols in Cartography. Ann Arbor: University Microfilms Inc., 1964.

Castner, Henry $W$. and Robinson, Arthur H. "Dot Area Symbols in Cartography: The Influence of Pattern on their Perception." Technical Monograph No. CA-4, American Congress on Surveying and Mapping (June 1969).

Clarke, John I. "Statistical Map Reading." Geography XLIV (April 1959):96-104.

Cox, Carleton W. "Adaptation-Level Theory as an Aid to the Understanding of Map Perception." Proceedings of the American Congress on Surveying and Mapping, 33rd Annual Meeting (1973), pp. 334-359.

Dacey, Michael F., and Tung, Tze-Hsiung. "The Identification of Randomness in Point Patterns, I." Journal of Regional Science IV (Summer 1963):83-96.

Dacey, Michael F., and Karaska; Gerald. "Some Experimental Evidence on the Perception of Dot Patterns and Two Dimensional Shapes." Discussion Paper Series: No. 2, Regional Science Research Institute, June 1963 .

Dahlberg, Richard E. "Towards the Improvement of the Dot Map." International Yearbook of Cartography VII $(1967): 157-166$. 
Dallenbach, Karl M. "Attributive Vs. Cognitive Clearness." Journal of Experimental Psychology III (June 1920):183-230.

de Geer, Sten. "A Map of the Distribution of Population in Sweden: Methods of Preparation and General Results." Geographical Review XII (January 1922): 72-83.

Dickinson, G. C. Statistical Mapping and the Presentation of Statistics. London: Edward Arnold (Publishers) Ltd., 1963.

Ekman, G., Lindman, R., and Olsson, W. W. "A Psychophysical Study of Cartographic Symbols." Perceptual. and Motor Skills XIII (December 1961):355-368.

Fawcett, C. B. "Population Maps: A Discussion." Geographical Journal LXXXV (February 1935): 142-159.

Fernberger, Samue1 W. "A Preliminary Study of the Range of Visual Apprehension." American Journal of Psychology XXXII (January 1921):121-133.

Flannery, James J. "The Relative Effectiveness of Some Common Graduated Point Symbols in the Presentation of Quantitative Data." The Canadian Cartographer VIII (December 1971):96-109.

Freeman, Frank N. "Experiments on the Perception of Number in Children and Adults." Psychological Bulletin VIII (December 1911):43-44.

French, Robert $S$. "The Discrimination of Dot Patterns as a Function of Number and Average Separation of Dots." Journal of Experimental Psychology. XLVI (July 1953): 1-9.

Hargreaves, R. P. "The First Use of the Dot Technique." Professional Geographer XIII (September 1961):37-39.

Helson, Harry, and Kozaki, Aiko. "Anchor Effects Using Numerical Estimates of Simple Dot Patterns." Perception and Psychophysics IV (March 1968): 163-164.

Hunter, W. S., and Sigler, M. "The Span of Visual Discrimination as a Function of Time and Intensity of Stimulation." Journal of Experimental Psychology XL (January 1940): $160-180$. 
Jenks, George F. "Pointillism as a Cartographic Technique." Professional Geographer V (September 1953): $4-6$.

- "Generalization in Statistical Mapping." Annals, Association of American Geographers LIII (March 1963): 15-26.

Jensen, E. M., Reese, E. P., and Reese, T. W. "The Subitizing and Counting of Visually Presented Fields of Dots." Journal of Psychology XXX (October 1950): 363-392.

Jones, F. Nowell and Marcus, Maxine. "The Subject Effect in Judgments of Subjective Magnitude." Journal of Experimental Psychology LXI (January 1961):40-43.

Kaufmann, E. L., Lord, M. W., Reese, T. W., and Volkmann, $\mathrm{J}$. "The Discrimination of Visual Number." American Journal of Psychology LXII (October 1949):498-525.

Klemmer, E. F., and Frick, F. C. "Assimilation of Information from Dot and Matrix Patterns." Journal of Experimental Psychology XLV (January 1953): 15-19.

Krueger, Lester E. "Perceived Numerosity." Perception and Psychophysics XI (January 1972):5-9.

Lechelt, Eugene C., and Nelson, Thomas M. "Numerosity Discrimination Under Varying Conditions of Steady Illumination: A Temporal Analysis of a Spatial Factor." Journal of General Psychology LXXIV (January 1971): 121-131.

Mackay, J. Ross. "Experiments with Some Symbols and Map Projections." Annals, Association of American Geographers, XLIV (June 1954):225-226.

"Dotting the Dot Map: An Analysis of Dot Size, Number, and Visual Tone Density." Surveying and Mapping IX (January 1949):3-10. - "Percentage Dot Maps." Economic Geography XXIX (July 1953): 263-266.

McCleary, George F. "Beyond Simple Psychophysics: Approaches to the Understanding of Map Perception." Papers from the 30th Annual Meeting, American Congress on Surveying and Mapping (1970), pp. .189-209. 
Meihoeffer, Hans-J. "The Utility of the Circle as an

Effective Cartographic Symbol." The Canadian

Cartographer VI (December 1969): 105-117.

- "The Visual Perception of the Circle in Thematic Maps/Experimental Results." Canadian

Cartographer X (June 1973):63-84.

Miller, G. S. "The Magical Number Seven, Plus or Minus Two." Psychological Review LXIII (March 1956):

81-97.

Minturn, A. L., and Reese, T. W. "The Effect of

Differential Reinforcement on the Discrimination of

Visual Number." Journal of Psychology XXXI (April

1951) : 201-231.

Oberly, Sherman H. "The Range for Visual Attention, Cognition and Apprehension." American Journal of Psychology XXXV (July 1924): 332-352.

Philip, R. B. "The Frame of Reference Concept." Canadian Journal of Psychology III (June 1949): 73-79.

Raisz, E. Principles of Cartography. New York: McGrawHill Book Company, 1962.

Restle, Frank, Rae, James, and Kiesler, Charles. "The Probability of Detecting Small Numbers of Dots." Journal of Experimental Psychology LXI (March 1961): 218-221.

Robinson, A. H. "A Method for Producing Shaded Relief from Areal Slope Data." Surveying and Mapping VIII (July 1948):157-160.

Robinson, A. H., and Sale, R. D. Elements of Cartography. New York: John Wiley and Sons, Inc., 1969.

Saltzman, I. V. and Garner, W. R. "Reaction Time as a Measure of Span of Attention." Journal of Psychology XXV (April 1948):227-241.

Sherif, Muzafer, Taub, Daniel, and Hovland, Carl I. "Assimilation and Contrast Effects of Anchoring Stimuli on Judgments." Journal of Experimental Psychology LV (January 1955):150-155.

Stevens, S. S. "On the Psychophysical Law." Psychological Review LXIV (May 1957):153-181. 
Taves, Ernest H. "Two Mechanisms for the Perception of Visual Numerousness." Archives of Psychology XXXVII (September 1941): 5-47.

Thomas, Edwin N. "Balanced Colors for Use in the MultiColor Dot Map." Professional Geographer VII (November 1955):8-10.

Vernon, Magdalene D. A Further Study of Visual. Perception. Cambridge: University Press, 1952.

Winterbotham, J. L. "Dots and Distributions." Geography XIX (September 1934):211-213.

Wright, J. K. "A Method of Mapping Densities of Population with Cape Cod as an Example." Geographical Review XXVI (January 1936): 103-110.

"The Terminology of Certain Map Symbols." Geographical Review XXXIV (October 1944):653-654. 


\section{APPENDICES}


APPENDIX 1

THE YEAR AND AREA OF STUDY OF THE SUBJECTS

PARTICIPATING IN THE TESTS 


\section{APPENDIX 1}

TABLE I

THE YEAR AND AREA OF STUDY OF THE SUBJECTS PARTICIPATING IN TEST \# 1

\begin{tabular}{|c|c|c|c|c|c|c|}
\hline Class Level & Fr. & So. & Jr。 & Sr. & Grad. & Total \\
\hline Total Number & 43 & 23 & 35 & 46 & 18 & 165 \\
\hline Percent of Total & 26 & 14 & 21 & 28 & 11 & 100 \\
\hline Area of Study & $\begin{array}{c}\text { Total } \\
\text { Number } \\
\end{array}$ & $\begin{array}{l}\text { Percent } \\
\text { of Total } \\
\end{array}$ & \multicolumn{2}{|c|}{ Area of Study } & $\begin{array}{c}\text { Total } \\
\text { Number }\end{array}$ & $\begin{array}{l}\text { Percent } \\
\text { of Total } \\
\end{array}$ \\
\hline Anthropology & 2 & 1 & \multicolumn{2}{|c|}{ Liberal Studies } & 3 & 2.4 \\
\hline Art & 25 & 15 & \multicolumn{2}{|l|}{ Math } & 1 & 1 \\
\hline Biology & 8 & 5 & \multicolumn{2}{|l|}{ Music } & 4 & 2.4 \\
\hline Business & 6 & 4 & \multicolumn{2}{|c|}{ Pan African Studies } & 1 & 1 \\
\hline Engineering. & 5 & 3 & \multicolumn{2}{|c|}{ Psychology } & 7 & 4 \\
\hline English & 2 & 1 & \multicolumn{2}{|c|}{ Radio and T.V. } & 2 & 1 \\
\hline Geography. & 52 & 32 & \multicolumn{2}{|c|}{ Recreation } & 9 & 5 \\
\hline Geology & 4 & 2.4 & \multicolumn{2}{|l|}{ Spanish } & 2 & 1 \\
\hline Health Science & 4 & 2.4 & \multicolumn{2}{|l|}{ Speech } & 2 & 1 \\
\hline History & 4 & 2.4 & \multicolumn{2}{|c|}{ Undetermined } & 18 & 11 \\
\hline Journalism & 4 & 2.4 & Total & & $\overline{165}$ & \\
\hline
\end{tabular}


TABLE 2

THE YEAR AND AREA OF STUDY OF THE SUBJECTS PARTICIPATING IN TEST \#2

$\begin{array}{lccccrr}\text { Class Level } & \text { Fr. } & \text { So. } & \text { Jr. } & \text { Sr。 } & \text { Grad. } & \text { Total } \\ \text { Total Number } & 9 & 10 & 34 & 33 & 13 & 99 \\ \text { Percent of Total } & 9 & 10 & 35 & 33 & 13 & 100\end{array}$

\begin{tabular}{|c|c|c|c|c|c|}
\hline Area of Study & $\begin{array}{c}\text { Total } \\
\text { Number }\end{array}$ & $\begin{array}{c}\text { Percent } \\
\text { of Total }\end{array}$ & Area of Study & $\begin{array}{c}\text { Total } \\
\text { Number }\end{array}$ & $\begin{array}{l}\text { Percent } \\
\text { of Total }\end{array}$ \\
\hline Anthropology & 1 & 1 & Liberal Studies & 12 & 12 \\
\hline Art & 4 & 4 & Music & 3 & 3 \\
\hline Business & 7 & 7 & Psychology & 3 & 3 \\
\hline Engineering & 2 & 2 & Recreation & 3 & 3 \\
\hline English & 1 & 1 & Spanish & 2 & 2 \\
\hline Geography & 49 & 50 & Urban Studies & 2 & 2 \\
\hline Geology & 3. & 3 & Undetermined & 4 & 4 \\
\hline History & 3 & 3 & Total & $\overline{99}$ & \\
\hline
\end{tabular}


TABLE 3

THE YEAR AND AREA OF STUDY OF THE SUBJECTS PARTICIPATING IN TEST \#3

$\begin{array}{lcccccr}\text { Class Level } & \text { Fr. } & \text { So. } & \text { Jr. } & \text { Sr. } & \text { Grad. } & \text { Total } \\ \text { Total Number } & 8 & 12 & 30 & 35 & 14 & 99 \\ \text { Percent of Total } & 8 & 12 & 30 & 36 & 14 & 100\end{array}$

\begin{tabular}{|c|c|c|c|c|c|}
\hline Area of Study & $\begin{array}{c}\text { Total } \\
\text { Number }\end{array}$ & $\begin{array}{c}\text { Percent } \\
\text { of Total } \\
\end{array}$ & Area of Study & $\begin{array}{l}\text { Total } \\
\text { Number }\end{array}$ & $\begin{array}{l}\text { Percent } \\
\text { of Total }\end{array}$ \\
\hline & & & $=$ & & \\
\hline Anthropology & 3 & 3 & History & 1 & 1 \\
\hline Art & 8 & 8 & Liberal Studies & 4 & 4 \\
\hline Biology & 2 & 2 & Math & 1 & 1 \\
\hline Business & 4 & 4 & Music & 2 & 2 \\
\hline Earth Science & 1 & 1 & Psychology & 2 & 2 \\
\hline Education & 1. & 1 & Physical Education & 1 & 1 \\
\hline Engineering & $i$ & 1 & Spanish & 1 & 1 \\
\hline English & 3 & 3 & Urban Studies & 2 & 2 \\
\hline Geography & 56 & 57 & Undetermined & 2 & 2 \\
\hline Geology & 3 & 3 & Total & $\overline{99}$ & \\
\hline
\end{tabular}


TABLE 4

THE YEAR AND AREA OF STUDY OF THE SUBJECTS PARTICIPATING IN TEST \#4

\begin{tabular}{|c|c|c|c|c|c|c|}
\hline Class Level & Fr. & So. & Jr. & Sr. & Grad. & Total \\
\hline Total Number & 20 & 26 & 23 & 22 & 30 & 121 \\
\hline Percent of Total & 17 & 21 & 19 & 18 & 25 & 100 \\
\hline
\end{tabular}

\begin{tabular}{|c|c|c|c|c|c|}
\hline Area of Study & $\begin{array}{c}\text { Total } \\
\text { Number }\end{array}$ & $\begin{array}{l}\text { Percent } \\
\text { of Total } \\
\end{array}$ & Area of Study & $\begin{array}{l}\text { Total } \\
\text { Number }\end{array}$ & $\begin{array}{l}\text { Percent } \\
\text { of Total }\end{array}$ \\
\hline $\begin{array}{l}\text { Anthropology } \\
\text { Art } \\
\text { Biology } \\
\text { Business } \\
\text { Engineering } \\
\text { English } \\
\text { Geography } \\
\text { Geology } \\
\text { Health Science } \\
\text { History } \\
\text { Journalism }\end{array}$ & $\begin{array}{r}1 \\
5 \\
3 \\
5 \\
1 \\
5 \\
33 \\
1 \\
3 \\
3 \\
1\end{array}$ & $\begin{array}{l}1 \\
4 \\
2.5 \\
4 \\
1 \\
4 \\
27 \\
1 \\
2.5 \\
2.5 \\
1\end{array}$ & $\begin{array}{l}\text { Liberal Studies } \\
\text { Math } \\
\text { Music } \\
\text { Psychology. } \\
\text { Recreation } \\
\text { Education } \\
\text { Foreign Language } \\
\text { Law } \\
\text { Science } \\
\text { Social Science } \\
\text { Undetermined } \\
\quad \text { Total }\end{array}$ & $\begin{array}{r}8 \\
1 \\
4 \\
2 \\
7 \\
21 \\
1 \\
1 \\
2 \\
2 \\
11 \\
121\end{array}$ & $\begin{array}{l}7 \\
1 \\
3 \\
1 \cdot 5 \\
6 \\
17 \\
1 \\
1 \\
1 \cdot 5 \\
1 \cdot 5 \\
9\end{array}$ \\
\hline
\end{tabular}


APPENDIX 2

ANSWER SHEETS USED FOR THE TESTS 


\section{GENERAL INFORMATION}

1. This test is part of a study in dot map perception. It will in no way affect your grade in this course.

2. The map on the following page is a dot map showing the distribution of population over a certain region. Each dot on the map represents a given number of people.

\section{DIRECTIONS}

1. Fill in all information before answering any questions.

2. On the dot map accompanying this hand-out there are six boxes, equal in size, lettered A through F. You are asked to estimate the number of dots that are contained in these lettered boxes. Do not try to count the dots for your answers.

3. Write your answers in the spaces provided below. Thank you for your cooperation.

NAME

MAJOR

YEAR FR. So. JR. SR. GR.

NUMBER OF DOTS IN BOX A BOX B BOX C BOX D BOX E BOX F

(ANSWER SHEET FOR TEST ONE (CONTROL) AND TESTS TWO AND THREE) 


\section{GENERAL INFORMATION}

1. This test is part of a study in dot map perception. It will in no way affect your grade in this course.

2. The map on the following page is a dot map showing the distribution of population over a certain region. Each dot on the map represents a given number of people.

\section{DIRECTIONS}

1. Fill in all information before answering any questions.

2. On the dot map accompanying this hand-out there are six boxes, equal in size, lettered $A$ through $F$. On the upper left corner a legend is given with the number indicating the number of dots contained. You are asked to use the legend as a guide, and to estimate the number of dots that are contained in the lettered boxes. Do not try to count the dots for your answers.

3. Write your answers in the spaces provided below. Thank you for your cooperation.

NAME

MAJOR

YEAR FR. so. JR. SR. GR •

NUMBER OF DOTS IN BOX A

BOX B BOX C BOX D

BOX E

BOX F

(ANSWER SHEET FOR TEST ONE SECTIONS 2, 3, 4, AND 5) 


\section{GENERAL INFORMATION}

1. This test is part of a study in dot map perception.

It will in no way affect your grade in this course.

2. The map on the following page is a dot map showing the distribution of population over a certain region. Each dot on the map represents a given number of people.

\section{DIRECTIONS}

1. Fill in all information before answering any questions.

2. On the dot map accompanying this hand-out there are six boxes, equal in size, lettered A through F. You are asked to estimate the number of dots that are contained in these lettered boxes. Do not try to count the dots for your answers.

3. Write your answers in the spaces provided below. Thank you for your cooperation.

NAME

MAJOR

YEAR FR. SO. JR. SR. GR •

NUMBER OF DOTS IN BOX A

BOX B BOX $\mathrm{C}$ $\mathrm{BOX} \mathrm{D}$ BOX E $\mathrm{BOX} \mathrm{F}$

( ANSWER SHEET, TEST FOUR, VERTICAL AND HORIZONTAL RECTANGLES, CLASS RANK, AND AREA OF STUDY) 
GENERAL INFORMATION

1. This test is part of a study in dot map perception. It will in no way affect your grade in this course.

2. The map on the following page is a dot map showing the distribution of population over a certain region. Each dot on the map represents a given number of people.

\section{DIRECTIONS}

1. Fill in all information before answering any questions.

2. On the dot map accompanying this hand-out there are six circles, equal in size, lettered $A$ through $F$. You are asked to estimate the number of dots that are contained in these lettered circles. Do not try to count the dots for your answers.

3. Write your answers in the spaces provided below. Thank you for your cooperation.

NAME

MAJOR

YEAR FR.__ SO.__ JR.___ SR._ GR.__

NUMBER OF DOTS IN BOX A

BOX B

BOX $C$

BOX D

BOX E

BOX

(ANSWER SHEET, TEST FOUR, CIRCLE) 


\section{GENERAL INFORMATION}

1. This test is part of a study in dot map perception. It will in no way affect your grade in this course.

2. The map on the following page is a dot map showing the distribution of population over a certain region. Each dot on the map represents a given number of people.

\section{DIRECTIONS}

1. Fill in all information before answering any questions.

2. On the dot map accompanying this hand-out there are six ovals, equal in size, lettered A through F. You are asked to estimate the number of dots that are contained in these lettered ovals. Do not try to count the dots for your answers.

3. Write your answers in the spaces provided below. Thank you for your cooperation.

NAME

MAJOR

YEAR FR. SO. JR. SR. GR •

NUMBER OF DOTS IN BOX A BOX B BOX C BOX D BOX E BOX F

(ANSWER SHEET, TEST FOUR, OVAL) 
APPENDIX 3

STATISTICAL SUMMARY OF TEST RESULTS 
APPENDIX 3

TEST 1

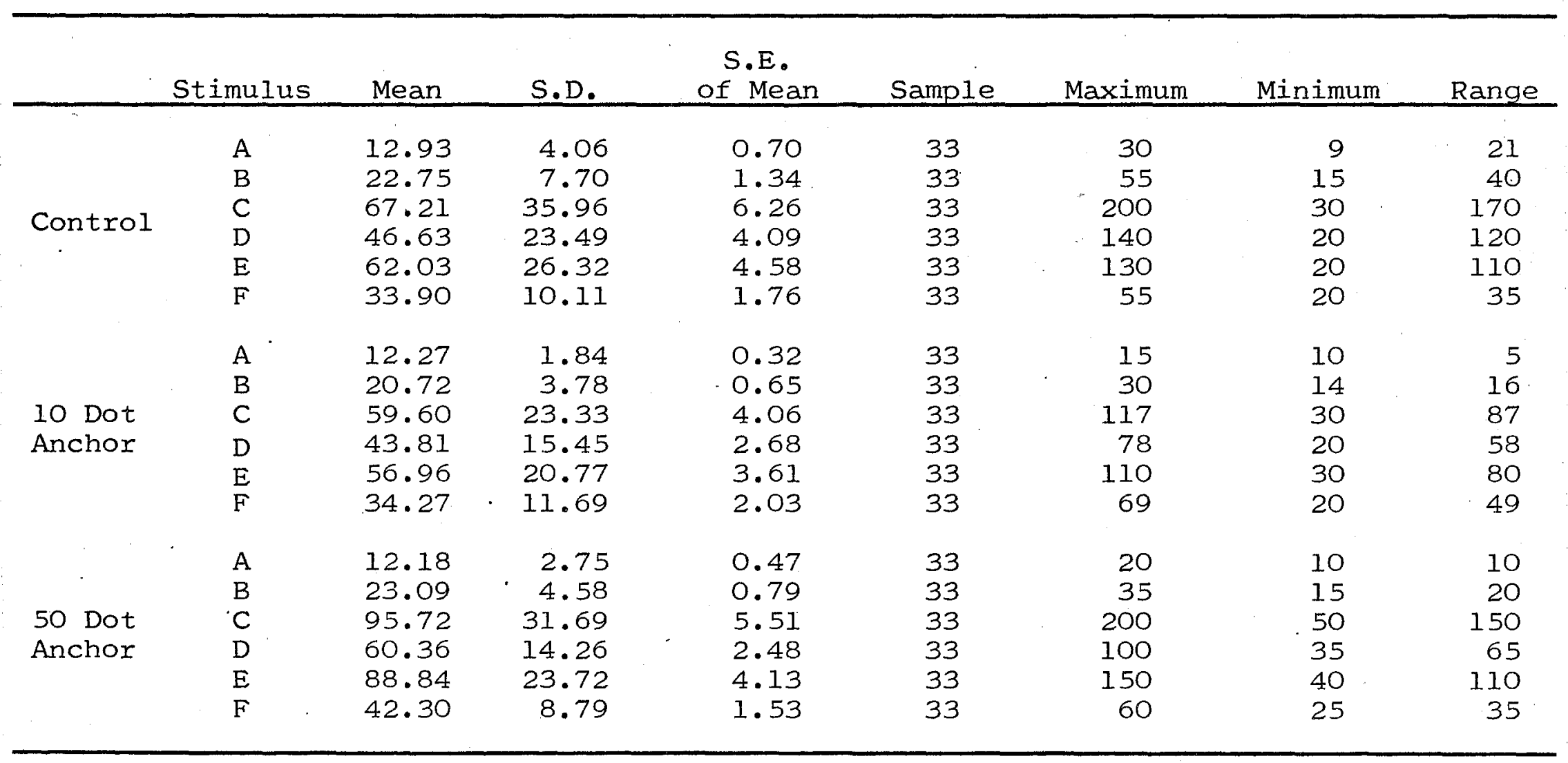


TEST 1 - Continued

\begin{tabular}{|c|c|c|c|c|c|c|c|c|}
\hline & Stimulus & Mean & S.D. & $\begin{array}{c}\text { S.E. } \\
\text { of Mean } \\
\end{array}$ & Sample & Maximum & Minimum & Rarige \\
\hline & $\mathrm{A}$ & 12.39 & 3.10 & 0.54 & 33 & 20 & 10 & 10 \\
\hline & $B$ & 24.51 & 5.76 & 1.00 & 33 & 40 & 12 & 28 \\
\hline 100 Dot & $\mathrm{C}$ & 97.84 & 13.51 & 2.35 & 33 & 125 & 60 & 65 \\
\hline \multirow[t]{3}{*}{ Anchor } & $\mathrm{D}$ & 63.27 & 13.92 & 2.42 & 33 & 90 & 35 & 5.5 \\
\hline & $E$ & 86.42 & 11.66 & 2.03 & 33 & 115 & 70 & 45 \\
\hline & $\mathrm{F}$ & 45.48 & 10.78 & 1.87 & 33 & 75 & 23 & 52. \\
\hline \multirow{2}{*}{$\pi$} & $\mathrm{A}$ & 11.87 & 2.01 & 0.35 & 33 & 5 & 10 & 5 \\
\hline & $\mathrm{B}$ & 22.09 & 5.64 & 0.98 & 33 & 30 & 10 & 20 \\
\hline Full Range & $\bar{C}$ & 95.21 & 8.61 & 1.50 & 33 & 115 & 75 & 40 \\
\hline \multirow{3}{*}{ Anchor } & $\mathrm{D}$ & 62.63 & 9.33 & 1.62 & 33 & 80 & 50 & 30 \\
\hline & $E$ & 87.87 & 10.31 & 1.79 & 33 & 115 & 65 & 50 \\
\hline & $\mathrm{F}$ & 43.72 & 6.98 & 1.21 & 33 & 60 & 30 & 30 \\
\hline
\end{tabular}


TEST 2

\begin{tabular}{|c|c|c|c|c|c|c|c|c|}
\hline & Stimulus & Mean & S.D. & $\begin{array}{c}\text { S.E. } \\
\text { of Mean } \\
\end{array}$ & Sample & Maximum & Minimum & Range \\
\hline \multirow{6}{*}{ Control } & A & 12.93 & 4.06 & 0.70 & 33 & 30 & 9 & 21 \\
\hline & B & 22.75 & 7.70 & 1.34 & 33 & 55 & 15 & 40 \\
\hline & C & 67.21 & 35.96 & 6.26 & 33 & 200 & 30 & 170 \\
\hline & $\mathrm{D}$ & 46.63 & 23.49 & 4.09 & 33 & 140 & 20 & 120 \\
\hline & $E$ & 52.03 & 26.32 & 4.58 & 33 & 130 & 20 & 110 \\
\hline & $\mathrm{F}$ & 33.90 & 10.11 & 1.76 & 33 & 55 & 20 & 35 \\
\hline & A & 12.18 & 2.06 & 0.36 & 33 & 15 & 7 & 8 \\
\hline & $B$ & 24.39 & 5.06 & 0.88 & 33 & 30 & 15 & 15 \\
\hline Medium & $\mathrm{C}$ & 72.60 & 26.41 & 4.59 & 33 & 146 & 30 & 116 \\
\hline \multirow[t]{3}{*}{ Dot } & $\mathrm{D}$ & 48.90 & 14.22 & 2.47 & 33 & 80 & 25 & 55 \\
\hline & $E$ & 59.84 & 17.60 & 3.06 & 33 & 104 & 30 & 74 \\
\hline & $F$ & 36.39 & 7.94 & 1.38 & 33 & 60 & 25 & 35 \\
\hline & A & 12.30 & 1.94 & 0.33 & 33 & 15 & 9 & 6 \\
\hline & $\mathrm{B}$ & 22.57 & 4.61 & 0.80 & 33 & 32 & 14 & 18 \\
\hline Smal1 & C & 67.75 & 20.83 & 3.62 & 33 & 120 & 38 & 82 \\
\hline \multirow[t]{3}{*}{ Dot } & $\mathrm{D}$ & 51.12 & 16.06 & 2.79 & 33 & 100 & 30 & 70 \\
\hline & $E$ & 66.12 & 22.87 & 3.98 & 33 & 125 & 36 & 89 \\
\hline & F & 36.45 & 9.68 & 1.68 & 33 & 60 & 19 & 41 \\
\hline
\end{tabular}


TEST 3

\begin{tabular}{|c|c|c|c|c|c|c|c|c|}
\hline & Stimulus & Mean & S.D. & $\begin{array}{c}\text { S.E. } \\
\text { of Mean }\end{array}$ & Sample & Maximum & Minimum & Range \\
\hline \multirow{6}{*}{ Control } & A & 12.93 & 4.06 & 0.70 & 33 & 30 & 9 & 21 \\
\hline & $\mathrm{B}$ & 22.75 & 7.70 & 1.34 & 33 & 55 & 15 & 40 \\
\hline & $\mathrm{C}$ & 67.21 & 35.96 & 6.26 & 33 & 200 & 30 & 170 \\
\hline & $\mathrm{D}$ & 46.63 & 23.49 & 4.09 & 33 & 140 & 20 & 120 \\
\hline & $E$ & 62.03 & 26.32 & 4.58 & 33 & 130 & 20 & 110 \\
\hline & $F$ & 33.90 & 10.11 & 1.76 & 33 & 55 & 20 & 35 \\
\hline \multirow{6}{*}{$\begin{array}{l}10 \% \\
\text { Screen }\end{array}$} & A. & 12.81 & 3.27 & 0.56 & 33 & \multirow{6}{*}{$\begin{array}{r}25 \\
45 \\
150 \\
120 \\
200 \\
90\end{array}$} & 8 & 17 \\
\hline & B & 23.63 & 6.72 & 1.17 & 33 & & 15 & 30 \\
\hline & C & 76.78 & 29.07 & 5.06 & 33 & & 30 & 120 \\
\hline & $\mathrm{D}$ & 53.09 & 22.91 & 3.98 & 33 & & 25 & 95 \\
\hline & $\mathrm{E}$ & 73.72 & 31.34 & 5.45 & 33 & & 30 & 170 \\
\hline & $\mathrm{F}$ & 39.21 & 16.32 & 2.84 & 33 & & 20 & .70 \\
\hline \multirow{6}{*}{$\begin{array}{l}30 \% \\
\text { Screen }\end{array}$} & A & 11.72 & 2.88 & 0.50 & 33 & 20 & 7 & 13 \\
\hline & B & 23.30 & 5.90 & 1.02 & 33 & 38 & 10 & 28 \\
\hline & C & 71.42 & 25.70 & 4.47 & 33 & 150 & 28 & 122 \\
\hline & D & 48.18 & 13.24 & 2.30 & 33 & 75 & 20 & 55 \\
\hline & $E$ & 62.96 & 19.07 & 3.32 & 33 & 100 & 25 & 75 \\
\hline & $\mathrm{F}$ & 36.33 & 11.83 & 2.06 & 33 & 63 & 15 & 48 \\
\hline
\end{tabular}


TEST 4 - STIMULUS AREA SHAPE

\begin{tabular}{|c|c|c|c|c|c|c|c|c|}
\hline & Stimulus & Mean & S.D. & $\begin{array}{c}\text { S.E. } \\
\text { of Mean }\end{array}$ & Sample & Maximum & Minimum & Range \\
\hline $\begin{array}{l}\text { Vertical } \\
\text { Rectangle }\end{array}$ & $\begin{array}{l}A \\
B \\
C \\
D \\
E \\
F\end{array}$ & $\begin{array}{l}12.41 \\
54.70 \\
24.12 \\
41.20 \\
67.58 \\
37.50\end{array}$ & $\begin{array}{r}1.69 \\
21.98 \\
5.03 \\
15.32 \\
28.10 \\
10.86\end{array}$ & $\begin{array}{l}0.34 \\
4.48 \\
1.02 \\
3.12 \\
5.73 \\
2.21\end{array}$ & $\begin{array}{l}24 \\
24 \\
24 \\
24 \\
24 \\
24\end{array}$ & $\begin{array}{r}15 \\
100 \\
32 \\
80 \\
120 \\
63\end{array}$ & $\begin{array}{l}10 \\
30 \\
15 \\
20 \\
18 \\
17\end{array}$ & $\begin{array}{r}5 \\
70 \\
17 \\
60 \\
102 \\
46\end{array}$ \\
\hline $\begin{array}{l}\text { Horizontal } \\
\text { Rectangle }\end{array}$ & $\begin{array}{l}\text { A. } \\
B \\
C \\
D \\
E \\
F\end{array}$ & $\begin{array}{l}12.20 \\
21.25 \\
63.66 \\
45.33 \\
61.95 \\
33.12\end{array}$ & $\begin{array}{r}2.50 \\
3.55 \\
21.35 \\
16.50 \\
24.32 \\
9.01\end{array}$ & $\begin{array}{l}0.51 \\
0.72 \\
4.35 \\
3.36 \\
4.96 \\
1.84\end{array}$ & $\begin{array}{l}24 \\
24 \\
24 \\
24 \\
24 \\
24\end{array}$ & $\begin{array}{r}20 \\
27 \\
120 \\
100 \\
130 \\
55\end{array}$ & $\begin{array}{l}10 \\
15 \\
40 \\
25 \\
32 \\
20\end{array}$ & $\begin{array}{l}10 \\
12 \\
80 \\
75 \\
98 \\
35\end{array}$ \\
\hline
\end{tabular}


TEST 4 - STIMULUS AREA SHAPE

(Continued)

\begin{tabular}{|c|c|c|c|c|c|c|c|c|}
\hline & Stimulus & Mean & S.D. & $\begin{array}{c}\text { S.E. } \\
\text { of Mean } \\
\end{array}$ & Sample & Maximum & Minimum & Range \\
\hline Circle & $\begin{array}{l}A \\
B \\
C \\
D \\
E \\
F\end{array}$ & $\begin{array}{l}21.79 \\
11.91 \\
34.54 \\
68.75 \\
50.41 \\
65.45\end{array}$ & $\begin{array}{r}5.24 \\
1.74 \\
6.10 \\
13.97 \\
13.14 \\
15.05\end{array}$ & $\begin{array}{l}1.07 \\
0.35 \\
1.24 \\
2.85 \\
2.68 \\
3.07\end{array}$ & $\begin{array}{l}24 \\
24 \\
24 \\
24 \\
24 \\
24\end{array}$ & $\begin{array}{r}35 \\
15 \\
50 \\
100 \\
75 \\
100\end{array}$ & $\begin{array}{r}15 \\
8 \\
25 \\
40 \\
20 \\
30\end{array}$ & $\begin{array}{r}20 \\
7 \\
25 \\
60 \\
55 \\
70\end{array}$ \\
\hline Oval & $\begin{array}{l}A \\
B \\
C \\
D \\
E \\
F\end{array}$ & $\begin{array}{l}22.04 \\
12.37 \\
56.25 \\
41.58 \\
68.12 \\
38.87\end{array}$ & $\begin{array}{r}4.52 \\
1.90 \\
22.57 \\
14.83 \\
26.42 \\
13.81\end{array}$ & $\begin{array}{l}0.92 \\
0.38 \\
4.60 \\
3.02 \\
5.39 \\
2.81\end{array}$ & $\begin{array}{l}24 \\
24 \\
24 \\
24 \\
24 \\
24\end{array}$ & $\begin{array}{r}30 \\
15 \\
110 \\
80 \\
140 \\
74\end{array}$ & $\begin{array}{r}15 \\
9 \\
30 \\
24 \\
25 \\
20\end{array}$ & $\begin{array}{r}15 \\
6 \\
80 \\
56 \\
115 \\
54\end{array}$ \\
\hline
\end{tabular}


TEST 4 - CLASS RANK

\begin{tabular}{|c|c|c|c|c|c|c|c|c|}
\hline & Stimulus & Mean & S.D. & $\begin{array}{c}\text { S.E. } \\
\text { of Mean } \\
\end{array}$ & Sample & Maximum & Minimum & Rarioe \\
\hline Fr. Soph. & $\begin{array}{l}A \\
B \\
C \\
D \\
E \\
F\end{array}$ & $\begin{array}{l}12.01 \\
22.92 \\
67.92 \\
44.21 \\
60.59 \\
35.44\end{array}$ & $\begin{array}{r}1.92 \\
5.05 \\
23.53 \\
13.45 \\
20.61 \\
10.07\end{array}$ & $\begin{array}{l}0.26 \\
0.70 \\
3.26 \\
1.86 \\
2.85 \\
1.39\end{array}$ & $\begin{array}{l}52 \\
52 \\
52 \\
52 \\
52 \\
52\end{array}$ & $\begin{array}{r}16 \\
35 \\
140 \\
80 \\
110 \\
60\end{array}$ & $\begin{array}{r}8 \\
15 \\
25 \\
25 \\
30 \\
20\end{array}$ & $\begin{array}{r}8 \\
20 \\
115 \\
55 \\
80 \\
40\end{array}$ \\
\hline Sr. Gr. & $\begin{array}{l}A \\
B \\
C \\
D \\
E \\
F\end{array}$ & $\begin{array}{l}12.25 \\
21.56 \\
65.27 \\
45.09 \\
58.40 \\
36.13\end{array}$ & $\begin{array}{r}1.67 \\
14.15 \\
20.67 \\
17.25 \\
22.44 \\
10.46\end{array}$ & $\begin{array}{l}0.25 \\
0.62 \\
3.11 \\
2.60 \\
3.38 \\
1.57\end{array}$ & $\begin{array}{l}44 \\
44 \\
44 \\
44 \\
44 \\
44\end{array}$ & $\begin{array}{r}15 \\
32 \\
120 \\
100 \\
130 \\
74\end{array}$ & $\begin{array}{l}10 \\
15 \\
18 \\
20 \\
30 \\
17\end{array}$ & $\begin{array}{r}5 \\
17 \\
102 \\
80 \\
100 \\
57\end{array}$ \\
\hline
\end{tabular}


TEST 4

\begin{tabular}{|c|c|c|c|c|c|c|c|c|}
\hline & Stimulus & Mean & S.D. & $\begin{array}{c}\text { S.E. } \\
\text { of Mean } \\
\end{array}$ & Sample & Maximum & Minimum & Range \\
\hline $\begin{array}{l}\text { Geogra- } \\
\text { phers }\end{array}$ & $\begin{array}{l}A \\
B \\
C \\
D \\
E \\
F\end{array}$ & $\begin{array}{l}11.75 \\
21.69 \\
64.96 \\
43.54 \\
57.39 \\
33.69\end{array}$ & $\begin{array}{r}2.79 \\
5.97 \\
26.06 \\
13.80 \\
19.99 \\
11.47\end{array}$ & $\begin{array}{l}0.48 \\
1.03 \\
4.53 \\
2.40 \\
3.47 \\
1.99\end{array}$ & $\begin{array}{l}33 \\
33 \\
33 \\
33 \\
33 \\
33\end{array}$ & $\begin{array}{r}20 \\
38 \\
150 \\
70 \\
100 \\
55\end{array}$ & $\begin{array}{r}8 \\
10 \\
28 \\
20 \\
20 \\
15\end{array}$ & $\begin{array}{r}12 \\
28 \\
122 \\
50 \\
80 \\
40\end{array}$ \\
\hline $\begin{array}{l}\text { Non Geog- } \\
\text { raphers }\end{array}$ & $\begin{array}{l}A \\
B \\
C \\
D \\
E \\
F\end{array}$ & $\begin{array}{l}12.33 \\
22.18 \\
66.72 \\
41.81 \\
56.06 \\
37.27\end{array}$ & $\begin{array}{r}1.99 \\
4.61 \\
23.82 \\
14.16 \\
20.45 \\
13.13\end{array}$ & $\begin{array}{l}0.34 \\
0.80 \\
4.14 \\
2.46 \\
3.56 \\
2.28\end{array}$ & $\begin{array}{l}33 \\
33 \\
33 \\
33 \\
33 \\
33\end{array}$ & $\begin{array}{r}15 \\
30 \\
120 \\
80 \\
110 \\
74\end{array}$ & $\begin{array}{l}10 \\
15 \\
25 \\
24 \\
30 \\
20\end{array}$ & $\begin{array}{r}5 \\
15 \\
95 \\
56 \\
80 \\
54\end{array}$ \\
\hline
\end{tabular}

